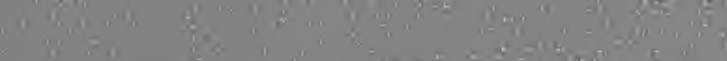

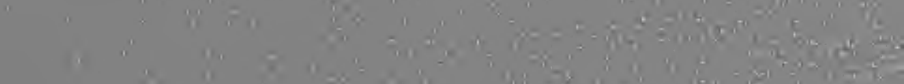

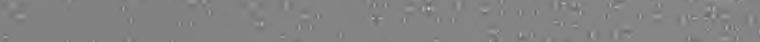

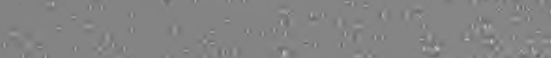

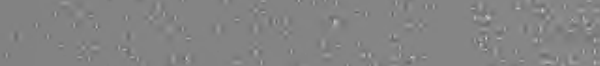

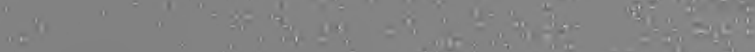

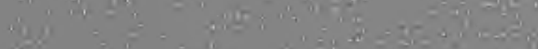

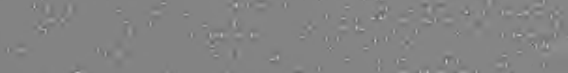

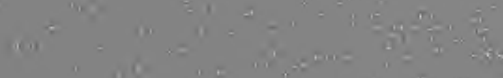

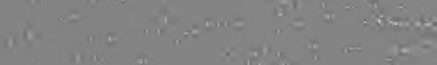

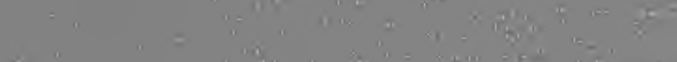
it.

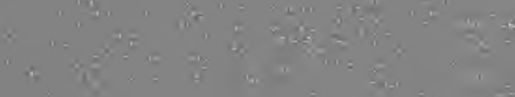
$=\quad i^{2}$<smiles>C#[W]#CC#N</smiles>

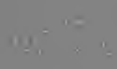
10 $x$

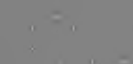

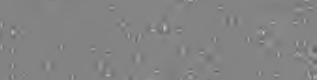
$=\sin$

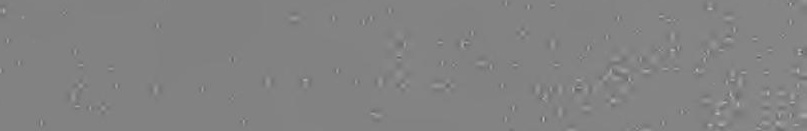

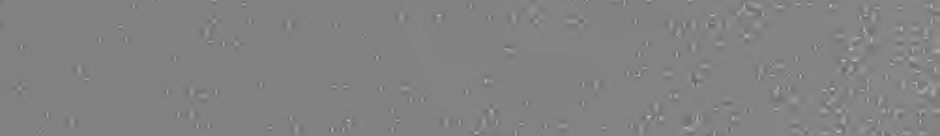

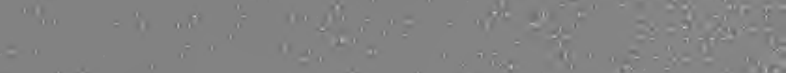

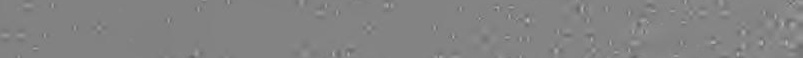

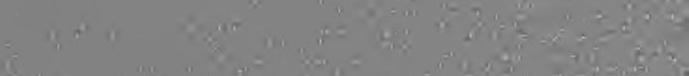

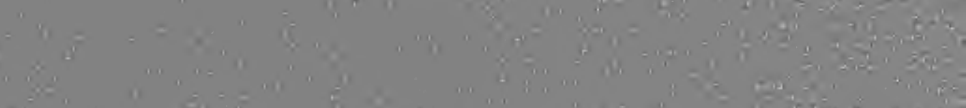

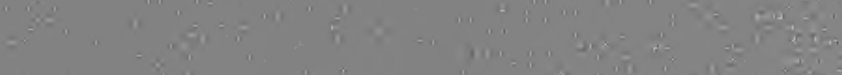

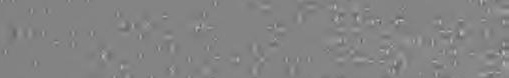
"

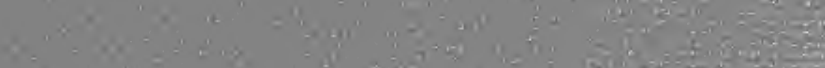

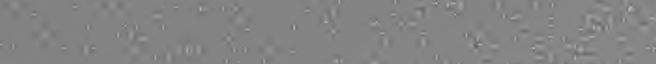

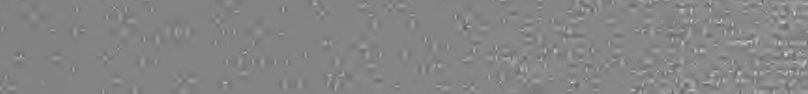

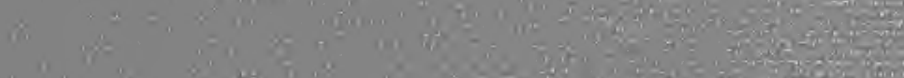

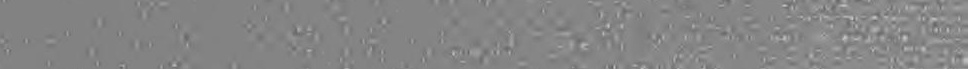

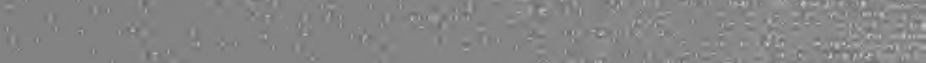

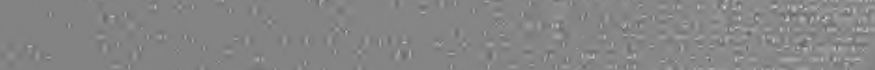

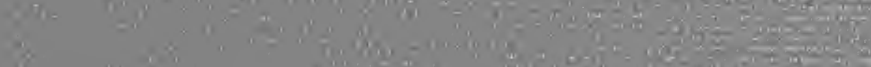

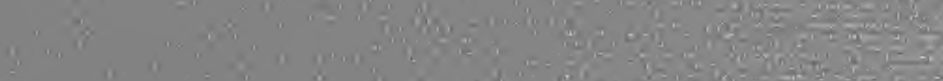

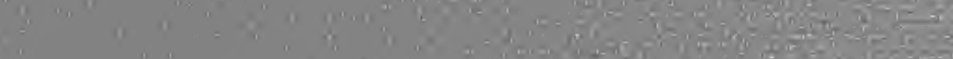


BY
PROFESSOR JAMES BISSETT PRATT

THE PSYCHOLOGY OF RELIGIOUS BELIEF

WHAT IS PRAGMATISM?

INDIA AND ITS FAITHS

DEMOCRACY AND PEACE

ESSAYS IN CRITICAL REALISM

(Written in collaboration with six others)

THE RELIGIOUS CONSCIOUSNESS

MATTER AND SPIRIT: A STUDY OF

MIND AND BODY IN THEIR RELATION TO THE SPIRITUAL LIFE 


\section{MATTER AND SPIRIT}

A STUDY OF MIND AND BODY IN THEIR RELATION TO THE SPIRITUAL LIFE.

BY

JAMES BISSETT PRATT, PH.D.

PROFESSOR OF PHILOSOPHY IN WILLIAMS COLLEGE

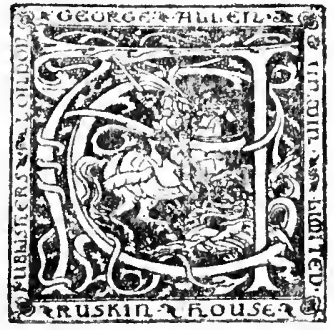

LONDON: GEORGE ALLEN \& UNWIN LTD. RUSKIN HOUSE, to MUSEUM STREET, W.C. I 


$$
\begin{aligned}
& B D \\
& 331 \\
& P 7 \\
& 1923
\end{aligned}
$$

Copyright, 1922,

BY THE MACMILLAN COMPANY

First Published in Great Britain, 192:3

$$
\text { LIBRAM }
$$

UNIVERSITY OF TORONTO 


\section{IN \\ GRATEFUL MEMORY \\ $\mathrm{OF}$}

WILLIAM JAMES 



\section{PREFACE}

The principal excuse for a new book on the eternal problem of matter and mind is just the fact that the problem is eternal. And not only is it eternal: it is so complex that there is no end of illuminating ways in which it may be presented. A further excuse, if it be needed, is to be found in the many new attitudes toward the question which contemporary thought has suggested. A fairly rapid survey of the various answers, old and new, which have been given to our question--a bird's eye view, so to speak, of this ancient problem in its modern setting-seems to be called for by the times in which we live. The need for such a review becomes more patent the moment one stops to consider the absolutely central place of the mind-body problem in metaphysical speculation, and the fundamental nature of metaphysics in knowledge and in life. If we knew just how mind affects body and how body affects mind we should have the clew to many a philosophical riddle, and a clew that would give us much-needed guidance not only in philosophy but in many a 
region of practical, moral, and religious activity and experience in which our generation is groping rather blindly and is longing very eagerly for more light.

If there be anything individual about this book it is, I suppose, its outspoken defense of Dualism. The time has come, as it seems to me, for those of us (and we are many) who refuse to be brow-beaten by the fantastic exaggerations of a dogmatic Naturalism and who are no longer to be fooled by the spiritual phraseology of a monistic Idealism which is really no less destructive to most of man's spiritual values and most of his dearest hopes than is Naturalism itself-it is time, I say, for those of us who cannot accept either of these most unempirical philosophies to come forward frankly with the opposing view and call ourselves dualists before our critics have the opportunity of branding us with that opprobrious title. For my part, at any rate, I am glad to accept the accusation and to be called, as a writer in a religious periodical recently called me, "an avowed dualist and unashamed." Derogatory epithets seldom hurt if accepted willingly. "Puritan" and "Unitarian" have long since become at least respectable, and even "Yankee" has not proved fatal. 
The material here presented is a somewhat amplified form of the Nathaniel W. Taylor Lectures which I delivered at the Yale Divinity School in April, 1922. One of the additions to the original addresses - which is now the latter part of Lecture Iappeared, in modified form, in the Journal of Philosophy; ${ }^{1}$ and to the editors of that periodical I am indebted for their kind permission to reprint it here. Most of all am I indebted to my kind hosts at New Haven-notably Professor Sneath, Professor Macintosh, and Dean Brown-for the stimulus and the encouragement which made the original lectures possible and which emboldened me to publish them in their present form.

Williamstown, Mass.,

$$
\text { July, } 1922 .
$$

1 For June 22, 1922; under the title "The New Materialism." 



\section{CONTENTS}

LECTURE

I The Mind-Body Problem and the Mate-

PAGE RIALISTIC SOlUtion • • • • • 3

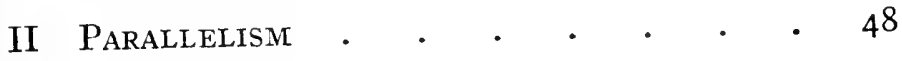

III The Denial of the Problem • • • 89

IV The Difficulties of Interaction • . I3 I

V A Dualism of Process . • • • • 167

VI The Consequences of Dualisin in MoralITY AND RELIGION • • • • • • 197

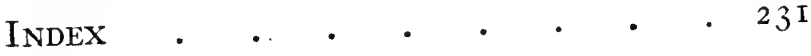



MATTER AND SPIRIT 



\section{MATTER AND SPIRIT}

\section{LECTURE I}

THE MIND-BODY PROBLEM AND THE MATERIALISTIC SOLUTION

It is a reproach commonly leveled against metaphysics that the problems it deals with are immeasurably remote from the life of man. To their remoteness from life is usually attributed both their apparent insolubility and their alleged lack of real importance. Plainly, therefore, the question of their importance and of the possibility of their solution would take on a very different aspect, even to the popular mind, if it could be shown that one of the most crucial and fundamental of all metaphysical problems is to be found not in the starry heavens nor in the distant æons of unimaginable time, but centering round a process that is going on within the psychophysical organism of each one of us at every moment of his waking life. That such is the actual situation is my firm belief, - a conviction that grows 
upon me with every year of further pondering. I refer, of course, to the processes found in sensation and voluntary activity. If we could understand what really happens when we see each other's faces, or when we lift our hands or speak each other's names, we should have the clue to many a mystery; and the point of view that we shall take upon the nature of these common events will determine for us the major portion of our metaphysics.

The crucial significance of the mind-body relation is no new discovery. Not only the ancient Greek philosophers, but thousands of years before them primitive men the world over made it the starting point of their thought and based upon their particular solution of this question nearly the whole of their philosophy of life and nature. But while they understood very well the decisive position of this problem they had little inkling of its real difficulty, nor did they even imagine the varied ways in which the mind-body relation is capable of being expressed. As a fact, since the days of the Greek philosophers some eight or nine different solutions have been offered, and as much of the best philosophic thought has busied itself with this problem for many centuries it seems unlikely that anything very radically 
new will be suggested in the future. In fact it can be shown in something like mathematical fashion that we have in our hands already all the possible solutions. For either body and mind are causally related or they are not. If for the present we leave on one side the denial of such relationship, the number of possible ways in which they may be related is obviously limited. I hasten to add that I mean the word "causally" as used above to be taken in sufficiently large fashion to include every kind of implication or influence; and that for our present purposes the word body, or matter, may be interpreted in either realistic or idealistic fashion. Whatever interpretation we put upon matter, idealists and realists alike will acknowledge that the words matter and mind have distinguishable meanings. With so much agreed upon, we can easily work out the chief ways in which the two may conceivably be related. If for the moment we omit detailed variations within the principal groups, there are four and only four of such possible relations. Firstly, mind and body may mutually influence each other. Secondly, body may alone be causally effective and mind merely a result. Thirdly, mind and body may flow on parallel with each other, each causally efficient 
within its own banks, so to speak, but neither ever affecting the other. Fourthly, mind alone may be efficient, and body merely a resultant or appearance of mind. Variations of detail may be suggested and have been suggested within most of these principal types of relationship; but plainly no other relationship of a general nature is thinkable. The diagram on page 7 will, I trust, make plainer the four types of theory and their principal subdivisions.

If, then, mind and body are causally related their relation must be one of the four kinds here suggested. And if, either by positive arguments in favor of one of these views, or negatively through the elimination of three of them, we can determine which of the four is true, we shall find not only that this particular problem is solved, but that we have a new and piercing light into many a hitherto obscure corner of our universe- a light which may dissipate not only some of our theoretical doubts but even some of our practical uncertainties.

The first of the four general views that I mentioned above, commonly referred to as the theory of fruim Interaction, is naturally the first to present itself to the naive mind. It appears indeed to rest upon actually observed facts-in sensation we seem to find 


\section{THE MIND-BODY PROBLEM}
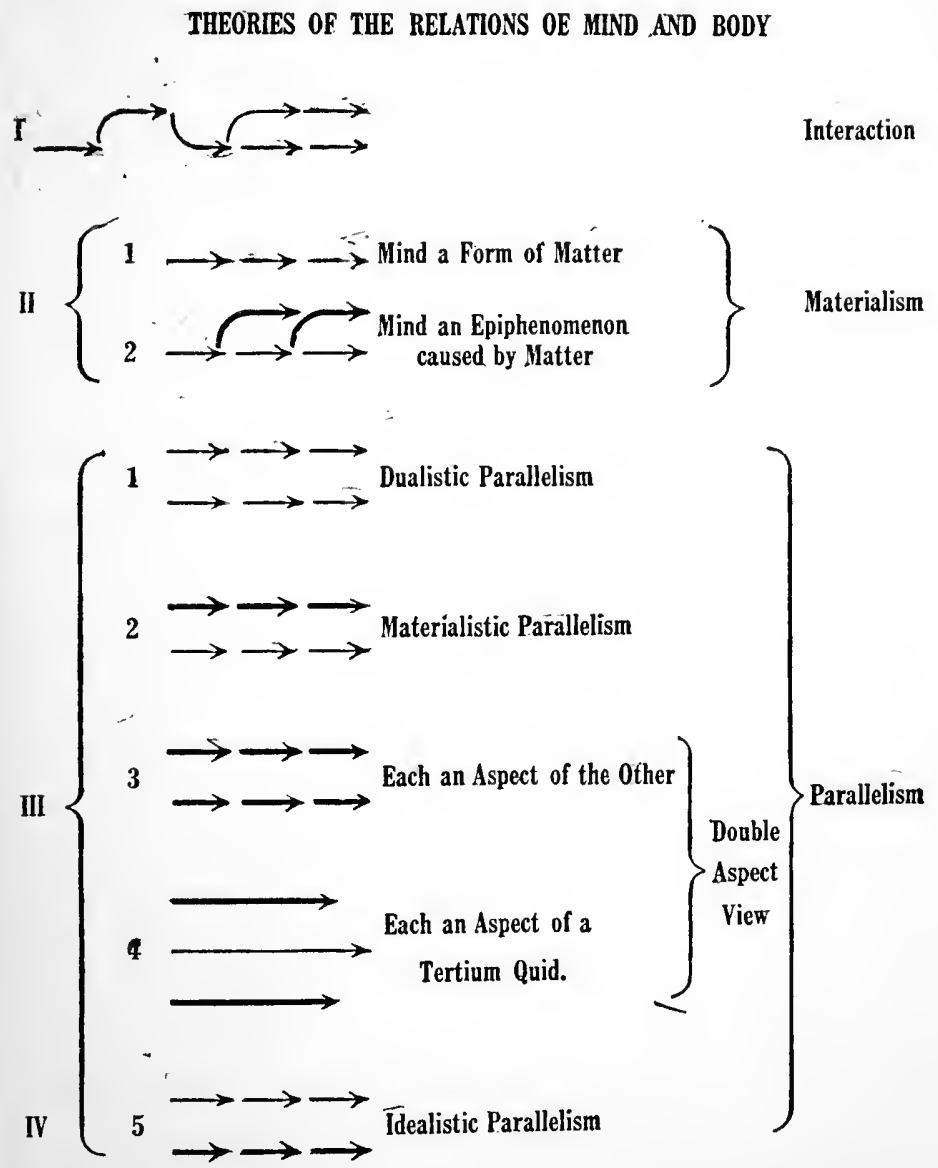

NoTE.-In each case the arrows in the upper line represent mind, those in the lower line matter or physical energy. The light arrows indicate a real entity, the heavy black an epiphenomenon, aopearance, or aspect. 
a physical process operating upon our consciousness, and in volition we feel ourselves, as psychical beings, operating upon the physical world. It is not strange, therefore, that Interaction should be the first theory of mind and body to be explicitly developed, both by the individual and by the race. Primitive man founded his animistic philosophy upon it; and both Socrates and Plato were convinced interactionists. They made a sharp distinction between body and soul, a distinction which they regarded as of the utmost importance; and it could easily be shown that most of their moral and religious teachings and much of their cosmic speculation would go to pieces if based on any other foundation than the interaction theory. It was an essential part of the larger Platonic dualism, and it formed the basis of Plato's firm conviction in the soul's immortality. The rise of Christianity brought additional strength to the doctrine, for the Christian Fathers regarded body and soul as distinct entities and in their mutual influence upon each other they found much of the cosmic struggle centering. It was not strange that with Christianity and Platonism uniting their forces in its support the doctrine of Interaction should have held the field almost without a rival for well over 1,500 years. 


\section{THE MIND-BODY PROBLEM}

With the rise of modern natural science, however, new considerations and new motives appeared upon the scene which were destined to put Interaction upon the defensive and give its rivals an enormous advantage. A new conception of physical nature came over men's minds. Mathematical and mechanical laws were found to dominate regions of the universe where their presence had hardly been suspected. Everywhere quality came to be reduced to quantity, the indefinite to the measurable. Once the mechanistic explanation was thoroughly applied to the inorganic world the attempt to extend it to the realms of life and mind became inevitable. And this for two reasons. The world of living matter being made of the same elements as the inorganic world, and forming as it does so minute a portion of the whole of Nature, it seemed most improbable that the laws which hold everywhere else should be subject to exception in this little corner. And secondly it was seen that the extension of mechanical law to this last region would make the entire physical universe an open book to science, all of it at length being susceptible to the same sort of description, explanation, and prediction. The door to this last conquest of mechanistic science was, oddly enough, opened by 
the greatest interactionist of his century, René Descartes. For, though he maintained that body and mind were absolutely distinct in man, he taught that animals were merely automata, and that all their actions must be accounted for on mechanical principles only. It was but a step from this to the suggestion that in man also consciousness, though of course present, never interfered with the activities of the body and that all these might be explained by physical laws alone. Two further advances of Science, made in the 19th Century, added enormously to the strength of this naturalistic attack upon Interaction. These were the formulation of the law of the conservation of energy and the Darwinian doctrine of evolution. For if no energy can ever be created or destroyed, plainly mind cannot interfere with bodily processes; and since man is descended from the lower animals there is no reason why his actions should not be explicable by the same general law as theirs.

Thus it has come about that when the natural scientist approaches the mind-body problem he almost invariably rules out Interaction first of all, as being quite out of the question. This procedure he justifies by two general reasons. The first is the 


\section{THE MIND-BODY PROBLEM 11}

incompatibility, already referred to, of Interaction with the mechanical view of physical nature, and in particular with the law of the conservation of energy. The second reason is of a more philosophical sortthe difficulty, namely, that has been pointed out ever since the days of Descartes in seeing how two such diverse things as matter and mind could possibly affect each other. How indeed can one imagine an idea producing a motion in the matter of the brain? As easily, says Clifford, might we picture the two halves of a heavy train kept together by the feelings of amity between the stoker and the guard.

The naturalistic movement, having discredited Interaction, was bound to offer some theory of mind and body in its place. As a fact it offered two, each of which in turn possessed two or more variations. I refer to Materialism and Parallelism. Materialism in its origin was largely a psychological reaction from the extreme spiritualistic position of scholasticism. It has two sub-types although its adherents have not always recognized the fact nor distinguished them clearly enough in their own minds for us to be invariably certain which of the two types, in any given case, they are upholding. The first of these materialistic views maintains that consciousness is a 
form of brain activity; - that it is either some fine and subtle kind of matter, or (more commonly) some form of energy, either kinetic or potential. This type of Materialism had a considerable vogue in Büchner's day, but fortunately for your patience we need not dwell upon it, for it has been pretty generally discredited. To say that consciousness is a form of matter or of motion is to use words without meaning. The identification of consciousness and motion indeed can never be refuted; but only because he who does not see the absurdity of such a statement can never be made to see anything. Argument against any given position must regularly take the general form of the reductio ad absurdam. He, therefore, who chooses at the beginning a position which is as absurd as any that can be imagined is in the happy situation of being armor proof against all argument. He can never be "reduced to the absurd" because he is already there. If he cannot see that, though consciousness and motion may be related as intimately âs you please, we mean different things by the two words, that though consciousness may be caused by motion, it is not itself what we mean by motion any more than it is green cheese-if he cannot see this there is no arguing with him, But while we cer- 
tainly cannot convince him we may properly ignore him in all discussions of the subject; for he has put himself in a position where all discussion is impossible.

We turn, therefore, to the much more defensible form of Materialism which declares that while consciousness is not to be identified with anything physical it is caused by physical processes that occur in the brain, and that it, on its side, never influences either the brain processes nor any subsequent portions of its own stream. In the words of Professor Warren: "Intelligence is a function not of conscious 'intuition' but of the connection between afferent and efferent nerve tracts. It denotes an adjustment between the environmental situation and the responsive activity, and this adjustment is brought about either by inherited neural paths or by individually acquired connections. The motor impulse in every case presumably follows the path of least resistance. There is no need to assume a non-physical 'guiding' agent in order to explain why the nervous current comes to follow certain paths rather than others." "The mechanics of intelligent activity follows the same pattern as other movements and transformations of energy. . . . The laws of physics and chem- 
istry hold for intelligent organisms as well as for atoms and electrons." ${ }^{1}$ Consciousness, in other words, is always a result, never a cause; every portion of every psychic state is fully determined by the accompanying or preceding brain state. It is the universal mechanical laws of the physical world that produce and regulate and fix our thoughts; our preceding thoughts and the laws of logic having no real efficacy in the matter whatever. Consciousness, in short, is but "a lyric cry in the midst of business." " In support of this proposition the materialist points first of all to the scientific presuppositions that we have already discussed - the universality of mechanical law, the conservation of energy, the evolution of man and of man's consciousness. More specifically he dwells upon the following considerations. Comparative anatomy shows a fairly close correlation between brain capacity and mental ability. Recent studies in brain anatomy have enabled us to locate in various definite portions of the cortex the centers of sensation and the centers that control muscular action. The destruction of any of these cen617.

1 "The Mechanics of Intelligence," Phil. Rev., XXVI, pp. 6i5 and 2 Santayana's picturesque expression, see his Discussion in the Journal of Philosophy, III, p. 412 . 
ters results in the destruction or derangement of the corresponding functions of consciousness. It would seem, therefore, to follow, he argues, that consciousness is dependent upon brain.

The facts and principles to which the materialist appeals, however, are not conclusive. Both the parallelist and even the discouraged interactionist have their answers. United for once against a common foe, they point out that the facts of brain anatomy and physiology upon which the materialist relies are perfectly compatible with both Parallelism and Interaction. The interactionist has never deniedon the contrary, he has affirmed--that certain processes in the brain produce changes in consciousness; and the parallelist always insists that for every mental process there is a correlated brain process. In fact the parallelist goes farther than this and asserts that not only are the facts in question consistent with all three theories, but that the general principles of Naturalism, to which the materialist first of all appealed, are really inconsistent with Materialism. For if some of the physical energy in the brain is used in producing something (viz. consciousness) which is not physical, the doctrine of the conservation of energy is abrogated; you will have physical 
energy being destroyed-destroyed, that is, from the point of view of the physical world which alone in this question need to be considered.

There are, moreover, certain further considerations which seem to make the materialistic position quite untenable. The materialist has appealed to the evolution of human consciousness. Consciousness was not created, he tells us; it has developed, and is to be accounted for by Natural Selection. This view is obviously essential to his position, and in fact it was this view of the origin and development of consciousness that has led many a scientist to a materialistic interpretation of the relation of mind and body. Possibly something might be said on the other side. Possibly Natural Selection does not tell the whole story. Let us, however, take the materialist at his word and see for ourselves the exact consequences and implications of his evolutionary view. Consciousness, then, developed through the action of Natural Selection. That is to say, those individuals and those species whose reactions were influenced by conscious factors, such as sensation, pleasure, pain, memory, judgment, etc., had an advantage over their unconscious or less conscious rivals and were enabled thereby the better to escape danger, 


\section{THE MIND-BODY PROBLEM 17}

procure food, and rear their young. This naturalistic explanation will hold both for consciousness in general and for each conscious function in particular. Thus the emotion of fear with its strong impulse to flee or hide was selected and developed because of its biological utility, because the animal who felt afraid in certain circumstances was more likely to escape danger than one who had no conscious reaction to a really dangerous situation. In other words, both consciousness as a whole and each of its parts, aspects, or functions has been selected and developed because of its beneficial effect upon the behavior of the organism. Had it had no such effect, animal organisms would have developed as purely unconscious automata. So says the evolutionist and so says the materialist.

But, alas for the absent-minded materialist, he has forgotten one thing-in fact just the most fundamental principle of his whole mind-body doctrine. This fundamental principle, as you will all recall, is the assertion that consciousness has and can have no effect upon behavior whatsoever. Consciousness, says Materialism, is always an effect, never a cause. It was, indeed, just fear of allowing consciousness any influence over bodily activities that prompted the 
whole materialistic movement. Since consciousness, therefore, can have no influence, good or bad, upon the reactions of the organism, the evolutionary explanation of it, as due to Natural Selection, must be false. What then will the materialist suggest? Special creation is not to his taste; he will not be likely to turn to the Creator and ask for His assistance. Yet he may well feel that nothing short of divine intervention will save him in his sudden and bitter discovery that he has unintentionally, inadvertently, but none the less inevitably and irretrievably, declared war upon Darwin and all the evolutionists.

Let us continue a little farther the line of thought suggested by the materialist's denial of efficiency to consciousness. Since consciousness never interferes with physical processes, never affects them in any way, the whole of man's civilization, the sum total of his achievements, both material and spiritual, must be ascribed to purely physical laws. The whole tremendous mass of it through all the ages would have come about just the same if no scientist or inventor had ever had a thought, no poet or artist a sentiment, no moral or religious teacher an aspiration or ideal, no patriot a feeling of loyalty, no mother an emotion of love. But leaving these things on one side, let us 
consider in more detail one aspect of the denial of the efficiency of consciousness which should be of particular interest to our materialistic friend. Consciousness, he will remind us, is always an effect and never a cause. And this means, if Materialism is to be selfconsistent, that every psychic state, every feeling and every thought, is determined in its totality by the correlated brain process and never in any degree by any preceding psychic state. To say that a thought is even in a minute degree a co-cause of the following thought would be to wreck Materialism. In the process known as reasoning, therefore, it is a mistake to suppose that consciousness of logical relations has anything whatever to do with the result. It is not logical necessity but mechanical necessity that squeezes out our so-called reasoned conclusions. Take the familiar syllogism:
All men are mortal.
Socrates is a man.
$\therefore$ Socrates is mortal.

The materialist assures us that we should be falling back into the primitive superstitions of a pre-naturalistic age should we suppose that either of the premises had anything to do with our arriving at the conclusion. We finally assert that Socrates is mortal 
not because we have in mind the mortality of all men and the humanity of Socrates, nor for any other logical or psychological reason; but because certain mechanical processes in our brains force that thought into consciousness. Thus no conclusion is ever arrived at because of logical necessity. There is no logical necessity among mental processes but only physical necessity. The truth is, according to Materialism, we think the way we have to think, the way our mechanical brains constrain us to think. We may happen to think logically; but if we do, this is not because logic had anything to do with our conclusion, but because the brain molecules shake down, so to speak, in a lucky fashion. It is plain, therefore, that no conclusion that we men can reach can ever claim to be based on logic. It is forever impossible to demonstrate that any thesis is logically necessary. If we happen to entertain it we do, that is all; for demonstration is out of the question.

This seems plainly to be the inevitable outcome of the materialist doctrine. And it gives an interesting and somewhat surprising turn to the discussion. For suppose at this point we ask the materialist why he maintains that Materialism is true. If he hopes to convince us he can only reply that he considers Ma- 
terialism true because it is the logical conclusion from certain admitted facts, or that the falseness of all other theories can be logically demonstrated. . . . The hopeless self-contradiction of such a position is obvious. With one breath the materialist asserts that his doctrine is logically demonstrable and that there is no such thing as logical demonstration. As Bradley has put it, no theory can be true which is inconsistent with the possibility of our knowing it to be true.

Materialism, in the form I have presented, is as old as Büchner, or much older. In his day it had great popularity, but considerations such as those outlined above so discredited it that in the generation just past it seemed almost dead. Twenty years ago it had few serious defenders beside Professor Haeckel, whose courage in sticking to it reminded one forcibly of the boy who stood on the burning deck, whence all but he had fled. Eventually, in fact, the place got too hot even for Professor Haeckel, and shortly before his death he deserted this extreme form of Materialism and went over to the Double Aspect theory. In our day, however, there are signs of a revival of Materialism. Not to mention scientists like Loeb, there are several philosophers of re- 
pute who are attempting to breathe new life into the dry bones of the old theory. Among the leaders of this movement I shall mention only Professors Warren, Montague, Sellars, Santayana, and perhaps Professor Strong. Mr. Santayana, for his own part, is convinced of the absurdity of attributing physical efficacy to consciousness, ${ }^{1}$ but is not interested in making serious effort for the conversion of those who still cling to "superstitious" and "magical" views. It is doubtful whether Mr. Strong should be included among the materialists. When he wrote the book "Why the Mind Has a Body," he was an enthusiastic parallelist; his recent work on "The Origin of Consciousness," however, leaves me quite in the dark as to where he should be classed. Certainly he has moved far in the direction of Materialism since his first book was finished. If he really belongs to the materialist group his Materialism consists in an identification of psychic states with material particles. Such a position is, of course, open to the same very serious objections as the first form of the older Materialism. At times Mr. Strong seems to attempt a

1 Cf. the "Life of Reason," passim, notably the chapter "How Thought is Practical," in "Reason and Common Sense"; also his discussion on the Efficacy of Thought in the Journal of Philosophy, III, pp. 4IO-I2. 


\section{THE MIND-BODY PROBLEM 23}

justification of it by distinguishing between the psychical and the conscious. In addition to this distinction one must keep in mind Professor Strong's fundamental doctrine that introspection is always indirect and of the past. If we put these considerations together one may argue that we are never directly conscious of our psychic states and hence that they may, for aught we know, be identical with the brain. Yet I cannot see that this really avoids the old difficulty; for if psychic states are really psychic it is hard to put any meaning into the assertion that they are brain; and if they are not really psychic the cognizing of them must be, and the old difficulty will break out in a new place. Furthermore, it is exceedingly difficult for me, at least, to see how Panpsychism (to which Professor Strong still clings) is to be made consistent with his Critical Realism, or to understand how a psychic state can be extended and possess really (not as mere appearance) the various primary qualities. If it is by considerations such as these that the ills of Materialism are to be cured I fear the cure will prove worse than the disease. However, I am not at all sure that Professor Strong means this for Materialism, for, as I have said, he still clings (with modifications) to the panpsychic doctrine of 
his former days; and the "brain" which we contemplate retrospectively when we introspect our (past) psychic states does not seem to be the same "brain" which an outsider might examine with eye and hand. I should not therefore feel justified in including him among the new materialists, although many passages in "The Origin of Consciousness" seem to indicate that he is one.

Nor is it strictly correct to classify Professor Warren as a materialist, for he still clings to the DoubleAspect theory of Parallelism. Yet much of his writing on the mind-body problem ${ }^{1}$ is in defense of the thesis that all man's activities are explicable on mechanical or (very likely) physico-chemical principles; so that in effect if not in name he is a defender of the new Materialism. The form which this defensive argument assumes, however, is a little difficult to make out. It seems, taken in the large, to consist of two closely related parts. In the first place it maintains that even the most complex forms of thoughtful activity are built on the same general plan as ordinary ideo-motor action, and that, inasmuch as

1 "The Mental and the Physical," Psy. Rev., March, I9r4; "A Study of Purpose," Jour. of Phil., Jan. and Feb., IgI6; "The Mechanics of Intelligence," Phil. Review, Nov., I917; "Mechanism versus Vitalism," Phil. Review, Nov., I918. 


\section{THE MIND-BODY PROBLEM 25}

the latter can be fully explained mechanically, the highest forms of intelligent conduct need no further explanation. The other form of Professor Warren's argument consists in pointing us to a brain correlate for every type of conscious process, including even the most complicated and "intelligent."

As to the first of these arguments, it must be plain to all that the similarity between ideo-motor and "intelligently guided" action is accepted and demonstrable only so far as it is irrelevant to the present issue; and that when the similarity is depicted in such terms as to make it relevant to the issue and decisive, the presentation of it as a fact begs the question. That there is a similarity of a very general sort between all forms of bodily activity, that they all have stimulus, central process, and response, will be denied by no one; but to assert in addition to this that increased neural complexity is the only other factor involved in deliberately guided voluntary action beside what one finds in automatic reaction is to start with the conclusion which was to be proved. As I read it, at any rate, Professor Warren's attempted reduction of intelligent activity to the type of ideo-motor action either amounts merely to a harmless pointing out of irrelevant similarities, or else reads into the com- 
parison identities which he has done nothing to prove, and which cannot be admitted in advance without begging the question.

Professor Warren, however, seems to make his position more persuasive by the aid of his second argument. He of course does not deny that certain "higher" and more complex intellectual processes are involved in such things as chess playing than in mere ideo-motor action. But in all these, he assures us, the really efficient factor is the brain aspect of the psychical process. It is the "neural processes known introspectively as 'thoughts' of future situations" ${ }^{1}$ which really govern the movement of the chess pieces. Similarly "satisfaction appears to be the subjective aspect of a neural condition stimulated by systematic processes which are autonomically induced." " "Conscious endeavor to deliberate is a [neural] set in some direction." "Purpose" must not be taken to mean a conscious desire for a consciously conceived achievement but must be interpreted in behavioristic, and ultimately in physiological terms. ${ }^{3}$ When all conscious processes have

1 "The Mechanics of Intelligence," p. 613.

2 Ibid., p. 618.

3 "A Study of Purpose," passim; also "Mechanism vs. Vitalism," p. бі. 
been thus translated into neural terms, the explanation of the most complex human conduct, as, for example, chess playing, on purely physico-chemical principles becomes relatively easy. "The complexity of the thought process means that a large number of neural connections within the brain are formed prior to each play. Intelligence means, in neural terms, that the less satisfying plays find no motor outgothat only one out of many incipient reactions is completed." 1

It would be unjust, I think, to accuse Professor Warren of begging the question in this argument. One might indeed justifiably do so if the argument be interpreted as an attempt to prove Materialism. Plainly it proves Materialism only on condition that we admit the neural interpretation of intelligence to be the sole proper interpretation; only if we start with the conclusion that intelligence as such has nothing to do with action. But as I understand Professor Warren, he does not mean to have his argument taken in so ambitious a sense. He wishes merely to show us what the materialistic hypothesis is, to show that it is possible to express human conduct in physico-chemical terms and that Materialism is a per-

1 "The Mechanics of Intelligence," 6rз3. 
fectly statable view, even in face of such seemingly intelligent action as chess playing.

If this is Professor Warren's point I think he has made it. Materialism is a perfectly statable hypothesis. The question still remains, Is it true? Is it or is the opposing hypothesis true? For as Professor Warren recognizes, the anti-materialistic view of intelligent activity is also perfectly statable. We have, in short, on our hands the two opposing hypotheses that we have always had, and the difficulties of each are exactly what they always were. The trouble with Professor Warren's type of Materialism has always been that it denies the efficiency of consciousness and thereby gets itself into all the tangle of difficulties faintly suggested earlier in this lecture. Nor can I see that Professor Warren has done anything to avoid or to diminish those difficulties. In fact he seems at times not even to realize what they are. At the close of his paper on "The Mechanics of Intelligence" he deals briefly with "the rôle of consciousness," and all he has to say as to the dangers which Materialism runs in denying to consciousness all real efficiency is the following: "However much my actions may be determined mechanistically or unconsciously or subconsciously, it is my 


\section{THE MIND-BODY PROBLEM 29}

conscious experiences,--my perceptions, feelings, imaginings and thoughts,-that mean life to me. The proved value of consciousness is the subjective life which it furnishes to the mind." 1

It is of course plain that this response does not even come in sight of the real difficulties involved in the denial of the efficiency of consciousness-difficulties which resulted in the almost universal rejection of Materialism twenty years ago. My conclusion, therefore, is that, so far as Professor Warren's arguments are concerned, the New Materialism is in no better case than the old and that, like its predecessor, it demands of us an amount of credulity utterly unjustifiable by any considerations it has to offer.

No one, I imagine, sees more plainly the difficulties we have just been considering than Professor Montague. To him, as to most anti-materialists, the efficiency of consciousness is so obvious that it is futile to deny it. In fact it is with great hesitation that I include him among the materialists. In many respects his view approximates closely to Interaction. Yet I have two reasons for calling him a materialist which, I think, justify me in doing so: the first is 1 "The Mechanics of Intelligence," p. 620. 
that he calls himself one, ${ }^{1}$ and the second that he identifies consciousness with a form of physical energy in the brain, much as did the first form of the older Materialism. His improvement upon the older view consists in giving up the obviously absurd assertion that consciousness is the motion of brain molecules and suggesting instead that it may be some form of potential energy stored up in the brain, and presumably at the synapses. It was in this form that Professor Montague first expressed his hypothesis in his paper, "Are Mental Processes in Space?" 2 and in his contribution ${ }^{3}$ to the "Essays Philosophical and Psychological in Honor of William James," both published in 1908. The thought was carried farther, with certain epistemological modifications, in his essay on "Truth and Error" in the "New Realism" (1912), in which he identified consciousness with causality. More recently in his paper on "Variation, Heredity, and Consciousness" ${ }^{4}$ he has proposed a new analysis of potential energy which in his opinion makes the identification of it with consciousness the more acceptable. According to this most recent suggestion,

1 Proceedings of the Aristotelian Society, XXI, p. 47.

2 Monist, XVIII, 2I-29.

3 "Consciousness as a Form of Energy."

4 Proceedings of the Aristotelian Society for 1920, pp. 13-50. 


\section{THE MIND-BODY PROBLEM 31}

just as kinetic energy is motion, potential energy is rest. A mass may move, and it also may stick to the same spot. It may move fast and it may also stick fast. And as there are many degrees of the fastness with which a thing may move, so there may be many degrees of the fastness with which it may stick. Just as motion may have any number of positive velocities, so rest, which is negative motion or negative energy, may have any number of degrees of negative velocity. This "negative energy would be a tendency to cling or endure in one position. It would, perhaps, be related to velocity as inertia is related to acceleration."

For this new concept of relative immovability, or negative energy, Professor Montague proposes the new name anergy. His thesis now takes the form of asserting that the anergy present at the synapses of the brain is to be identified with consciousness. "When a vibration-wave proceeding over a sensory nerve is gradually brought to a stop by the resistance of the synapse, its energy is transformed from a visible kinetic form to an invisible and potential form. As its velocity passes through the zero-phase, its slowness passes through an infinity-phase. I ask you to entertain the suggestion that this infinity-phase of 
slowness is the common stuff of all sensations and that the critical points of zero and infinity through which the motion and slowness respectively pass afford the basis for that qualitative absoluteness and discontinuity that differentiate sensations from mere rates of change." ${ }^{1}$ In other words, the potential energy stored up within the synapses is consciousness; and since there are as many rates of slowness or "anergy" below the zero point of motion as there are rates of vibration above it, there is ample room for all the variations which we find in conscious life.

Professor Montague has been at great pains to build up a new conception of potential energy and "anergy," and it is, I fear, a little unkind and unfriendly to assert that in all this he has done nothing to make the identification of consciousness with brain energy any easier. Nevertheless, that is the conclusion to which I am driven. It may perhaps be true that some of the difficulties which the imagination feels in identifying consciousness with moving molecules is avoided if instead of calling it motion we tuck it away quietly in the synapses where it may be out of sight, and make it less obtrusive to the mind's eye 1 Op. cit., p. 42. 
by keeping it very quiet at many degrees of motionlessness. But in the last analysis it is really as impossible to put meaning into the assertion that consciousness is rest as into the assertion that it is motion. Once and for all, by our psychic states we mean one thing, and by the physical states of our brains we mean another; and it makes no difference whether these latter be interpreted as motion or as rest, as quantitative or qualitative, as kinetic or potential, as energy or anergy.

I hasten to add that Professor Montague foresaw just this criticism and has left no stone unturned to find an answer to it. In the first place he points out that his view of matter and of mind are very different from that of Descartes; that matter should be conceived as possessing the secondary as well as the primary qualities; and that "each man feels his consciousness to pervade not only his body but the outer space in which objects appear." " If the limits of this lecture permitted it would be possible to show that both of these assertions would be very hard to prove, and a theory which rested upon them would be in much the same predicament as that of a house built upon the sand. As to the latter as1 "Consciousness as a Form of Energy," p. I20. 
sertion especially one wonders whether in Professor Montague's opinion the potential energy in the synapses of my cortex, which is identical with my consciousness, also "pervades the outer space in which objects appear." It is not necessary for our present purposes, however, to go into these matters; for even if we present Professor Montague with all the secondary qualities he wishes for his material world and endow his consciousness (and also his cortex) with the magical power of pervading all space, the identification of thought with brain energy would still be as absurd as ever. All the secondary qualities and all the pervasion of space imaginable will not help us in the least to see how his thought of Julius Cæsar can be a certain amount of anergy in his frontal or occipital lobes. Professor Montague argues that if we accept his non-Cartesian view of space and consciousness, "then the change of the kinetic energy of the stimulus into the potential energy of the sensation will not be a mysterious change of sheer quantity into quality." " This may be admitted, and the more willingly since it completely misses the point of the objection and still fails to put any meaning into the identification of consciousness with a "qualitative 


\section{THE MIND-BODY PROBLEM 35}

form of stress" in the brain synapses. Nor does it help matters to identify consciousness, as Professor Montague proposes to do, with the "higher phases of intensive energy." ${ }^{1}$ Finally, the series of analogies which are pointed out in several of Professor Montague's articles between potential energy and consciousness, while mildly interesting, are quite as unpersuasive and unimpressive as arguments from analogy usually prove. And even were they immensely more striking than they are they would do nothing toward overcoming the essential impossibility involved in the materialistic position. The hopelessness of the undertaking is seen even by materialists themselves, - that is, by those who adhere to what I have called the second form of Materialism. In Professor Warren's words, "If Professor Montague believes that potential energy is another name for consciousnessthat the two are identical-his assumption seems like identifying visual surface with the mass which we lift." 2

The identification of consciousness with energy and the denial of the efficiency of consciousness are the two horns of a dilemma which has in the past regu-

1 Op. cit., pp. I3I-32; “A re Mental Processes in Space?" pp. 27-28.

2 "The Mental and the Physical," Psy'. Rez', XXI, p. 83. 


\section{6

larly proved fatal for Materialism. Either one may be avoided but not both. The two defenders of the New Materialism whom we have thus far considered chose different horns to be avoided. Each carefully evaded one of the horns, each deliberately took his chance with the other, and each, as I have tried to show, came to grief. The third and last advocate of the old faith whose position we shall examine is more wary than his colleagues. He knows the dangerous nature of both horns of the dilemma and means to be transfixed by neither. In two articles and in chapters of three books ${ }^{1}$ Professor Sellars has sought to expound a view which (though indeed he does not himself explicitly call it Materialism) is, in its defense of Naturalism, essentially materialistic; and yet at the same time he insists that consciousness is neither to be identified with matter nor with brain energy ${ }^{2}$ nor to be robbed of its efficiency. "Consciousness is not extended after the manner of a physical thing for the very simple reason that it is not a physical thing." ${ }^{3}$ "It is nonsense to say that

1 "Critical Realism," I9I6 (Chapter IX); “The Essentials of Philosophy," 1917 (Chapter XXII); "An Approach to the Mind Body Problem," Phil. Rev. for March, I918; "Evolutionary Naturalism and the Mind Body Problem," Monist for October, 1920;

"Evolutionary Naturalism," I922 (Chapter XIV).

2 "Critical Realism," 223-24.

${ }^{3}$ Ibid., 244. 
the motion of atoms is consciousness." " The function of consciousness "is to aid in the bringing together of the parts [of a neural system] into a new integration by the cues it affords. Literally it assists the brain to solve problems." : "In deliberation we have a conscious process of survey, selection and combination. Ideas are led to their consequences and judged by them. And our decision certainly takes the form of a plan which guides our behavior and without which our actions would be quite different." ${ }^{3}$

Professor Sellars believes that his doctrine is able to avoid the two great difficulties of the older Materialism (which we have been discussing in this lecture) and yet to maintain a strict Naturalism; and that it can do this by means of two advances which thought has made in our century. One of these is a more adequate epistemology than was possessed by former defenders of Materialism, the other a new view of the nature of matter and its varied "levels."

Critical Realism, in contrast both to Naive Realism, to Neo-realism, and to Idealism, identifies conscious-

1 "Essentials," 260.

2 "Approach to the Mind Body Problem," I58. See also I57 and I 59.

3 "Evolutionary Naturalism," 3I2. See also 3 I I and 3I3. Cf. also "Critical Realism," 238, 249-50; "Evolutionary Naturalism" in the Monist, 590 . 
ness with the whole field of the individual's experience and at the same time insists upon the reality and the knowability of the physical. Consciousness is that which can be immediately experienced-or rather it is immediate experience; whereas the physical world is never directly intuited (as Naive Realism believes) and yet (contrary to the assertion of Idealism) it can be indirectly known. ${ }^{.}$This physical world, moreover, modern science seems to show, is not organized on simply one plan, nor subject to merely one set of laws. "If evolution is more than appearance, it surely implies a change in the mode of activity of parts of nature." 2 "It is no longer possible for a fair critic to identify Naturalism with the mechanical view of the world." ${ }^{3}$

The new and true Naturalism is therefore Evolutionary Naturalism. It must be remembered, however, that it is the material world that is evolving, and that the new laws of action on its higher levels are still the laws of the material world, nor can it be admitted by the defender of Evolutionary Naturalism

1 "Critical Realism," 215-217, 247; "Approach," 155-56; "Evolutionary Naturalism," 294-95, 303-05, 307, 310.

2 "Critical Realism," 235.

3 "Evolutionary Naturalism," i9. See also 292, 297, 302, all of Chapter I; in fact the whole volume is devoted to this contention. See also "Approach," I 59. 


\section{THE MIND-BODY PROBLEM 39}

that in any of these levels anything independent of the physical interferes with the regular physical activities. Anything like interaction between consciousness and the brain is strongly repudiated. The physical world is a closed system. The laws of action of the lower material levels, moreover, are not abrogated. The new categories which apply to the new levels are continuous with the old ones and must not conflict with them. ${ }^{2}$ The old laws must be obeyed, the new ones being apparently additive merely.

The question must of course immediately present itself to every reader: Can this kind of modified Naturalism be really compatible with the efficiency of consciousness? Professor Sellars thinks that it can be if the true relation of consciousness to the brain be understood. "My thesis is that the living organism, when properly and adequately conceived, includes consciousness." "When the cortex functions, consciousness forms part of the nature of the brain." " The brain has at least two "variants," one of them neural activity, the other conscious content.

1 "Evolutionary Naturalism," 3I 4 .

2 "Approach," 154 .

3 "Ibid., I 52.

4 "Critical Realism," 247. Sce also 228-29, 231 ; "Evolutionary Naturalism," 298, 308; "Essentials," 264-65. 
Consciousness is thus a "variant" of the brain." "Psychical entities are not substances, but rather peculiar characteristics of neural wholes and inseparable from them." ${ }^{2}$ "Consciousness is the brain become conscious." ${ }^{3}$

This identification of consciousness with the brain does not, in Professor Sellars' opinion, involve the logical inconsistencies of the older Materialism; for "we do not mean that the same categories are applicable to the physical as known by the physical sciences and to consciousness." "As classes thought about by scientists, the physical and the psychical have contradictory attributes. This must not be confused with the question whether the physical as an existent can absorb consciousness." 4 In other words, Professor Sellars does not identify consciousness as such with brain substance or brain activity as such; but both consciousness and brain activity are variants of one organism. He simply means that "consciousness is not alien to the physical." 5 The brain thinks.

1 "When we call it a variant of the brain we imply that it is inseparable from the brain and penetrates it with right as a part of the reality of the brain." "Critical Realism," 244.

2 "Evolutionary Naturalism," 3I6 and 3I7.

3 "Critical Realism," 245.

4 Ibid., 228, 229.

5 Ibid., Chapter IX. 
We may be able to go all this way with Professor Sellars and still be unable to see any real answer to the question how Naturalism is to be made compatible with the efficiency of consciousness. Consciousness and the neural activity which controls our muscles and our conduct may well be two "variants" of the organism; but if this be proposed as an answer to our question, the old difficulty breaks out again in the further question, What is the relation of these two "variants" to each other? The answer proposed by Parallelism, that they are two parallel aspects of one reality and that they run along with no mutual influence, Professor Sellars explicitly and repeatedly rejects; ${ }^{1}$ and he is, naturally, even more determined in his opposition to Interaction. ${ }^{2}$ To be sure, "consciousness literally assists the brain to meet new situations" " ${ }^{3}$ yet consciousness and the brain never interact. Interaction would imply, as Professor Sellars points out, some degree of independence on the part of consciousness, at least while it lasts; and such independence and interaction would be incompatible with Naturalism. It is, indeed, hard to see how the

1 "Critical Realism," 246; “Essentials," 257-58; “Approach," I57; "Evolutionary Naturalism," 289-95.

2"Essentials," 254-57: Monist, 569-75; "Evolutionary Naturalism." $287-94$.

3 "Evolutionary Naturalism," 313. 
denial of Interaction can be compatible with the view that consciousness "literally assists the brain" and "guides behavior" so that without it "our actions would be quite different." One way out of the difficulty-and I confess the only one I can think ofis the way taken by Professor Montague,-namely that of restoring efficacy to consciousness by making it a form of neural energy. Something like this view indeed Professor Sellars seems often to take. "Consciousness is existentially present to that part of the cortex which is functioning, and the brain's space is its space." ${ }^{1}$ That is, it is in the brain, as light is in the diamond or electricity in the wire. "There is no valid reason to deny that consciousness is an extended manifold. It arises in and is effective in the physical world. Its unity is that of the integrative activity of the brain which it helps to direct. Hence it is as extended as the brain is." ${ }^{2}$ That Professor Sellars at times seeks to solve the difficulty of the efficiency of consciousness through the identification of consciousness with the activity of the brain-an identification which at other times he emphatically denies-is made more evident through his explicit

1 "Critical Realism," 244.

2 Ibid., 247. Cf. also 245-49. 
identification of the mind with the organization of the brain ${ }^{1}$ and his occasional implicit identification of conscious processes with mental processes. Intelligent behavior is to be accounted for by nervous processes, ${ }^{2}$ since mind is a physical category. "Our view takes the sensori-motor process as a unit and holds that cortical integration of which consciousness is an element is always genetically continuous with a motor pattern of the brain. In other words, cortical integrations arise in one system with motor tracts." 3 "Psychical entities are peculiar characteristics of neural wholes and inseparable from them. . . As soon as they are conceived as more than contents, as more than they themselves reveal, as soon as they are given by themselves power to do things, they become to the deceived thinker non-physical and alien to physical reality." " "The brain as mind is a more or less integrated system of propensities and interests which respond to the situation in which the individual is placed. And such interests must not be thought of as physiological in any sense that excludes discriminative appreciation. They are neu-

1 "Critical Realism," 252-53. "Evolutionary Naturalism," 300-02, 315-I6.

"Evolutionary Naturalism," 300.

3 Ibid., $3 \mathbf{I} 4$.

4 Ibid., 3 I 7. 
rological systems whose urgencies are inclusive of mental contents. Consciousness must be connected psychophysically with neural processes of some reach. Attention itself can be understood only as a forward movement or passage in which the cerebral activity makes its path. What we must seek to do is to deepen our conception of the brain as at once activity and content. It is sensori-motor, ideo-motor; it is a stream of tendencies lit up by consciousness. The brain is synthetic because it is active. It is a more or less unitary process controlled by the neuronic system which is functionally uppermost." ${ }^{1}$

I cannot say I am perfectly sure what these last quotations mean. But this at least is plain to me: that if they offer a method by which the universality of Naturalism can be made compatible with the efficiency of consciousness, this method consists exactly in identifying the psychical with the physical. If this identification is not intended by Professor Sellars I cannot understand either how he proposes to save the efficiency of consciousness or what it is he means by interpreting propensities, interests, discriminative appreciation and attention as neurological systems or forward movements of cerebral activity.

1 "Evolutionary Naturalism," 315-16. 


\section{THE MIND-BODY PROBLEM 45}

In other words, I cannot see that Professor Sellars has done anything to help Materialism out of its old dilemma of being forced either to identify consciousness with the brain or to deny its efficacy. Neither of the advances he has made over his predecessors of a former generation has really made the difficulty any less real. Critical Realism is perhaps compatible with Materialism; but it is at least equally compatible with Interaction. Nor does the existence of "higher levels" of matter in the organic world give any real assistance. For even on these higher levels, we are told, nothing can conflict with the mechanical laws; and the new and higher laws of these levels are also, of course, still physical. Neither the old laws nor the new, therefore, can be interfered with or modified by consciousness (unless consciousness itself be physical) without wrecking Naturalism and the whole materialistic scheme quite as disastrously as Interaction ever threatened to do. Professor Sellars does not seem to realize that the ultimate difficulty of Materialism lies not in the kind of physical laws which it sets in absolute control of mind and of human behavior, but in the setting any physical laws in absolute control. Let matter be as highly evolved as you like, if its processes completely determine action, the 
efficiency of consciousness goes by the board. To seek to dodge this uncomfortable fact by glowing accounts of the subtlety and fineness of modern matter on its "higher levels" is like trying to console the condemned criminal on his way to the gallows by assuring him that the rope with which he is to be hung is not made of common hemp but of the finest and strongest silk. And any doctrine that denies the efficiency of consciousness must face all the serious and, I believe, fatal consequences which proved so disastrous to the older Materialism.

Other writers than those considered in this lecture might, of course, be added to the list of neo-materialists. But the three we have examined are typical in the sense that between them they seem to exhaust the possibilities. Professor Warren avoids the absurdity of identifying consciousness with brain but does so only by making consciousness inefficient and thereby committing himself to consequences that seem equally difficult of acceptance. Professor Montague clings to the efficiency of consciousness but only at the cost of calling consciousness a form of neural energy. Professor Sellars is unwilling to commit himself to either of these difficulties; and ends by falling a victim to both. My conclusion can only be that the 


\section{THE MIND-BODY PROBLEM 47}

New Materialism has failed to bring forth a single consideration that makes the materialistic hypothesis really easier of acceptance than it was at the time when nearly every thinker gave it up, twenty years ago. 


\section{LECTURE II}

\section{PARALLELISM}

In the preceding lecture we considered the general nature of the mind-body problem and the materialistic solution of it. We saw the reasons-and very conclusive ones indeed they seemed-which led almost all thinkers toward the close of the Nineteenth Century to abandon Materialism; and we considered also the attempt by some of our contemporaries to resuscitate it. The new arguments, we saw, were quite helpless before the old difficulties, and we were, therefore, forced to conclude that Materialism, whether old or new, was an altogether untenable and hopeless position. The result of the lecture thus seemed purely negative. Yet it was not wholly so. For it was a considerable step in the process of elimination by which we may well hope to reach in the end a positive solution. It is, therefore, with renewed courage that we turn to the much more promising theory of Parallelism.

In turning from Materialism to Parallelism we are in fact following the example of most Nineteenth 
Century materialists. For it was in Parallelism that nearly all of them took refuge when the difficulties of their former doctrine were fully revealed; and their choice of refuge was well made. For Parallelism seems to possess all the naturalistic advantages of Materialism with none of its difficulties. Unlike both Materialism and Interaction, it is no naive and primitive doctrine, but a careful, artistic, and selfconscious effort to avoid the difficulties which proved so serious to its rivals. With these difficulties in mind it has aimed chiefly at three things. The first of these is the application of the mechanical laws of Naturalism to all physical processes, those of the human brain included. Every physical event, the behavior of men as well as the falling of stones, must be entirely explicable on purely physical principles; and the law of the conservation of energy must be nowhere infringed. This is the primary motive of Parallelism and by strict adherence to it the difficulties of Interaction are clearly avoided. But of almost equal importance to the parallelist (if we may believe his protestations) is his second aim, namely to retain the independence of consciousness within its own realm and thereby to avoid the difficulties of Materialism. To apply mechanical laws to all human 
behavior and yet to retain belief in the independence of consciousness, of course, seems at first sight a difficult feat; but the parallelist is persuaded he can achieve it by avoiding, finally, a pitfall into which, ms, both the interactionist and the materialist fell,namely the belief in causal action between two such diverse entities as mind and body. Causal action, says the parallelist, may be found in the physical stream, or in the psychical stream, or in both, but never crossing from one to the other. Bodily events and mental events flow parallel to each other in coordinate series, but without mutual influence. But though there is no interchange of causal activity between the two streams there is a strict concomitance. For every mental state there is a corresponding bodily state and vice versa; and this one-to-one correspondence holds not only of the mental and bodily states as wholes but also of their parts-as indeed it obviously must if the doctrine is to be self-consistent.

( Such is the theory of Parallelism in general. So much all its adherents, as I understand them, maintain. But the theory is a very elaborate and subtle one, and, as might be expected, it has several subtypes or variations. Conceivably there are at least five possible ways in which mind and body 
might be represented as running parallel to each other without causal relation. ${ }^{1}$ The first of these is frankly dualistic, while the four others have more or less of a monistic slant. Dualistic Parallelism simply states the parallelist view (as I have attempted to do above) without explanation.; But this bald form of the doctrine need not detain us, inasmuch as no one, so far as I know, has ever defended it. It has no real adherents for obvious reasons. (If mind and body be regarded as two separate kinds of being, neither of them in any way dominating or influencing the other, their unfailing concomitance would be one of the most astonishing facts in the universe-an unbroken succession of unaccountable coincidences which could at best be attributed only to some sort of miraculous agency or Pre-established Harmony. ) For a somewhat similar reason we may dismiss, as almost all parallelists have done, a second possible form of the doctrine, which would make the physical series funda-mental, and the psychical merely an epiphenomenon. Although this view seems to be upheld by both Münsterberg and Ziehen, it is plainly open either to the difficulties of Dualistic Parallelism just considered or to the equally serious difficulties of Materialism. 1 See the diagram on page 7 . 
There remain for our consideration the two great forms of Parallelism to one or the other of which practically all the adherents of the school belong. These are the so-called Double Aspect View, in its two subordinate types, and Idealistic Parallelism.

The Double Aspect View depicts the mental and the bodily series as equally real, yet does not, like mere Dualistic Parallelism, leave us with a series of unexplained coincidences on our hands, but shows us why the two series are always parallel. This reason is to be found in the hypothesis that mind and body are not independent and substantive things but are merely two aspects of the same Reality. The commonest illustration is that of the curved line, which on one side is convex, on the other concave. Suppose such a line with many curvings and twistings; the succession of concavities and convexities on one side would correspond exactly to the convexities and concavities on the other, and yet without any interchange of causal activity between them. Many other illustrations have been suggested, one of the most recent being that of Professor Warren-the relation, namely, between the mass and the surface of a physical object. These two vary concomitantly, yet neither is the cause of the other. 
Unfortunately for my exposition and your understanding, there are two forms of this doctrine; and it is not always easy in reading the expositions of its adherents to know which is the one intended. That both mind and body are merely aspects of something else is strenuously maintained, but just what they are aspects of is not always clear. A careful reading, however, discloses two distinct suggestions. Sometimes it is maintained that mind and body are aspects of each other; sometimes that they are aspects of some known or unknown Tertium Quid. I think the first of these doctrines should not detain us a great while. If mind and matter are not aspects of some third reality they presumably constitute between them at any rate the major part of the actual universe. If now one of these two forms of reality is nothing but an aspect of the other, and if the other likewise is nothing but an aspect of the one, our universe shrinks into two mere appearances which are not the appearances of anything and do not appear to any one. We are presented merely with two shadows, each the shadow of the other. It is hard to take such a suggestion seriously; and in reading grave expositions of this view one feels transported into the Wonderland where Alice had her remarkable ad- 
ventures, and one seems to see the smile of the Cheshire Cat still hanging on in the sky, long after the cat itself has completely dissolved into thin air.

If we are to accept the Double Aspect View, then plainly we must assert that mind and body are aspects of some third thing, the true reality back of the two diverse appearances. The proposition seems in many ways exceedingly attractive. Questions, however, throng upon one the moment one seeks to be clear about the real meaning intended. How shall one construe this Tertium Quid which by hypothesis is neither mental nor physical? If it be really neither of these can we know anything about it? And if it be an Unknowable, how can we get from it any real explanation? We have constructed it only for the sake of explaining by its aid certain facts of our life; but how can we hope to explain the known by recourse to the Unknowable- "that refuge of ignorance"? Nor can it be said that the illustrations proposed really throw any light whatever on our problem. We can see very well how the convex and concave sides of a line parallel and must parallel each other. But we see this because convexities and concavities are both curves-both the same sort of thing -and because, knowing what a line is we see how 
its two sides follow from its nature. But can it be seriously maintained that this in the least helps us to see how two things admittedly so diverse as mind and body can be two sides of a Something-I-knownot-what? The best that can be said for the proposition is that inasmuch as we know nothing of the Unknowable we know not what aspects it may have. But surely such an assertion is far from illuminating; and instead of being a positive theory concerning empirically known facts it is merely a confession of ignorance about an arbitrarily assumed entity so constructed that no one ever could know it.

The curved line with convex and concave sides, then, throws little light on our problem. Nor can it be said that the other illustrations of things with two aspects, suggested by various writers, are any more helpful. Höffding's example of the idea that is expressed by different words in different languages; Lasswitz's suggestion of the sum of borrowed money which for one person is an asset, for the other a debt; Fechner's later illustration of the solar system which from the earth appears to move in Ptolemaic fashion, from the sun in Copernican-these proposals in so far as they are helpful at all are merely aids to the imagination, not to thought; in fact they darken 
thought by obscuring the real situation and persuading us to be satisfied with a verbal solution and a visual image. Possibly Professor Warren's comparison already referred to-the mass and the surface of a material object-may have some ad antages over its predecessors; but if so they are not sufficient to make the illustration really helpful-as a moment's careful examination will make plain. Mass and surface are the diverse ways in which an identical physical object-perhaps in itself a center of force-affects respectively the muscular and the visual senses. If this is to be taken as a serious illustration of the way in which mind and matter may be regarded as two aspects of the same thing, we may suppose that the Tertium Quid-whether center of force, Unknowable, or what-not-affects two different senses and two different brain centers in two different ways, and that mind and matter are just these ways. Matter then is to be conceived as the way in which the Tertium Quid affects certain sense organs and brain centers. But what are these organs and centers? Of course they too are matter. Thus we have defined matter as the effect which something has upon matter. Such a view is patently unstatablethe thing defined is presupposed in the definition. 
There is only one other way in which Professor Warren's illustration can be applied to our problemonly one other way, in fact, so far as I can see, in which the Double Aspect Theory can be given any meaning at all. This is obviously to say that mind and matter are the two ways in which the Tertium Quid appears. But the question at once asks itself: "Appears" to whom? If you define a thing as an appearance you necessarily presuppose some one to whom it appears. An appearance must be an appearance in or to some conscious being. What then is this conscious being? What is this consciousness to which consciousness appears? . . Again we have included within our definition the thing to be defined. We have been able to put meaning into our Double Aspect Theory only by presupposing the very things which we seek to explain. We shall, I think, agree that a theory which cannot even be definitely formulated need detain us no longer.

Of the list of possible answers to the mind-body problem with which we started there remains but one unexamined. For Idealistic Parallelism is identical with the fourth general type of theory to which reference was made in the first lecture-that, namely, according to which mind alone is efficient while body 
is merely the resultant or appearance of it. We start our consideration of it, therefore, very favorably inclined in advance. When we come to closer terms with it, moreover, we find it in possession of one very obvious and weighty advantage over all its rivals. It is able, namely, to render unto Cæsar the things that are Cæsar's and unto God the things that are God's. While giving a perfectly definite account of what it means and while making it abundantly clear why mental and physical processes run always parallel, it is able to grant mechanical science full swing throughout the entire sphere of the physical with no least exception, and yet maintain not only that mind is independent of body but that mind is the true reality, and body merely its appearance.

In stating this great merit of Idealistic Parallelism I have, in fact, stated the theory itself. The only genuine reality, it maintains, is psychical in its nature. Body, on the other hand, is merely the phenomenon of mind,- the way in which one center of consciousness appears to another. And not only is this true of our brains and our bodies but of the whole physical world. For if this kind of Parallelism is to be consistent with itself it must be extended to a universal Parallelism. It must give a panpsychic in- 
terpretation of everything. Though this fact has not been fully realized by all adherents of the doctrine it can easily be shown to be necessary. For the changes that occur within one's experience and which, like sensations, cannot be accounted for by preceding events within it, must be explained by reference to the outer world; and since all causal influence of the physical upon the psychical is precluded by Parallelism, this outer world must be interpreted as being, upon its inner side and in its true nature, of the same psychic sort as our own experience-though presumably of a much lower and simpler order. This panpsychic interpretation is, in fact, gladly and eagerly accepted and proclaimed by the more philosophical advocates of Idealistic Parallelism. For the physical world as a whole being thus interpreted in idealistic fashion, the values of the spirit appear at length safe. Materialism is forever overcome. Yet, as Paulsen points out, it is overcome "not in the sense of being altogether false and groundless, for it surely is not that. Its demand that everything that exists be explained physically is perfectly well founded and this demand Parallelism fully satisfies. The physicist must still assume the universe to be a physical nexus embracing the whole of reality. Materialism, how- 
ever, is vanquished in so far as it now appears to be a one-sided view of existence that can and must be supplemented. . . . The corporeal world is at bottom but an accidental concept, an inadequate representation of existence in our sensibility." 1

Thus the age-long conflict between the demands of natural science and the needs of the spirit seems at length ended by a peace that is fully satisfying and honorable to both sides. The philosophical defender of the concept of causality is shown to be justified in his contention that between two such diverse entities as mind and matter are commonly depicted as being, there can be no interchange of causal influence. The natural scientist is allowed to stride through the whole of the physical universe explaining every minutest event within it on purely mechanistic principles. The law of the conservation of energy is nowhere questioned. No private domain is hedged off, even within man's brain, in which the laws of physical science are refused absolute dominion. No interference is allowed with them even by the human will. And yet the whole of this complete, mechanistic physical world is shown to be merely the outer side, the phenomenal appearance, of the true reality within-a reality

1 "Introduction to Philosophy," English Translation, pp. Iro, III. 
which in itself is not physical at all. Thus the truth of matter is seen to be spirit.

So much for the theory in general. So important and promising a doctrine, however, deserves further analysis. And first of all we must note once more the fairly obvious fact that Idealistic Parallelism is and means to be Parallelism. Let me quote at some length an expository passage from one of its most prominent proponents, the late Professor Paulsen. "The physical processes in the brain form a closed causal nexus. There is no member [of it] that is not physical in its nature. One would see as little of psychical processes, of ideas and thoughts [in the brain] as in the movement of a mill. A man crosses the street. Suddenly his name is called; he turns around and walks toward the person who called him. The omniscient physiologist would explain the whole process in a purely mechanical way. He would show how the physical effect of the sound-waves upon the organ of hearing excited a definite nervous process in the auditory nerve, how this process was conducted to the central organ, how it released certain physical processes there which finally led to the innervation of certain groups of motor nerves, the ultimate result of which was the turning and movement of the body in 
the direction of the sound-waves. All these occurrences together combine into an unbroken chain of physical processes. Alongside of this, another process occurred of which the physiologist as such sees nothing or needs to know nothing but with which, however, he is acquainted as a thinking being who interprets his percepts: there are auditory sensations which aroused ideas and feelings. The person called heard his name, he turned around in order to see who had called him, and why he was addressed; he perceived an old acquaintance and went to greet him. These occurrences accompany the physical series without interfering with it; perception and presentation are not members of the physical causal series." ${ }^{1}$

The physical and chemical laws are thus nowhere interfered with, not even in human purposeful activity. The absolute universality of mechanical law is preserved. That is the First and Great Commandment of Parallelism. And the Second is like unto it. Physical processes never interfere with psychical processes. The two series simply accompany each other. So much for the parallelist side of Idealistic Parallelism. Now for the idealist side. The physical

1 "Introduction to Philosophy," English Translation, p. 84. 
and psychical series always and invariably and exactly accompany each other because the physical is merely the appearance of the psychical. The facts of sense-perception as well as the whole line of argument emanating from Berkeley and his school show conclusively that physical objects are not in themselves what they appear to be. Certainly their color, taste, temperature, and possibly also their spatial characters they get from the peculiarities of our senseperception. Hence, argue the idealists, they cannot be in themselves identical with their appearance in our sensations. How then shall we construe the inner nature of physical reality? Let us, they answer, try to unlock this mystery by the only key that we possess. Only in self-knowledge, only in the experience of our own mental states do we get at reality directly,reality in itself and not mere appearance. This in fact is what we do in interpreting each other. So far as your perception is concerned, I am to you but a body, a collection of matter. But the real self of me you interpret on the analogy of your own mental states. Why not use the same method in interpreting the rest of the material world? It is, at any rate, by considerations of this sort that the panpsychist reaches his conclusion. Matter everywhere is merely 
the appearance of mind; it is merely the effectactual or possible-produced by various psychic centers upon the sensibilities of various perceivers. This general idealistic view being accepted, it is easy to see how Parallelism may naturally result.

But we must be still more detailed in our analysis. Every portion of matter in the world is the appearance, or the possible appearance, of a psychic state; and every psychic state appears or may appear to some perceiver as a material object. The second half of this proposition does not follow necessarily from panpsychism, but it is the view held by all idealistic parallelists. What then is the material appearance of your consciousness and mine-the consciousness with which the mind-body problem is primarily concerned? Plainly it is not our hands and feet, for these may be cut off and our consciousness continue what it was before. Hands and feet, to be sure, and every cell of the body, like other physical objects, must, on panpsychic principles, be the appearance of psychic centers, but these presumably are centers of lower degrees of development than the personal consciousness. Where, then, shall we look for the material side, so to speak, of the personal consciousness? Careful parallelists, such as Professor Strong, agree 


\section{PARALLELISM}

in maintaining that this is to be found in the cortex of the cerebrum. Since this is recognized by all physiologists as the real and only direct correlate of consciousness, the only part of the body whose activities can conceivably be regarded as parallel to the activities of the mind, Strong's conclusion and that of the great majority of parallelists is unavoidable. The cortex is the appearance, the phenomenon, of the personal consciousness. This is a most important and fundamental part of the doctrine in question. That is to say, the cortex is the effect which the personal consciousness makes or the possible effect that it might make, upon other perceivers. The personal consciousness, in its turn, is the inner reality of the cortex; it is that which appears (or which would under suitable conditions appear) to the eye of the observer as a collection of gray neural matter. If the personal consciousness has any physical correlate or appearance it is this; and since on parallelist principles it must have' a physical correlate or appearance, this it must be. Parallelism, therefore, plainly stands or falls with this identification of the personal consciousness with the cortex. If we can prove it true we shall have refuted all opposing theories,although, of course, if this identification should turn 
out to be false, Idealistic Parallelism would be put in a serious situation.

Is it possible to find a test case that will settle this crucial question of fact? Fortunately it is. An actual experiment may be tried by which the question may be definitely settled whether or not the cortex is the appearance of the personal consciousness. For there is one situation in which the personal consciousness vanishes and hence ceases to appear altogether. I refer, of course, to death. Whatever else death may be, and whatever theories we may hold about it, we all agree that death is either the complete cessation of the personal consciousness or at least the severance of it from all relation to the body. The lower cells of the body continue in existence, according to Idealistic Parallelism, because the lower conscious centers, of which they are the appearance, continue to be conscious. But the personal consciousness has disappeared. It has ceased to have any "appearance." It has quite vanished. Hence, as good parallelists, on opening up the skull of the dead man we shall know what to expect. If our theory is true we shall indeed find the white matter of the brain intact, but there will be no gray matter, no cortex. 
I need not tell you that, as good parallelists, we shall be disappointed. We open up the skull and there before us is the gray cortex, appearing, as unmistakably as anything can, just as if the personal consciousness of which it is merely the appearance had not disappeared. What shall we make of this situation? Certainly it is an odd fact that almost the only time when the cortex is ever actually seen is just the time when according to our theory it ought to have disappeared altogether!

However humbled we may feel as parallelists at the result of our experiment, we shall as searchers for the truth be thankful that after so much theorizing on our problem we have at any rate come upon one solid, incontrovertible fact. Whatever else may be true of their interrelation, we know that the cortex is not the appearance of the mind. Can Idealistic Parallelism be reconstructed so as to make room for this fact? Two alternatives are open to us. We might, in the first place, while retaining our Panpsychism, change our interpretation of it so as to assert that the psychical centers back of the cortex are, like those back of the other parts of the body, centers of lower grade than our personal consciousness, and that this is why the cortex continues to appear after the 
personal consciousness has vanished. But if we take this view, there will be no portion of the brain or body left for the personal consciousness to parallel, nor any physical series to be its appearance. The personal consciousness would thus be without physical correlate or phenomenon. Such a view might be defensible, but it would not be Parallelism. For thus the personal consciousness, whose relation to the body Parallelism is seeking to explain, would be left unexplained. The second alternative would be to deny the idealistic view altogether and to interpret the brain in frankly realistic fashion. This would, of course, be to abandon Idealistic Parallelism, but the parallelistic part of the doctrine might still be saved. Yet it must be noted that if we abandon the idealistic interpretation of the cortex as the appearance of the mind we are thrown back on one of the two indefensible forms of Parallelism which we examined and were forced to reject in the first part of this lecture. We have no more reason than we had then to say that cortex and mind are two aspects of the same thing; nor can we present the two series as simply parallel, in the fashion of Dualistic Parallelism, without the same impossible appeal to an unthinkable succession of unaccountable coincidences. 


\section{PARALLELISM}

I can think of no way in which Idealistic Parallelism can get out of the difficulties which face it as soon as one grasps the unquestionable fact that the cortex is certainly not the appearance of the mind. Yet, inasmuch as the theory has been such a favorite among psychologists it may be well to submit it to still further analysis. For the moment, then, let us suppose that in some unimaginable fashion the ideal. istic parallelist can retain his theory (in spite of the facts) that brain events are the appearance of mind events. It is interesting to note that if this be the case, the two series are not contemporaneous but successive. The physical event must always follow the psychical event with which it is correlated. Professor Strong, to be sure, in the concluding chapter of "Why the Mind Has a Body" denies this; but he does so only by surrendering for the moment his entire idealistic theory and going over (temporarily) to the Double Aspect or Identity Theory, which he had vigorously repudiated a few pages before. The parallelist, indeed, is fortunate in possessing three or four different theories, each of which is, to be sure, inconsistent with the others, but all of which pass under the same general name of Parallelism; so when he gets into difficulties by pursuing one type of Par- 
allelism he can speedily take refuge in another till these calamities be overpast. If we insist upon thinking straight, however, it is easy to keep the various Parallelisms separate; and it is perfectly plain that if we are to call the brain the appearance of the mind, that is, the actual or possible effect of the psychical series upon the sensibility of some other perceiver, then a minute portion of time will be required for this process of appearance or perception to take place; and hence the physical event will be subsequent to the psychical event. This, of course, is not inconsistent with Parallelism though it makes it look a bit tipsy. But a much more interesting consideration follows as a corollary from these conclusions. The physical event, namely, is not only subsequent to the psychical event but it must be regarded as caused by the psychical event. The parallelist cannot get around this. If the word appearance means anything for him it means that something appears to some one; that is, that it produces an effect in some one's sensibility, in some one's consciousness. Physiological psychology describes this perceptual process in causal terms, and so far as I am aware, no parallelist questions the description. He translates it, of course, into psychical terms, but this means that he merely puts physical 
causation back into psychical causation. That is to say, one psychical center affects another psychical center in such a fashion that the second experiences a certain sensation. A series of psychical events cause a series of percepts. The parallelist can hardly deny this causal influence in the production of the percept or physical appearance; for to do so would be to return to mere Dualistic Parallelism with its inexplicable series of miracles. This causal relation, however, is not of the physical sort-for physical causation is, of course, only appearance. The only true causality, as distinct from appearance, is that found within each of the psychical series, and between one psychical series and another. In the latter case, this psychical causation would appear to be a kind of telepathy-an immediate influence of one conscious center upon another without the intervention of anything physical. Within the physical series, on the other hand, there is no causal influence or activity whatever. Each link in the chain of the physical appearance is pulled along not by the preceding physical link but by the preceding psychical link. Thus the idealistic parallelists misstate the matter when they say that we have two independent series which run off parallel with each other. It is not true (as Paul- 
sen maintains) that the psychical occurrences simply "accompany the physical series without interfering with it." Such a description would hold of Dualistic Parallelism and of Double Aspect Parallelism, but not of Idealistic Parallelism. The typical parallelist scheme which Paulsen thinks he is defending might be represented thus:

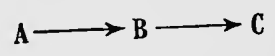

1

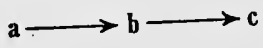

Capitals symbolize psychical events and small letters physical events, while arrows indicate causation or productive influence.

But this scheme, as I have said, applies only to the two kinds of Parallelism which we rejected early in this lecture and which Paulsen and Strong reject. Idealistic Parallelism must be represented thus:

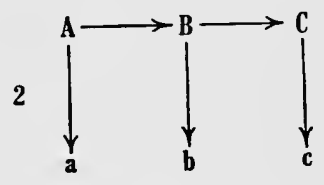

It will be seen that the physical is as completely stripped of causal efficiency by this view as the psy- 
chical was stripped of it by Materialism. No physical state, on the hypothesis of Idealistic Parallelism, ever causes another physical state, but each is directly caused by a psychical state.

Such a theory seems odd enough in all conscience. Yet the oddest part of it remains to be mentioned. The panpsychist with no parallelist leanings might indeed maintain it simply in the form I have stated; but the parallelist invariably goes on and adds the further assertion (which to him is fundamental), that though the psychical series is the only one that acts, the only one with any causal efficacy, it always acts in such a way that its appearance-the physical series -will invariably unroll in accordance with mechanical laws. I suppose a parallelist might be conceived who would not make this additional demand but would be content with the simple panpsychic formula. But as a fact I have never heard of such an easily contented parallelist and I do not believe there is or there ever has been one. The reason for this is plain. Parallelism, as we have seen, is a very artificial and carefully constructed scheme and the great motive in its construction is to find a way in which universal mechanism may be maintained. One who had no such ax to grind, one who came at the facts with 
an entirely free mind and sought merely to report what he seemed to find, would never think of Parallelism. This is something which deserves repeating. The known facts of brain physiology, taken by themselves and out of their relation to the rest of the physical world, would never suggest Parallelism. To suppose that Parallelism is based on the empirical discoveries of physiological psychology is completely to misunderstand the situation. Parallelism is based not on facts, but on a theory-on the theory, namely, that mechanical laws are universal. It is an attempt to devise a way in which this theory may be made consistent with the facts of physiological psychology. Hence the strained and somewhat fantastic nature of the resultant, the odd mixture arising from the combination of universal mechanical law with a view of the brain which makes it merely an appearance of the mind-and usually a non-actual but only possible appearance at that. The real events (the psychical series) must take care, whatever else they do, to preserve appearances-to maintain scrupulously the scientific regularity of their physical phenomena. Suppose now that we have a condition of my brain and of the rest of the physical world-condition A let us call it - which is such as to necessitate, accord- 
ing to mechanical laws, that it be followed by condition B. Suppose condition B is such as necessarily to let loose certain motor impulses into my muscles and bring about action C. Suppose, however, that while my brain is in condition A, I decide-for purposeful, logical, or æsthetic reasons-not to do C but to do N. What will happen? Either I can do N, and do so and thereby break the mechanical laws; or else I cannot do $\mathrm{N}$, nor even decide to do $\mathrm{N}$. The latter view will, of course, be that taken by the parallelist. He will insist that once my brain was in condition $\mathrm{A}$ the mind state which should accompany brain state B was already determined-a mind state, namely, that would be a desire to perform the act C. Thus it is really the mechanical laws of the appearance or of the merely possible appearance that determine the activity of the real being back of the appearance. The appearance of the mind-namely the brain-has no causal efficacy whatever, not even within its own series; throughout the life of almost every one of us it never is even a real appearance but only a possible one. Yet the mechanical laws of its behavior, and not the teleological, rational, æsthetic, hedonic relations between ideas and impulses, dominate every process not only within the physical but 
also within the psychical series. The action of the reality is altogether determined by the laws of its merely possible appearance. It is a remarkable case of the tail wagging the dog.

The seriousness of this situation must be realized quite irrespective of its incongruity. It involves the necessity of really giving up all teleology even in the mental life. It means that it is not the consciousness of logic and of purpose, nor the laws which introspective psychology studies, that control the flow of our thoughts, the course of our reasonings, and the sequence of our actions upon our purposes; not psychical laws determine these things but the same mechanical laws, never guessed at in introspection, which govern the dance of atoms in the chemist's retort and the fall of snowflakes in the polar regions.

The same conclusion forces itself upon us if we consider the parallelist view of the nature of mind; and what I shall have to say on this topic applies not only to the idealistic parallelist but to every form of Parallelism. In order that Parallelism may be true we must suppose a correspondence between mind and brain so complete that not only shall the two parallel each other in a general way but that each part or section or aspect of the one shall find an equivalent 
part, section, or aspect in the other. Corresponding to every brain state and brain part there must be a mind state and mind part. For back of every appearance the idealistic parallelist must find a reality that appears; and the upholder of the Double Aspect Theory must insist that all the details of one aspect stand in one-to-one correspondence with the details of the other. The reverse is also true; for every state of consciousness and every change in it there must be a corresponding section or activity of the cortex. Otherwise our Parallelism would be broken.

This doctrine of complete correspondence, unavoidable for the parallelist, determines his view of the nature of mind. Brain is a collection of parts, each of which is indefinitely divisible into smaller parts; hence mind also must be a collection, must be constituted of parts each susceptible of indefinite further analysis. The seeming unity of mind must be explained away, and such things as comparison, apprehension of likeness and of difference, the sense of our own continued identity, the consciousness of meaning, must be analyzed into a mere succession of simple psychic states. Nor can the parallelist stop here. Inasmuch as the brain is divisible into parts much smaller than any that can be thought of as cor- 
responding to even our simplest feelings or sensations, both sensations and feelings must be analyzed into simpler and simpler parts, parts which indeed are still called psychic but which we never experience. Thus all thought, feeling, conviction, choice is explained by a kind of mental chemistry; and the whole human mind and human personality is reduced to a collection of presumably homogeneous mind-dust,a mind-dust which, of course, like other dust, acts in strict obedience to the universal laws of mechanics.

Concerning the unity of consciousness in its more general sense I shall have something to say in another connection. Here I wish to dwell for a moment upon the particular aspect of the question raised by the Mind-dust Theory. That all our conscious states are made up ultimately of minute psychic elements which somehow fuse,- - a position made popular by the support it received from Spencer, Clifford, and Münsterberg,--seemed to be forever refuted by Professor James' famous argument, in Chapter VI of his "Principles of Psychology." The assertion, he tells us, that mental units can be compounded with themselves so as to produce the conscious states which we know, is logically unintelligible; for "it leaves out the essential feature of all the combinations we actually 
know. All the 'combinations' which we actually know are effects wrought by the units said to be 'combined' upon some entity other than themselves. Without this feature of a medium or vehicle, the notion of combination has no sense. ... No possible number of entities can sum themselves together. Each remains in the sum what it always was; and the sum itself exists only for a bystander who happens to overlook the units and to apprehend the sum as such; or else it exists in the shape of some other effect on an entity external to the sum itself. . . . Where the elemental units are supposed to be feelings, the case is in no wise altered. Take a hundred of them, shuffle them and pack them as close together as you can (whatever that may mean); still each remains the same feeling it always was, shut in its own skin, windowless, ignorant of what the other feelings are and mean. There would be a hundred and first feeling there if when a group or series of such feelings were set up a consciousness belonging to the group as such should emerge. And this 101st feeling would be a totally new fact. . . . The 'integration' of a thousand psychic units must be either just the units over again, simply rebaptized, or else something real, but then other than and addi- 
tional to those units; if a certain existing fact is that of a thousand feelings it cannot at the same time be that of one feeling; for the essence of feeling is to be felt, and as a psychic existent feels so it must $b e$. If the one feeling feels like no one of the thousand, in what sense can it be said to be the thousand? " 1

This argument of Professor James, as I was saying, has for years been regarded pretty generally as having given the coup de grâce to the Mind-dust Theory. Within very recent times, however, the whole question has been reopened by Professor Strong, who with his usual keen sense for key positions, challenges James' central thesis, namely that the essence of feeling is to be felt and that as a psychic existent feels so it must be. On Professor Strong's view, consciousness is to be sharply distinguished from psychic states; introspection is never of the present but always of the past and hence indirect; and our psychic states, being thus only indirectly introspected, need not be what they seem, and do not, existentially, possess the unity which has commonly been attributed to them. To revert to James' figure, there are only the hundred feelings; 1 "Principles of Psychology," Vol. I, pp. 158-63. 
the one hundred and first does not exist at all. The seeming unity of consciousness is purely specious. It is due to the action of attention upon the many diverse psychic states. "It is attention then, not consciousness, that individuates. We should be more correct to speak of the 'unity of attention' than of the 'unity of consciousness.' . . . Attention has the inevitable effect of singling out and isolating the object on which it is turned and giving to it unity. But this unity is made; it is neither in the object itself nor in the psychic state." 1

The conception has been put somewhat more clearly by one of Professor Strong's disciples (if so I may call him), Dr. Picard. "It is the merit of Dr. Strong's work to have shown us that sensation (and of course every other seeming fusion as well) has no existential unity, but is the result of a certain convenience of treatment of psychic states controlled by the limitations of the attention process. The way is open, therefore, not to reëstablishing the doctrine of a fusion of separate sensations in the old sense, but to a new conception of fusion based on certain features of the mechanism of attention. Under this new conception of fusion, the fusion will not be con1 "Origin of Consciousness," 280, 28r. 
ceived as of sensations in their own right, but it will appear as a fusion in our attitude toward psychic states that are in themselves quite unalterably distinct. In shoveling coal into a furnace the separate coals in the shovel are not fused into one larger coal, but it is convenient for me to treat the coals en masse as one shovelful while I am performing the operation of shoveling." 1

The strength of this position-what strength it has-will plainly depend upon the tenability of Professor Strong's doctrine that we cannot introspect a present feeling and that psychic states exist normally - or always? - outside of consciousness, and hence that the essence of a feeling by no means consists in being felt but that on the contrary we can form very little notion of what a feeling really is like by feeling it. For that remarkable book, "The Origin of Consciousness," I have great admiration; yet most readers, I believe, will come away from it still unconverted from the old and fairly obvious belief that "as a psychic existent feels, so it must be." For if by a "feeling" we do not mean the way we feel when we feel it, it is hard to say what intelligible meaning the term can bear.

1 "The Unity of Consciousness," Jour. of Phil., XVIII, 350. 
Even if, however, for the sake of the argument we go with Professor Strong and Dr. Picard the whole distance so far as the unity of consciousness is concerned, we do not seem to be so far away from the point where Professor James and we started as would at first appear. For the seeming solution presented us is not a final solution but merely a restatement of the problem; we have shifted our difficulty from the nature of consciousness to the nature of attention. Psychic states, we are told, have no unity of their own; they get their specious unity from attention which makes what unity they appear to have. The shovelful of coals which I put in the furnace is not itself a unity; it gets its unity from me. What then am $I$,-or, more exactly,- -what is attention?

There are three possible doctrines as to the nature of attention, which I think will be found to include between them all possible views. We may take it, namely, in the behavioristic sense, as meaning the contraction of certain muscles and the adaptation of sense organs to stimuli. Or, if we are to view it in a psychical rather than a physiological way, we may look at it either from what Professor Breese calls the "content side" or from the "subject side." ${ }^{1}$ We

${ }^{1}$ Cf. Chapters I and III of his "Psychology." 
may, that is, identify it simply with the "clearer" portion of our total mental content, or we may use the word to indicate the activity and the concentrating power of the mind or self. Professor Strong and Dr. Picard may have their choice from these three uses; I am not able to imagine their inventing a fourth. Among the three their choice will pretty certainly light upon the first. ${ }^{2}$ Yet a moment's consideration will show that this physical interpretation of attention will be utterly useless to them. The processes that go on in the muscles of the brow and in the sense organs have, in the first place, no unity of their own. As Professor Strong himself puts it, "The motor attitude, as an objective fact, is obviously plural and complex, having only a unity given to it by its purposiveness or by our convenience in taking it as one." ${ }_{2}$ Moreover, it would be quite impossible to take seriously the proposition that these physical processes somehow pounce upon and single out certain past psychic states and put unity into them.

1 So Dr. Picard assures me, and so we might well guess from Prof. Strong's general position. Explicitly he gives us no direct answer. On page 269 of the "Origin of Consciousness" he tells us that "selective attention is evidently partly a matter of individual sensitiveness and partly a matter of instinct." $\mathrm{He}$ also speaks of the "muscles of attention." This is as near as he comes to telling us what he means by the word.

2 "Origin of Consciousness," p. 278. 
Nor is the second general meaning of attention any better suited to the unity-making function than was the first. If attention be merely a name for those parts of our mental content which possess the quality of clearness, it is a purely passive state and can do nothing. The third doctrine of attention does indeed furnish to Professor Strong and Dr. Picard all they could wish for. Attention thus conceived is an active power of the mind or self, and as such might well unify the otherwise chaotic psychic states. But from this doctrine of attention, the only one that can be of any service to Professor Strong, he will flee as from the pestilence. And not for nothing. For this doctrine of attention, while explaining fully the "specious" unity of consciousness, would be more fatal to the Mind-dust Theory than the admission of all other kinds of "unity" combined. For such attention would have a unity of its own, and one so genuine and so significant in its implications that if once acknowledged it would shatter to hopeless fragments the whole scheme of mind-stuff and mental chemistry.

Much more might well be said upon this theme and upon its obvious bearing on the parallelist view of the indefinite divisibility of mind and the possibil- 
ity of correlating a psychic state of minute proportions with each of the minute sections or specks into which the brain might conceivably be divided. But for this there is no further time; and I shall simply confess in passing not only that I find it difficult to view human personality as an organization of minddust, but that I find it difficult even to understand what is meant when the most recent and most philosophic defender of Parallelism assures me that feeling is not really what I find when I feel but is rather "something truly of the nature of feeling but in arrangement more like matter in motion" (!) But leaving the parallelist view of mind without further criticism, let me point out that it leads, just as an analysis of the structure of Idealistic Parallelism leads, to an absolute denial of all efficiency to what we know as consciousness. The personal consciousness, with its purposes and wishes, its logical and æsthetic and hedonic motives, is really a collection of mind-dust which is combined and which acts in obedience to purely mechanical laws. From two points of view, then, we have seen that the efficiency of consciousness is incompatible with Parallelism. As a fact we might have seen, in advance of our ex-

2 "The Origin of Consciousness," 319. 


\section{PARALLELISM}

amination, that this conclusion was inevitable. For plainly no one who holds to the universality of mechanical law can consistently maintain the efficiency of consciousness. If non-purposeful, non-logical, non-æsthetic laws absolutely and alone control human behavior, then purposeful, logical, æsthetic laws do not control it and are incapable of influencing it. One cannot eat one's cake and keep it too.

The necessity of giving up the efficacy of consciousness need not be fatal to Parallelism. But if one means to maintain it, he should do so with his eyes open. He should realize all that is involved. The consequences of such a position are varied. Let me remind you of two of them, bearing, namely, upon biological evolution and human activity. As to the first, the parallelist must face the same dilemma as that which proved so difficult for the materialist. Professor Strong has developed a parallelist theory in carefully thought-out details to the extent of two volumes in order to account for the origin of consciousness. His solution of this problem is, to say the best of it, one that raises more questions than it settles; and whatever he has done for the origin of consciousness he has, for all his pains, made the $d e$ velopment of consciousness altogether inexplicable. 
For if the mechanical laws of matter and energy determine every case of human or animal activity, then plainly the conscious processes of instinct, pleasure, pain, desire, and thought do not influence activity. Hence they have contributed nothing toward the preservation of individual or species; and therefore their preservation and development cannot be in the least explained by the Darwinian principle of Natural Selection.

The parallelist must account for the evolution of the race as best he can without any help from consciousness. He must do the same for the advance of human civilization and for the productions and activities of individuals. In the words of Paulsen himself, the parallelist must "explain the author of the 'Critique of Pure Reason' just as he would explain clock work." ${ }^{1}$ Well, perhaps he can do it. But I submit that the proposition is so preposterous that unless we are shown more compelling reasons than the parallelist has as yet furnished, most of us will look further in the hope of finding a position which will demand of us a little less primitive credulity.

1 "Introduction to Philosophy," p. 88. 


\section{LECTURE III}

THE DENIAL OF THE PROBLEM

In the preceding lecture we saw that Parallelism is quite as untenable as Materialism; that the acceptance of it involves one in absurdities to which very few, once they realize the true nature of the situation, would care to commit themselves. This fact about Parallelism, indeed, did not escape the thinking world until revealed by my lecture. The logical untenability of Parallelism began to dawn upon many of its former defenders some time since. Fifteen years ago, to be sure, yes, ten years ago, it was still the accepted creed of the great majority of those interested in the mind-body problem and scarcely a voice was raised against it. But its inherent difficulties were struggling to the surface and making its defenders increasingly uncomfortable; and to-day its popularity is rapidly-almost tragically-oozing away, lyric praise is giving place to indifference or even to contempt, and many of its former adherents are deserting it as rats desert a leaking ship. 
Whither are they going? Whither can they go? If we look back over our list of the possible solutions of the mind-body problem we shall see that we have reached the end. If Parallelism be not true, where shall we look?

As a matter of fact, while our list certainly included all the proposed, and probably all the possible solutions of the problem, it did not include all the attitudes that may be taken toward it. There is, at any rate, one important attitude which we did not consider and which is being adopted by a constantly increasing number of contemporary thinkers. These people come from various schools of thought and differ among themselves on many important questions, but they are at one in rejecting all the historical solutions of the mind-body problem, not indeed as being false but as being gratuitous. For, say they, there is really no such thing as the mind-body problem at all.

The difficulties we have been cudgeling our brains for so many centuries to get over, are, it seems, all of our own making, all purely artificial, all the result of our foolish insistence on setting up two imaginary entities, called mind and body. That clever fool Descartes started us wrong at the very beginning of 


\section{DENIAL OF THE PROBLEM 91}

modern philosophy; and ever since his day, following his absurd example, we have been wasting our time by the self-defeating process of first defining mind and body in such terms that they can never be related and then wracking our brains to see how we can relate them. For mind and matter are not two disparate things but one thing; the problem, therefore, of their "relation" is altogether artificial, and is dependent upon a false and dualistic prejudice. The so-called mind-body problem can never be solved, and never need be; but it can and it should be avoided.

Our natural humiliation at the discovery that we have wasted two entire lectures-and that our philosophic forebears have been chewing cotton for nearly four centuries-over a purely imaginary diffculty, will, I am sure, be quickly forgotten in the satisfaction of realizing that the difficulty we had thought so great is actually non-existent and that things are really all so simple. Provided, that is, that they are all so simple. And indeed we have it on the best authority that they are. It is the very latest thing in philosophy and psychology and it has the backing of the most influential schools. Thinkers so far apart as the neo-realists and certain of the ob- 
jective idealists clasp hands when it comes to this question; and reinforcements are constantly arriving for this entente cordial from the camps of the behaviorists and the pragmatists. We may take it from them, therefore, that there really isn't any problem here to be discussed and that we might as well pack up and go home, with no more stupid lectures on a stupid subject to be delivered and listened tosurely a consummation devoutly to be wished.

Welcome though this is, it seems all a bit bewildering, at least for old-fogies; and perhaps we can do nothing better with the remainder of this hour than try to find out just how it is that mind and body are really one and how the problem of their relation may, therefore, be avoided.

The answer to this question we must seek chiefly from the neo-realists and the behaviorists. No one, to be sure, is louder in declaiming the otiose, artificial, and gratuitous nature of the mind-body problem than the pragmatists; but unfortunately they give us very little definite information as to how it is to be avoided. Perhaps the clearest pragmatic statements on the subject are to be found in the writings of Professor Bode. It fell to him to deal with the subject "Consciousness and Psychology" in the coöper- 


\section{DENIAL OF THE PROBLEM 93}

ative volume ${ }^{1}$ put out a few years ago by a group of American pragmatists, and in such a paper the question of the relation of mind and body could hardly be avoided. Professor Bode's solution of the problem consists in pointing out that its seemingly great difficulties may be traced back to a "prejudice," the prejudice, namely, of regarding experience or knowing as distinguishable from the material objects experienced or known. "A careful inventory of our assets brings to light no such entities as those which have been placed to our credit. We do not find body and object and consciousness, but only body and object. . . . The process of intelligence is something that goes on, not in our minds, but in things." 2 The pragmatist, in other words, seeks to avoid the mind-body problem by denying that there is any such thing as mind or consciousness, in the ordinary subjective sense, at all. Consciousness is to be interpreted wholly in an objective sense. It is, namely, "a certain unique type of control" possessed by the stimulus; a characteristic of the "object" by which the object controls the "body." The control is of such a sort that one may speak of

1 "Creative Intelligence."

${ }^{2}$ Pp. 254-55. 
the resulting behavior as "forward-looking," and in this sense one may say that the behavior is "controlled by the future." Thus "behavior is conscious or intelligent, not because there are psychic links that get themselves inserted in the series of events, but because the process as a whole presents a specifiable differentiating trait." 1

Whether persuasive or not, this seems at least clear-clear at any rate to the extent of showing that the pragmatist avoids the mind-body problem by denying the existence of mind altogether-or, what amounts to the same thing, by interpreting it wholly in terms of the body. Such an attitude toward the problem is plainly Materialism once more, and we should know perfectly well what to do about it. But no sooner has the pragmatist succeeded in making his position clear to us in this fashion than he hastens to assure us that we have quite misunderstood him and that he really abhors Materialism. No one, in fact, is more insistent than he upon the efficiency of consciousness and upon the "creative" nature of intelligence. The intelligence which is creative, moreover, and the consciousness which is

1 Bode, "Intelligence and Behavior," Jour. of Phil., XVIII. 12 and 13. 


\section{DENIAL OF THE PROBLEM 95}

efficient, for which the pragmatist argues, cannot be interpreted to mean merely a "certain type of control" possessed by the object. To take it in that fashion would rob the pragmatist's contention of all significance. The whole point of his repeated protestation seems to center in the view that the object is iar from monopolizing the control. The behavior of both the body and the object, we are assured, are in fact controlled by the future, which is somehow present. A future which is somehow present is a perfectly intelligible suggestion if we take it to mean a present concept of a future situation or response, a "plan of action." In the article already cited Professor Bode, in fact, admits that the existence of concepts in just this old-fashioned psychic sense "is an indubitable fact." " But all of this means "dualism" and instead of a denial of the mind-body problem we would seem by the pragmatist's assertions to be forced to accept some form of Interaction. No sooner is this pointed out, however, than the pragmatist shies off once more as a frightened horse, hurls epithets of scorn on Interaction, Materialism, and Parallelism, and concludes by asseverating again, as Professor Bode does at the close of his recent

1 "Intelligence and Behavior," p. 17. 
article, that "the road to progress does not lead through the psychophysical problem at all, but around it."

To the pragmatist, as every one will remember, a thing is what it is known as; ${ }^{1}$ and a difficulty which is not known as a difficulty to the pragmatist of course isn't one. For the rest of us, however, who are not endowed with the pragmatic facility of avoiding difficulties by not knowing them, the pragmatist's course of thought which we have been seeking to follow is sufficiently confusing. My treatment of it has, of course, been almost unfairly brief; but I can only assure the reader who has no time to peruse the writings of the pragmatists themselves that, in my opinion at least, such further perusal would fail to throw any further light upon the way in which the mind-body problem is to be avoided. Fortunately the whole matter has been most lucidly and thoroughly discussed by Professor Lovejoy, and I can do no better than refer the reader to his papers on the subject. ${ }^{2}$

${ }^{1}$ Cf. Dewey, "The Postulate of Immediate Empiricism," Jour. of Phil.. II, 397 and 399.

2 "Pragmatism as Interaction," Jour. of Phil., XVII, 589-96, 62232; "Pragmatism and the New Materialism," Jour. of Phil., XIX, 5-15. See also his "Pragmatism versus the Pragmatist" in "Essays in Critical Realism." 


\section{DENIAL OF THE PROBLEM 97}

The pragmatist, then, has failed to show the rest of us where lies "the road of progress" which is to lead us "not through the psychophysical problem but around it." This road, whether straight or marvelously crooked, is at any rate a narrow one, and few there be who find it. But there are many who seek it. And among the number of those who both seek and tell us they have found this royal road which evades all difficulties, are to be counted not only the pragmatists but also (as I indicated above) some of the objective idealists. Not all objective idealists belong here; some recognize the problem and accept the interactionist solution, ${ }^{1}$ while some (I suppose) are parallelists. But, as I have said, there are other objective idealists who insist that the mind-body problem should be and must be avoided. Most of these-it would be safe to say all of them -apparently believe that the easiest way to avoid is to avoid, without spending too much thought on the problem how the avoiding is to be achieved or justified. I wish I could expound their position exactly, but nowhere does it seem to be definitely stated. The psychophysical problem as a rule is

1 For example, Dr. Laurie. See the note on Mind and Brain appended to Chap. XIV of his "Synthetica," Vol. I. 
simply shelved, omitted, passed by, as something too crude for the attention of those who, having once for all taken high ground, should fix their thoughts on higher things. For them, somehow, the problem has been aufgehoben, and those who make much of it are still in the gall and bitterness of dualism.

Bosanquet gives the problem more consideration than some members of his school. Yet the whole of his treatment of the subject, as found in his two volume work-the Gifford Lectures on the Individual-amounts to a little over two pages. His position is as follows: "Consciousness is not an epiphenomenon if we mean something extraneous and otiose, but it is a supervenient perfection." " "The difference between bodily change and mental action cannot be explained away, but while accepting it, we have no right to make capital of it in the way of multiplying differences praeter necessitatem. In saying that body is spatial and mind not spatial we have said in effect that body is a causal system and mind a logical one. But body is a causal system long disciplined and subordinated to a unitary self maintenance, and it has within it clearly and obviously the bases of all the motives and stimuli which 1 "Principle of Individuality and Value," p. 202. 


\section{DENIAL OF THE PROBLEM 99}

enter into mind. I believe we have just to accept the action and expression of a logical system through such a physical one. If it follows that matter is not confined to physico-chemical properties we should accept the conclusion. But it cannot follow that the principle of Uniformity, rightly understood, and of conservation of energy, are inapplicable to it. There is no ground for contending aggressively that rational prediction is inapplicable to its organic forms." ${ }^{1}$ "When we maintain that consciousness actually works in and through the systematic adaptation of a certain type of matter, we are not really adopting any one of the three dualistic doctrines, parallelism, interaction, epiphenomenalism. . . . The point, as it appears to me, is that in all these theories consciousness is conceived on intentionally dualistic lines, as a repetition or duplication of neuroses in a different medium or within a different attribute. ... The neurosis is there and complete without the psychosis. But there is a psychosis also, in relation or out of relation with the neurosis, and there is a problem about its supply of physical energy. Nothing of this applies to what I was attempting to express in the previous lectures [as quoted above]. It seems

1 "Principle of Individuality and Value," p. 203. 
to me that the fertile point of view lies in taking some neuroses-not all - as only complete in themselves by passing into a degree of psychosis. The question of duplicating a neurosis by a psychosis does not arise. There can be no problem of a special supply of energy for the psychosis. . . . The weighing of a situation, begun in a certain balance of nervous tensions or inhibitions, has to complete itself in a conscious form before the neural crisis can end in a motor reaction representing the logical solution. It is not repeating in another attribute what has happened in one; it is completing in a non-spatial activity what, having its source in spatial combinations, yet could not be completed by their means pure and simple. The change from spatial to non-spatial togetherness is of course inexplicable." ${ }^{1}$

I have quoted in his own words substantially all that Bosanquet has to say upon the mind-body problem-largely because I do not pretend to understand all that the two passages mean and hence feared to be unfair to Idealism if I should attempt to interpret it. This much, however, seems plainly to be intended: the mind-body problem, as ordinarily understood, is really specious because it involves Dualism, and such

1 "Value and Destiny of the Individual," pp. 2-4. 
Dualism there is none. Instead of two series which duplicate or supplement each other, we have but one. This one series may be looked at from two points of view, the logical and the causal. When viewed causally we call it body, and as such it obeys absolutely the "principle of Uniformity" (by which, presumably, physical uniformity is intended). The law of the conservation of energy holds of all processes within the human brain and body, and "rational prediction," based apparently upon the "principle of Uniformity" and the conservation of energy is as applicable to the activities of man's body as to any other part of physical nature. But these activities are interpretable not only causally but logically. As belonging to the logical category they are on a higher plane of being than when viewed physically, and it is only on this higher plane that they possess meaning. Personally I do not see how this is consistent with what Bosanquet says of the necessity of some neuroses passing into a conscious form before the neural crises can end in a motor reaction representing the logical solution. If there be such a necessity it would seem to me to imply that the "conscious form," the "non-spatial togetherness," contributed something toward the physical resultant. However 
3 that may be, I see in Bosanquet's words no suggestion of a means of avoiding Dualism and the mindbody problem unless it be in substance what $I$ have indicated above-supplemented perhaps by further considerations which should do away with individual awareness altogether.

If I am right, then, in my interpretation of Bosanquet, the mind-body problem is to be proved specious by doing away with Dualism and showing that the mental series and the physical series are neither parallel nor interacting but are merely points of view of what is fundamentally one. From the causal point of view it follows one set of laws, from that of logic or meaning, another. That there is a certain

\{ plausibility in this view so long as we remain in the region of abstract terms I shall not deny; but when we descend from the high ground to concrete cases all our old difficulties are back on our hands. Doubtless the physical event can be interpreted logically and spiritually; but how does that help us? Take, for example, a presidential election-let us say, the election of Lincoln in 1860. In November of that year between four and five million voters went to the poles and voted. The physical stimulus was the sight of certain ballots, the physical result the selec- 


\section{DENIAL OF THE PROBLEM 103}

tion of some or the marking of all, and the casting of them into ballot boxes. Now did the thought and the feeling of the voters-their "psychoses"-have anything to do with the physical outcome? Either they did or they did not; there is no tertium quid. If they did influence the physical outcome, then this outcome was not wholly determined by the "principle of Uniformity" and the conservation of energy; and "rational prediction" could not have predicted the outcome. In that case, moreover, we have a real relation between the mental and the physical, a relation, be it added, which is essentially Interaction, no matter by what name we camouflage it. If, on the other hand, the outcome could have been foretold by "rational prediction" on the basis of the "principle of Uniformity" and the conservation of energy, then psychoses and "non-spatial togetherness" had nothing to do with it. If this is the case, we are presented with a solution of the mind-body problem which only an objective idealist-or possibly a pragmatist-could distinguish from Materialism. Nor does it help in the least to remind us of the obvious fact that the physical resultant once it has happened, and no matter what it is, is interpretable after the fact by logic and spirit and the rest. 
So far as I can see there is no way of escaping the mind-body problem unless consciousness in the sense of individual awareness be abandoned. I do not see how Bosanquet can do this consistently with his repeated balancing of psychoses against neuroses. Others of his school, however,-notably Hoernlé,are in a better position to do so, and in fact seem to have taken this course. The logic and the actual tendency of Objective Idealism is, in fact, all in this direction, and I think we may expect to see an increasingly explicit recognition of it from objective idealists in the near future. For the present this hypothesis of the identity of the individual's awareness with its object is most clearly presented, not by the objective idealists, but by the neo-realists. It will doubtless seem odd if not paradoxical that two schools seemingly so antipodal as these should, on the important question of the nature of consciousness, be classed together; but that they are defending practically the same position can hardly be doubted by any reader who pierces through their terms to their meanings. The truth is that while the two schools started out in directions as diverse from each other as the East is from the West, one of them has gone so far west and the other so far 


\section{DENIAL OF THE PROBLEM 105}

east that they have met at the antipodes and joined forces, and so far as our problem is concerned, are now in fact, if not in name, almost indistinguishable. Both may well be classed under one title,-namely epistemological monists-since both maintain that no essential distinction is to be made between mind and matter. As the neo-realists have dealt with this question rather more definitely and more completely than their idealistic allies, we had best confine ourselves to their exposition of the question.

For the neo-realist, then, objects in and by themselves should not be called either mental or physical. In themselves they are neutral,-_"neutral entities" they may well be called. Such an object, neutral in itself, may enter into and pass out of various groups formed by other objects, and in so doing it may, for the time, become mental or physical, or both. When it is one of a group which is selected out, so to speak, by the action of our organs of perception and thought, it is called mental or conscious. In so far, on the other hand, as it is a member of a group of things in the common space we call it physical. It may be physical and psychical at the same time, and there is no more difficulty in this than there is in the 
same man being a member of two different clubs. Nor is this view strained and artificial, for is it really anything else than that of the plain man, who believes that he sees his objects directly and who makes no distinction between his percepts and the physical things which he perceives? When we look at the question in this way we see that consciousness ceases to be a special sort of substance or entity or type of being, and becomes instead merely a special sort of relation or grouping. Consciousness, in short, is but a name for those objects toward which an organism is at the given time reacting. Since, therefore, there is no such thing as consciousness in the old sense, consciousness as distinct from its objects, no dualism is left between body and mind and hence no theory is needed as to their relation.

Tempting as is this identification of mental content with physical and logical objects, I must say very frankly - and perforce very briefly - that it is to me profoundly unpersuasive and unsatisfactory. For I seem to find, and I think the man in the street finds, a great deal in what we know as consciousness which is not to be identified with any common and shareable objects, whether physical, logical, or imaginary. To be as concise as possible, each of the fol- 
lowing six objections seems to me so formidable as to be by itself fatal to the position of the epistemological monist.

(1) The physical and physiological processes of perception, as described by Science and never disputed, show conclusively that the physical object which starts the perceptive process agoing is not identifiable with the percept which results from it. Whether we take a realistic or an idealistic view, there is such a thing as this watch, and there is such an event as its reflection of ether waves. Physiological psychologists assure us (and nobody so far as I know denies it) that these waves strike upon the retina and thereby set up a certain process in the optic nerve which is carried on into the occipetal region of the brain. Either immediately after this brain process has been set up or concomitantly with it, a sensation is born which we call a sensation of the watch. Now the neo-realist is bound to hold that this sensation and the watch, which by its reflection of ether waves started the whole process going, are one and identical-in spite of the fact that between the two are intercalated the entire physical and physiological series of events indicated above, and in spite of the further fact that such an hypothesis 
would seem to identify the sensation with its cause and the watch with its effect.

(2) The visual images which two or more observers get from the same object, and which the same observer will get from it at varied distances and varied angles, since they differ from each other, cannot be identified with each other, and hence cannot be identical with the object (as Neo-Realism claims that they are). The only answer which the neorealist can make to this objection is to identify every object with all its actual and possible appearances at any and every angle and any and every distance, and thus explode each object to the extremest bounds of the spatial universe.

(3) Since the process of perception takes time, the event which I perceive happens at a different moment from that at which I perceive it. Plainly when I see a star reflecting light the event which I see was over long before $I$ saw it, and the star itself may have disappeared; and though in ordinary perception the time process is much shorter the principle remains the same. Similarly, when I remember an event of my childhood or picture the battle of Salamis, my mental content is an actuality of to-day, my object an event of forty or of 2400 years ago. Yet 


\section{DENIAL OF THE PROBLEM 109}

in all these cases Neo-realism would identify the present conscious content with the past object. This, of course, is a manifest contradiction in terms, and the only way it can be avoided is by exploding each event to the extremes of time, just as on the same theory every object had to be exploded to the extremities of space, thus making of the universe a chaotic and jelly-like welter of interpenetrating neutral entities.

(4) The neo-realist is forced to maintain that the content of one individual mind may be completely and numerically identical with that of other minds; that my thoughts, feelings, and impulses may be actually yours; that my pain may be numerically your pain, and that our minds have, in principle, no privacy which others cannot pierce. Against this view it seems to me that Professor James is right when he asserts that the breaches between "thoughts belonging to different personal minds .... are the most absolute breaches in nature." 1

(5) Some of the content of mind seems to be conspicuously private and subjective, and incapable of even that semi-plausible identification with outer objects which superficially seems possible in the case 1 "Psychology," p. I53. 
of veridical percepts and true ideas. I refer to such things as ideas of admittedly non-existent objects such as round-squares; emotions, impulses; pleasures and pains; values, consciousness of meaning, and peculiarly subjective qualities such as clearness.

(6) Sixthly and finally I cannot forget the existence of error, illusion, and halucination, nor can I conceive of any way in which these experiences can be explained unless we admit the distinction between the psychical and the physical as ultimate and different categories.

For these six reasons-each of which needs expansion to considerable length if one is to appreciate its real importance-I find it impossible to identify the content of consciousness with objects. And this holds whether we view the matter realistically or idealistically. In my reference to Objective Idealism, some pages back, I did not mean to imply that its view was in all respects identical with that of Neo-realism; and my six objections to the latter might not all apply to the idealistic view. But in so far as Objective Idealism differs from Neo-realism it does so by approximating more nearly to a dualistic view of consciousness and its objects. From many points of view, therefore, it seems to me that we are forced 


\section{DENIAL OF THE PROBLEM 111}

to recognize a substantial distinction-a distinction in existence-between conscious content and external, physical objects. But just in so far as we do this we have the old dualism once more on our hands and are faced again with the old and persistent question of the interrelation of the psychical and the physical. Consciousness as psychical content cannot be identified with external objects, and the attempt to dodge the mind-body problem in this fashion will not work.

Let us suppose for the moment, however, that we can forget our difficulties and put aside our doubts and accept the neo-realistic way of disposing of mental content. A further difficulty will still await us. What, namely, shall we do with mental processes? For the sake of the argument let us momentarily identify our percepts and our memory images with their external objects; what shall we do with the processes of attention and thought, with effort and will, and what shall we do with purpose and cognition?

It is at this point that the new psycho-philosophical tendency known as Behaviorism comes to the rescue of both Neo-realism, Objective Idealism, and Pragmatism. It provides them with a way of handling mental processes which involves no troublesome 
problem of the relation of the mental to the physical. But it would be a mistake to regard Behaviorism as merely an ally of these three schools. It is decidedly a principal in the controversy and it looms to-day, indeed, as the largest of the quadruple alliance.

Behaviorism originated as a method in animal psychology. Out of patience with the futile attempt to tell what the animal was thinking about or how it was feeling when put through various experiments, the investigators in this field at length said, Why bother our heads as to this unanswerable question? The important thing for science is to know how the animal reacts in the presence of various stimuli. Let us, therefore, frankly make the object of our study not the animal's hypothetical consciousness but its actual behavior. So successful was this reorganization of method in getting results that were truly objective, verifiable, and scientific, that certain of the bolder spirits proposed it should be applied also to human psychology; and applied it has been. The experimenter observes the reactions, the behavior, the physiological processes of his subject, makes objective measurements with instruments of precision, and never asks for his subject's introspection nor bothers as to his consciousness. The objectivity of 


\section{DENIAL OF THE PROBLEM 113}

these observations is one of the advantages claimed for the new method by its adherents, but they also enthusiastically recommend it as a welcome means of escaping the age-long psychophysical problem and of putting permanently on the shelf all its traditional solutions. "In Behaviorism," says Professor Watson, "one avoids both the Scylla of parallelism and the Charybdis of interaction. Those time-honored relics of philosophical speculation need trouble the student of behavior as little as they trouble the student of physics." " "The issue [as to the relation of mind and body] is not decided," writes another behaviorist; "but it is no longer a living one. A growing sense of its futility has come upon us. . . . The conviction has gained ground among us that such a belief is a survival of older modes of thought, in other fields happily outgrown." 2

These quotations indicate one of the ways in which the behaviorist succeeds in avoiding the mind-body problem. It does not "trouble" him. Though the issue between the proposed solutions "is not decided," "it is no longer a living one" for him. He feels increasingly that it is futile. For his own part,

1 "Behavior," p. 9.

${ }^{2}$ Mrs. De Laguna, "The Empirical Correlation of Mind and Body," Jour. of Phil., 1918, p. 533. 
he is not interested in it. He does not need to use the concept of consciousness in his business and he is not going to let theoretical questions of its relation to the physical take his attention from the real work of tracing out in scientific and objective fashion the facts of human behavior in terms of stimulus and response.

No one can very well criticize the behaviorist for taking this attitude. Here as elsewhere, de gustibus non disputandum; and if he is not interested in our problem we have no desire to thrust it down his throat. When, however, from this personal attitude of his own and of his fellows he draws the conclusion (as he usually does) that the mind-body problem is unreal, the comment is obvious. The fact that he is not interested in consciousness nor in the mind-body problem may be an interesting fact in his personal biography but it has no bearing whatever on the inherent interest and importance of the problem itself. There is no mind-body problem for him in just the same sense as that there is no mind-body problem for the lawyer and that the squaring of the circle is no problem for the Assyriologist. In other words, the bearing of Behaviorism upon the relation between consciousness and its physiological accom- 
paniments is not to be determined by the subjective tastes of the behaviorist, but can be settled only by an objective examination of Behaviorism.

The word Behaviorism is used in two quite distinct senses. It may, on the one hand, be taken as a method in psychology - the method, namely, which refuses to make any use of introspection or any reference to consciousness, and which insists that as psychologists we should study only bodily reactions and physiological processes. But secondly it may be taken in more metaphysical fashion; it may, namely, mean that consciousness is behavior, and that in any other sense it simply does not exist. Because of this ambiguity of the term, the critic of Behaviorism is constantly in danger of doing injustice to the behaviorist. The accusation is sometimes made against an individual behaviorist that he is denying the existence of consciousness when as a fact he means by his expressions merely to assert that for purposes of scientific description one should avail oneself only of the objective facts of observable behavior. On the other hand, the behaviorist himself is quite as likely as his critic to be seduced into a misleading use of this rather slippery term. He has been known, in fact,- and not infrequently - to take advantage 
116 MATTER AND SPIRIT

of the ambiguity so as to swing back and forth between methodology and metaphysics in such fashion as to baffle pursuit; to appear to be talking metaphysics and when threatened with certain unpleasant metaphysical consequences of his view to cry out indignantly that he meant nothing but methodology, and then when the danger was over to slide back once more into statements which must be taken metaphysically if they are to have any special significance. If, therefore, in analyzing Behaviorism we owe it to the behaviorist not to attribute to the terms he uses a meaning which he does not intend, we owe it to ourselves not to permit him to avoid the issue by dodging suddenly and repeatedly from one interpretation of his thesis to the other.

Let us, then, consider Behaviorism in the first place as merely a method of psychology. And on this little need here be said. For the difficult controversy between the behaviorists and the introspectionists concerns us in only one point. We may have our own opinions as to the possibility of giving a complete or even a very intelligent description of human nature by a method that leaves consciousness (in the ordinary sense of the word) entirely out of account; but so long as the behaviorist sticks 


\section{DENIAL OF THE PROBLEM 117}

to his measurements and makes no statements either explicit or implicit concerning consciousness we shall have nothing to say, because his assertions so far forth have no bearing upon the mind-body problem. But as a fact, the behaviorist means his method to have a very definite bearing upon the mind-body problem; it is, as we have often been told, a means of avoiding it altogether. Now so long as Behaviorism remains merely a method it is plain that there is only one way in which it can enable us to avoid this question of the relation of the psychical to the physical. This is, namely, by insisting that the psychical has no relation to the physical that is of any importance to science. In fact, this is exactly the presupposition of Behaviorism as a method. Human behavior, it maintains, can be adequately and completely described and explained by the anatomy and physiology of the body and by the nature of the various physical stimuli that play upon it. No reference to consciousness is either needed or in any way helpful. If at a single point a reference to consciousness were necessary in order to explain any detail of human conduct, that would constitute a lacuna in the chain of behavioristic explanations; and to admit such a 


\section{MATTER AND SPIRIT}

necessity would be to admit the insufficiency of Behaviorism as well as the need of some theory as to the relation of consciousness to its physiological correlates. Of this the behaviorist is thoroughly aware and as a fact he insists that consciousness can have no real effect upon conduct. "The pleasurable tone which accompanies certain of our acts," writes Dr. Peterson in the Psychological Review," "is of course only a subjective indication that the response is along the line of least resistance. . . . We are coming to a point now in psychology at which we cannot look upon states of feeling as causes of action." The little word "of course," which Dr. Peterson here brings in so naturally, is significant. Of course for the behaviorist pleasure can be only an accompaniment and not a cause. Indeed how could it or any other form of consciousness be a cause of action if all causes of action are summed up in physical stimuli and physiological processes or "sets"? On the question of the efficiency of consciousness, therefore, Behaviorism, even when understood only as a method, is obliged to take exactly the same position as Materialism.

But Behaviorism cannot take the position of Materialism and avoid its difficulties. If the behaviorist

1 Psychological Review, XXIII, 1916, pp. 157-58. 


\section{DENIAL OF THE PROBLEM 119}

psychology "cannot look upon states of feeling as causes of action" how is it going to explain their rise and development? If the animal who felt pain when acting in a way injurious to its health and who felt pleasure when acting in a way beneficial to itself and to the species had no advantage over the animal who felt neither pain nor pleasure, how came these feelings to be selected and transmitted? What is the use and what the survival value of a mere "subjective indication"? Why is any indication needed, and indeed to whom is it an indication? And not only is the evolution of consciousness quite impossible of explanation for the behaviorist; so is its odd persistence in human nature. For if the behaviorist method be justified, consciousness has no more influence upon the conduct of the man than upon the conduct of the tomato. Take the famous telegram case, suggested in another connection by Busse. ${ }^{1}$ A German father receives a telegram reading "Fritz angekommen" and spends the day in joyful and elaborate preparation for the return of his son from a long voyage. At night-fall he receives a second wire reading "Fritz umgekommen," which means that instead of Fritz having arrived at port, Fritz is dead. Prostrated at 1 "Geist und Körper," p. 310. 
the news the father faints and perhaps himself dies. Now the behaviorist must account for the enormous contrast between the vigorous activities of the morning and the fainting fit and heart failure of the night without any reference to the father's consciousness of the meaning of either telegram. The transformation of the man's behavior was due to the exchange of an $a$ for a $u$ in the stimulus.

There is one way in which the behaviorist may get out of his difficulty if he be bold enough, and that is to assert his Behaviorism not merely as a method but as a metaphysic. He may, namely, insist clearly and openly that there isn't any such thing as consciousness in the ordinary sense at all; that the only sort of consciousness existent is just physiological processes; and that therefore there isn't any problem to be solved. This, in fact, is exactly what the materialists and parallelists have all along yearned to do and what they would have done but that they lacked the courage. Consciousness has always been the great obstacle to a consistent and universal Naturalism; and adherents of that doctrine have really wished in the bottom of their hearts that the existence of consciousness might somehow be flatly denied. Experience has shown that if you give 


\section{DENIAL OF THE PROBLEM 121}

consciousness an inch it will take an ell, and through centuries of attempted compromise it has been painfully proved that with consciousness no compromise is possible. But up to our time, somehow, when it came to the pinch, courage has been lacking. The naturalists have longed to cry delenda est but have never quite dared. But whatever else we may think of the more extreme behaviorists, lack of courage is seldom one of their faults. They do not indeed deny in words that consciousness in its various forms exists; but they insist that consciousness is just behavior-muscular, glandular, and nervous processes, -and that in any other sense than this there is no such thing as consciousness. "It is a serious misunderstanding of the behaviorist position," writes Professor Watson, "to say, 'Of course a behaviorist does not deny that mental states exist; he merely prefers to ignore them.' He ignores them in the same sense that chemistry ignores alchemy, and astronomy horoscopy. The behaviorist does not concern himself with them because as the stream of his science broadens and deepens such older concepts are sucked under, never to reappear." " "Thought is not dif-

1 Reply to his critics in the Symposium at Oxford in 1920. British Jolirnal of Psychology, 1920, p. 94. 
ferent in essence from tennis playing, swimming, or any other activity except that it is hidden from ordinary observation and is more complex." ${ }^{1}$ To be more explicit, thought consists in the activity of the language mechanisms, if we may include within this term the activities not only of the glottis, larynx, tongue, and lips, but all the allied reactions of hand and body by which gesture and posture help out words. And this is meant quite literally. The activities of these bodily mechanisms are not the expressions of thought; they are thought, and behind them or beside them there is no so-called psychic state of thinking. In similar fashion Dr. Frost defines awareness as "the relation between two neural arcs," " and Professor Singer asserts, "Consciousness is not something inferred from behavior. It is behavior." 3

Illustrations of this extremely courageous metaphysical position might be added at considerable length. And it must be freely admitted that here at last we have a position which, if we can accept it, will enable us quite consistently to avoid and to repudiate the mind-body problem. But can we ac-

1 Watson, "Psychology from the Standpoint of a Behaviorist," p. 325 .

2"Cannot Psychology Dispense with Consciousness?" Psychol. Rev., XXI, pp. 204-II.

8 "Mind as an Observable Object," Jour. of Phil., VIII, p. I80. 


\section{DENIAL OF THE PROBLEM 123}

cept it? There's the rub! And this is a question, as it seems to me, that each man must answer for himself, for it is hardly susceptible of argument. Various considerations may indeed be referred toconsiderations such as those brought forward at the Symposium upon this subject held at Oxford in 1920, at which all the English psychologists who participated, without a single exception, put themselves on record as unalterably opposed to any attempt to identify consciousness with behavior. To these English thinkers, the proposal seemed preposterous. Various considerations, as I have indicated, were appealed to in defense of this view,-for which, since our time is short, let me refer you to the British Journal of Psychology for October, 1920. Still other considerations might well be added. Every new language one learns gives one a new vocal process for a given meaning. We have as many different bodily behaviors for an identical idea as we have languages. We have, of course, very many more. Within a given language any idea may be expressed by, or correlated with, a large number of processes of the language mechanism. Dr. Watson himself tells us that "one can take his pen in his right hand and write any given word by using thirty or more different finger 
and palm combinations." Dr. Lashley (a colleague of Dr. Watson) gets a different tracing every time his subject thinks over a given sentence. The musculature of the larynx and throat, Dr. Watson assures us, are so varied that "we can think the same word by many different muscular combinations." Fifty or a hundred different linguistic ways of expressing an idea, fifty or a hundred different forms of behavioristic thought, may thus all mean the same thing. But how can the one thought be identical with each of the fifty or one hundred processes? Conversely, the same word, produced by the same vocal or the same manual activity, may mean two or more quite different things-as for example well, sound, lark, - any word with a double meaning. It would seem that in these two sets of cases we have what Professor Perry might well call "independent variability" of thought and of linguistic process.

The only way out of this difficulty for the behaviorist, so far as I can see, is flatly to deny that we do or can mean the same thing in any two cases where the bodily processes are at all different; and conversely to assert boldly that in cases where the bodily processes are the same we mean the same, regardless of the mental images or the consciousness of meaning 
which we may find by introspection; that, for example, when I incipiently speak the word boom I mean the same thing whether the linguistic activity be accompanied by a visual image of part of a sailboat or by 'an auditory image connected with a cannon. I do not think this answer from the behaviorist would be very persuasive to any one outside the fold. But on the other hand I have no hope that the argument I have suggested against his view will have any effect upon the behaviorist. For, after all, the very question at issue is whether such things as mental images, ideas, meanings, exist at all.

Professor Lovejoy's "paradox of the thinking behaviorist" may have better success. He points out that while it is always possible for the behaviorist to deny the existence of subjective consciousness in the subjects whom he observes, he cannot deny it in his own case as an observer. His observations must be of the conscious sort and can hardly be interpreted as mere bodily behavior. They cannot be so interpreted because they profess, in the behaviorist's own account, to deal with things and events outside of his organism. "Thought constantly deals with the distant in space and with the remote in time; but the movements of the language mechanisms in which the 
thought of the given moment is supposed to consist are strictly inter-corporeal and are limited to that moment." 1 Moreover, the behaviorist "will certainly not deny that he 'observes' and thinks of things, things not contained within his own skin; he cannot take the first step in the formulation of his own account of the antecedents and determinants of bodily behavior without making this claim for himself." He does, moreover, repeatedly make the distinction between bodily processes which are observed and those which escape observation-a distinction which is meaningless if observation consist in just the bodily processes themselves. In conclusion, Professor Lovejoy points out, "if perceiving and thinking are what Watson says they are and nothing more, no organism can ever know either what it is doing or what object evokes its response; and therefore no psychological investigator can possess such knowledge. The only consistent behaviorist would be one who knew nothing whatever, who at no moment of his existence could do more than relax or contract his muscles, without being aware that he was doing so. And to maintain even a decent semblance of con1 "The Paradox of the Thinking Behaviorist," Phil. Review, XXXI, p. I42.

Ibid., p. 14I. 
sistency the behaviorist should at least refrain from professing to know anything. Behaviorism, in short, belongs to that class of theories which become absurd as soon as they become articulate. "The Paradox of the Thinking Behaviorist" deserves to take its place in the logic-books beside that of "Epimenides of Crete' to which it is closely related." "

I do not see that the behaviorist can avoid the logic of this argument. But that does not mean that it can be logically expected to have any effect upon him. Since logic in the sense in which Lovejoy means it does not exist, how can the behaviorist consistently allow himself to be affected by it? He is quite willing to be accused of not knowing anything whatever, -in Professor Lovejoy's sense of knowing. He can relax and contract his muscles, and is not that enough? Already nearly a dozen years ago a distinguished representative of the school dealt explicitly with this matter, writing thus: "I regard my own mind as behavior quite as frankly as I take my fellow's mind to be nothing else." ${ }^{2}$ The only way, he continues, in which he can tell whether so-called green objects and so-called red objects look alike to

1 Op. cit., p. 147.

2 Prof. Singer, "Mind as an Observable Object," Jour. of Phil., VIII, p. I84. 
him is by watching himself act; if he acts in the same way toward both he concludes that he gets only one sensation from the two. This last assertion, to be sure, looks like an unfortunate lapse into Lovejoy's trap, due to inadvertence; for watching himself act would seem to imply consciousness. But the consistent behaviorist might reply that "watching" is merely another form of behavior, and that he does not know that he is doing it or anything else.

In short, if the behaviorist will be sufficiently wary to avoid all statements involving knowledge or observation or, better still, if he will avoid making statements of any sort and will content himself with relaxing and contracting his muscles, he may make himself armor proof against all attack. Hence as I said some time ago, the question of the existence of consciousness seems hardly arguable. It must be settled for each man by himself. Do you or do you not, the real question reads, find-actually findwithin your own experience such things as conscious pains and pleasures, conscious thought processes, conscious purposes, conscious ones, mind you, in the oldfashioned sense of the word and not to be identified with any physiological processes no matter how subtle? For my own part I will hazard the guess that 


\section{DENIAL OF THE PROBLEM 129}

most of us assembled here would very emphatically answer Yes to this question: that most of us find our thought is of the old-fashioned conscious sort; although, if our behaviorist friends insist, it may be that courtesy will force us to accept their assertion that their thinking, - the thinking by which they have arrived at such remarkable conclusions-is really nothing more than the unconscious activity of the language mechanism.

Well, we have come to the end of our third lecture, and we seem farther from a solution of our problem than we were at the end of the first. All our results thus far have been negative. We have considered in principle all the answers to the problem that have yet been suggested, all that probably ever can be suggested, and not one of them has commended itself to our minds. Yet one of these answers must be true, for we have found that every attempt to deny or avoid the problem leads us to absurdities as great as those involved in the most absurd of the proposed solutions. What shall we do, what can we do about it? My only suggestion is the humiliating one that we may have been too hasty in our rejection of some of the proposed solutions, and hence that we go back on our steps and see whether any of them merits re- 
examination. This, however, will involve some detailed analysis, and we must, therefore, postpone it until our next lecture. A rather gloomy closing to this one that means, I confess. But personally I am hopeful that the light we have gained from these three negative lectures may yet aid us in reaching a real solution of our very real problem. 


\section{LECTURE IV}

THE DIFFICULTIES OF INTERACTION

Our last lecture came to a rather disappointing close. We had passed in review all the leading, and probably all the possible, hypotheses as to the relation of mind and body, and none of them had proved entirely satisfactory or acceptable. But on the other hand we had seen pretty plainly that there was nothing artificial about the problem and that all attempts to dodge it either led to manifest absurdities or were due to an ostrich-like attempt to destroy difficulties by refusing to look at them. The situation was perplexing; and as you will remember I finally suggested that the only way out might be to look back over our list of proposed solutions and see whether all of them were indeed as difficult of acceptance as we had supposed. To that closer scrutiny of our own previous criticisms I now invite your attention.

There can, I think, be no question whatever as to the reality and the crucial nature of the problem. Behaviorism and its allies have, as it seems to me, been altogether unsuccessful in their paradoxical at- 
tempts to deny the existence of any relation between mind and body. Parallelism in its leading forms we studied in considerable detail and, I think, in no unsympathetic spirit; and I see no conceivable reason for altering the unfavorable judgment to which we were forced. Materialism also we analyzed with some care; and the great difficulties which it involved were so patent that I feel sure nothing would be gained by a reconsideration of its assertions. Of all the proposed solutions of our problem Interaction alone was put aside with a rather summary and inadequate consideration. We hardly more than glanced at it, as you will remember, and not yet realizing how difficult was our problem, we hurried on to more promising suggestions. Having seen now, through a slow and I fear painful course of reasoning, how fallacious were all these promises, we owe it in fairness to ourselves to give to Interaction the same sort of serious consideration that we have given to each of the other hypotheses.

What then, we must ask ourselves, were the difficulties which we found with Interaction which made us pass it by as unsatisfactory? One of them which indeed we hardly made explicit at the time but which undoubtedly influenced our judgment con- 
siderably was the very obvious fact that Interaction is unpopular in scientific circles; that it is, in the words of one of its critics already once quoted, "a survival of older modes of thought, in other fields happily outgrown." None of us, I suppose, is altogether immune against the effect of social disapproval, and our original disinclination to accept a theory adherence to which is regarded by all up-todate minds as a sign of old-fogyism was very likely due in considerable degree to the subtle influence of social pressure. It hardly needs remarking, however, that such influence is not argument and that unpopularity in a theory does not spell refutation. The assertion that the tendency of contemporary thought is all against Interaction, moreover, will not seem tremendously impressive to any one whose memory goes back as far as fifteen or twenty years. Twenty years ago Idealism was accepted by almost every philosopher of any reputation as indisputably the last word in thought; and to be called a realist was to be called a fool, if not a knave. We have seen all that changed in cinematographic fashion. Today in many quarters the only idealists who dare show their heads without covering them with neorealistic caps are extraordinarily courageous souls. 
In the same twenty years, we have seen Pragmatism invade the land-and then quietly retreat from some of its advanced positions. Within the field of science things are being said by biologists about that holy thing called Darwinism which would have caused unspeakable pain to many an evolutionist of twenty years ago. And in Physics the unshakeable I need only mention the name Einstein and say no more. I repeat, then, that to one whose memory has a span of twenty years or so the popularity or unpopularity of a given doctrine in scientific circles is a remarkably unimpressive consideration. We may, therefore, properly put on one side the fact that belief in Interaction has been "happily outgrown" by many of our scientific contemporaries, and proceed to a consideration of its real difficulties.

These difficulties, you will doubtless recall, were two-fold. Interaction, namely, involved an impossible view of causation, and secondly it was inconsistent with the universality of mechanical law. This second difficulty divided itself into a more specific and a more general consideration. On the one hand Interaction seemed plainly incompatible with the principle of the conservation of energy; and on the other it as plainly made impossible unobstructed 
domination over all the world of matter and motion by the laws of physics, chemistry, and biology.

The first of these difficulties, the causal one, ${ }^{1}$ is plainly a question that can be settled only by philosophy. This seems too obvious to deserve mention, yet oddly enough it is quite forgotten by many objectors. In their opinion the matter is to be settled not by philosophy or thought but by imagination. Thus a distinguished scientist bids us "try to imagine the idea of a beefsteak binding two molecules together." We are assured we cannot do this, and the conclusion is immediately drawn that therefore mind and body can never influence each other. A remarkably simple and valuable scientific method this. Consistently adopted and skillfully applied it will solve all the problems of science and philosophy. Is the earth indeed spherical? The contemporaries of Columbus settled it conclusively in the negative by an appeal to this method. Try to imagine people stand-

1 It is thus expressed by Wundt: "Die cartesianische Theorie nahm volkommen consequent Bewegungen in beiden Richtungen an; der Körper wirkt nach ihr ebenso auf die Seele wie die Seele auf den Körper. Nun liegt der Grund, weshalb diese Theorie heute unhaltbar erscheint, lediglich darin, dass sie ein ursachliche Verbindung zwischen vollig unvergleichbaren Thatsachen voraussetzt. Eine Empfindung kann aus einer Bewegung ebenso wenig abgeleitet werden, wie eine Bewegung aus ciner Empfindung." "Philosophische Studien," Vol. VI, p. 353. 


\section{MATTER AND SPIRIT}

ing with their feet up and their heads down! "It is impossible." If, however, we are dissatisfied with this easy method of settling the problem of the possible causal relation of body and mind, we shall appeal, as I have said, not to the imagination but to philosophy.

Is Interaction, then, incompatible with causation? Is it conceivable or not that two things so diverse as matter and mind may be causally related? If philosophy is to settle this question it must first of all ask another and antecedent question, namely, what do we mean by causation? Now philosophers are far from being agreed on the details of this matter, but fortunately for us they are nearly all agreed on so much of the answer as is relevant to our problem. There are two negative characteristics of causation which were settled once for all by David Hume nearly three hundred years ago and which have seldom been seriously questioned by reputable philosophers since. The first of these negative characteristics of causation is the absence from it of any rational necessity. Neither causal relation nor the lack of it can be predicated by reason of any two objects or events, prior to experience. Without observing the actions of two objects you can never tell in advance whether 
one of them can effect the other or cannot do so. Causation, according to Hume, is merely regular and invariable sequence, and whether or not it holds between two kinds of things is to be determined only by experience. The second negative characteristic of causation which Hume pointed out is the absence of any observable "power" passing over from cause to effect or of any "real tie" binding them together. Watch one object or event cause another; you can never see any power in the first nor any tie between them. You see simply one event following another. As I have already said, Hume's position on these two matters has been almost universally accepted by both philosophy and science. We can neither see causation in any other sense than that of regular sequence nor argue to it deductively in any given instance. Prior to experience it is absurd for us to attempt to say what can and what cannot cause something else. Whether a given thing is the cause of another is in every case to be settled purely by appeal to experience. So much, we are safe in saying, practically all contemporary thinkers will admit; and not a few would go further and declare, with Bertrand Russell, that science no longer looks for causes "because there are no such things," and that "the law of causality is 


\section{MATTER AND SPIRIT}

a relic of a bygone age." ${ }^{1}$ In place of the older notion of causes and effects, these thinkers would substitute a certain uniformity of nature capable of being expressed in various differential equations.

Having now seen what causation means, let us return to the mind-body problem. We are asked, How can two things so dissimilar affect each other at all? To which the obvious reply is the further question, Why can they not? Is it so certain that dissimilar things must fail to influence each other? Whether they can do so or not must be settled not by an appeal to the imagination but by an appeal to experience. Our inability to answer the question, How can the sun attract the earth, is not generally held to make it impossible for the sun actually to do so. Likewise in dealing with body and mind, our question is not how one acts upon the other, but the simpler question, Do the two seem to be related in such fashion that certain bodily events are regularly followed by certain mind events, and certain mind events by certain bodily events? Prior to the appeal to experience, the a priori denial of the possibility of such causal relation is pure dogma.

What, then, has experience-experience rather 1 "On the Notion of Cause" in "Mysticism and Logic," p. I80. 
than theory-to say on this matter? If I am not tremendously mistaken, experience speaks here in no uncertain terms. And I refer to the simplest and commonest experiences of every day. If the electricity were suddenly turned off from this room, our visual sensations would all cease; if it were turned on again they would immediately return. And this experiment could be repeated endlessly with invariably the same result. Here, surely, we seem to have a case of invariable sequence if it is to be found anywhere, the physical change being regularly followed by the psychical change. Nor is regularity any more difficult to find in the reverse direction. I will to raise my hand and my hand rises; and this experiment and innumerable others like it can be repeated as long as the skeptical investigator wishes to stay and watch it. Surely if we are to be persuaded that physical stimuli have nothing to do with the production of sensations, or that will actions have nothing to do with the movements of our muscles, the persuader must rely upon something else than an appeal to experience. There seems, in fact, something almost perverse in the assertion, so popular in certain naturalistic circles, that the principle of simplicity de- 


\section{MATTER AND SPIRIT}

mands that we explain human conduct without any reference to the conscious thoughts and purposes which so indubitably and so obviously precede or accompany it. There they are, ready at hand as a means of explanation, and without them the activities of human beings are notoriously inexplicable. As Becher has put it in his work "Gehirn und Seele," if an astronomer finds an irregularity in the motion of a known star which he cannot explain, he assumes an unknown factor; but if another star whose influence has not yet been reckoned in is present, the astronomer is not prevented from bringing it into his calculation by any "principle of simplicity."

It is, moreover, not without significance that the very concept of causation is undoubtedly derived from the experience of individuals as active agents. This was not Hume's view to be sure; in his opinion it was the observation of many repetitions of a given sequence from which comes the notion of causation. But on this point modern psychology finds Hume's analysis quite inadequate and unpersuasive. In the words of Professor Ladd, "What we all do actually experience in trying to get a lifelike idea of the meaning of our judgment ' $A$ is the cause of $B$ ' is the process of mentally representing our own experience 


\section{INTERACTION DIFFICULTIES 141}

whenever self-conscious causation with its feeling of effort is followed by observed changes in our presentations of sense in a regular way." " "Only as being ourselves self-conscious agents and sufferers do we come to argue about 'energy' and 'causation' in the world of things." " "Were it not for the experience of mind as self-active and yet as dependent upon bodily changes for its particular experiences, and of the body as dependent for its particular changes upon states of mind, we should never have any conception of causation, or any so-called scientific principle of causation, or any law of the conservation and correlation of energy, or even any dispute as to whether the notion of causation applies properly to the relations of mind and body. Causality is most originally and concretely an experience of relations between body and mind." 3 Time permits no longer quotation from Professor Ladd's admirable psychological discussion of this matter, but I commend to all those who have not read it his lucid exposition ${ }^{4}$ of the absurdity of those who would forbid us to apply to the activity of mind a concept which is ultimately

1 "Philosophy of Mind," p. 220.

${ }^{2}$ Op. cit., p. 222.

3 Op. cit., p. 234.

$4 O$ p. cit., pp. $218-36$. 


\section{MATTER AND SPIRIT}

derived wholly from our experience of that activity.

There is therefore nothing in the nature of causation inconsistent with the view that mind and body act on each other; and experience would seem to indicate that such causal interaction is one of the commonest things observable. The first accusation against Interaction falls, therefore, to the ground. The second accusation raised against it, however, is much more difficult to deny, namely that the interaction of mind and body is incompatible with the principle of the conservation of energy. In considering this question it is necessary to be as clear as we can as to the meaning of this famous physical principle. As Wundt and Busse have pointed out, there are two theories which go under this name, and which, while closely related, are by no means identical. One of these deals only with transformations and may be phrased as follows: "When kinetic energy is changed into some other form and this in turn is changed back again into the kinetic form, the amount that is now restored is equal to that which was given up." 1 This dictum we may call the Theory of Equiv-

1 Stumpf's formulation, in his "Eröffnungsrede des Internationalen Kongressus für Psychologie" (München, I908), p. 9. 


\section{INTERACTION DIFFICULTIES 143}

alence. Taken in this sense plainly the principle of the conservation of energy need not be inconsistent with Interaction. It would, no doubt, demand a particular formulation of the Interaction Theory-one that should maintain that the amount of physical energy destroyed when body influences mind is ultimately exactly made good by the amount created when mind influences body. This condition might bring certain odd characteristics into the Interaction Theory. But the interaction part of it would remain intact.

It is rather more difficult to make Interaction compatible with the other form of the principle of conservation. This form-the more popular of the two-insists that the amount of energy in the universe is always fixed and constant,- - the Constancy Theory we may, therefore, call it. The difficulty of harmonizing Interaction with this theory is evident. If no energy can ever be created or destroyed how can the physical energy of the brain affect the mind, and how can the mind ever affect the brain? Should we not have in the one case the destruction, in the other the creation of energy?

Several ways out of the difficulty have been suggested, but none of them is altogether satisfactory. 
Professor Stumpf proposes the view ${ }^{1}$ that the physical stimulus might cause sensation without the expenditure of any energy, all its energy going into the changed condition of the brain; and that in like manner a volition might be one of two co-causes of a motor response, the other co-cause being the correlated brain activity which should furnish all the energy, the volition contributing none. The first of these proposals makes the causal action of the brain upon the mind very anomalous, though not inconceivable. The second has much greater difficulties; for either the physical co-cause, which contributes all the energy, wholly determines the motor event or it does not. If it does wholly determine it, then the psychical co-cause-the volition-is not really a cocause at all. If the physical co-cause does not wholly determine the event but is thwarted and its natural working is modified by the volition, then the volition is doing something for which energy is regularly needed; and either it must itself be a form of energy or else it must create energy. To assert that it performs what a physical thing must have energy in order to do, and yet to deny that it is either a form or a creator of energy, is to get out of a diffi- 
INTERACTION DIFFICULTIES 145

culty in a purely verbal fashion. It is, in fact, impossible to hold this view unless we regard consciousness as a form of energy or a creator of it. Similar difficulties await the other proposed reconciliations. Thus Wentscher, Wundt, and others have suggested that mind might prevent or delay the transformation of potential energy into kinetic and so affect very considerably the processes of the brain; and yet the amount of energy at the end of the operation would equal that at the beginning. Others have proposed that mind might intervene to change the direction of motion in brain molecules without altering either the mass or the acceleration, and thus neither increase nor decrease the amount of energy in the moving molecule. But it must be remembered that energy would be required to do this, and unless the mind itself be a form of energy it could do this only by creating at least an equivalent to the amount of energy that would be required of a physical thing to make the same change in direction. ${ }^{1}$ All these proposals, it will be remarked, are quite invalid unless we regard mind as itself a form of energy; and the suggestion that we should frankly make this supposition was, in fact, put forward by

1 The same objection holds of Maxwell's "demon." 
Professor Stumpf in his famous address in support of Interaction at the Congress for Psychology at Munich in 1896.

And indeed, when one considers the matter, the proposition does not seem altogether impossible. It may, of course, be put in a way that would seem to have most of the disadvantages of Materialism; ${ }^{1}$ but it may also be expressed in terms that will avoid at least the most obvious of the materialist's difficulties. For it is not necessary to assert that mind as such is identical with energy as such; one need only maintain that mind is one of those things that possess energy. If mind be taken in this sense it is quite possible to reconcile Interaction with the principle of conservation. For what is energy according to the physicists? When they leave their equations and speak of energy as something real-as indeed they must do when they speak of it as constant in amount - they can define it only as the ability to do work, or to exert influence upon the acceleration of mass or upon the distance through which a mass is moved. Now that mind has the ability to do work and to

1 This, in fact, was our criticism of Prof. Montague's identification of mind with potential energy. With a little modification, however, Prof. Montague's theory might be made over from Materialism into a form of Interaction. 


\section{INTERACTION DIFFICULTIES 147}

exert influence upon the molecules and masses of the brain is exactly the contention of Interaction. And there is nothing in the theory of the constancy of energy incompatible with this view provided we assert that the sum total of energy in the universe, kinetic and potential, possessed by physical systems and by minds, is constant.

While the upholder of the conservation of energy, however, may be induced in the manner suggested to compromise with the interactionist, it is very questionable whether the interactionist on his part will care to make the compromise. For if the sum total of the energy of the universe, in minds and in matter, be constant, then the amount at the disposal of each mind will be absolutely definite and absolutely limited and it will be quite impossible for the mind to create any new energy. The amount of energy which the mind possesses, moreover, will be determined almost or quite entirely by the amount it has received from matter, and it will be able to give out only so much as it has received. Thus mind, instead of being a genuine source of creative energy or a real power in the control of it, will be merely a kind of passive reservoir for its temporary storage or a channel for its flow. Such a view would not be incon- 
sistent with Interaction and one might work out on the basis of it, as Stumpf suggests, "a psycho-physical mechanics which should fit spiritual events into the universal causal organization of the world." But I doubt whether this bringing of mechanics into the soul will be acceptable to many interactionists. In such a partnership between the mechanical and the spiritual I fear the mechanical would always control the decisive vote, and thus we should have on our hands again the old materialistic difficulties as to the efficiency of consciousness. So far as I can see, the only way in which the efficiency of consciousness can be preserved is by insisting upon the creative power of the mind. If $i t$-it and not merely something of which it is the channel-is to have genuine influence upon conduct, it must be an originator of action absolutely undetermined by the laws of energy, it must be able to make something that is new. It is hard to see how it can do this unless it be a genuine creator of energy.

My personal conclusion is, therefore, that Interaction, in the sense in which it is really of importance, is not compatible with the theory of the constancy of energy. The two are antithetical. What must we 1 Op. cit., p. 19. 
INTERACTION DIFFICULTIES 149

conclude from this? That Interaction is therefore impossible? Perhaps so. Yet before doing this we must, if our method is to be logical or scientific, first ask how we know that the theory of the constancy of energy in the universe is true. If this theory is demonstrable, plainly it must be demonstrated, like everything else, in one of three ways. Either it must be a necessary logical truth, or it must be an observable fact, or it must be a law deducible empirically from the sum total of observed and relevant facts. In which of these three ways has the law of the conservation of energy (in the sense of constancy) been demonstrated? Certainly not in the first sense nor in the second. Not its most enthusiastic propounder would seriously maintain either that it is a necessary law of thought or that it is capable of verification by direct observation. It must, therefore, if demonstrable, rest upon induction, it must be empirically verifiable.

Where shall we look for this empirical verification? How shall we prove that in the relations between mind and matter no energy is ever created or destroyed? Within the inorganic world the amount of energy may well be constant. This indeed has never been proved and probably never will be. It is a 
postulate; but it is one that we are probably all willing to make. But the question of the universal application of the theory to the inorganic world is not the question we are talking about. What evidence is there that it applies also to conscious and reasoning beings?] So far as I am aware, only one serious attempt has been made to test its applicability to men-an experiment, namely, carried out between 1900 and 1902 by Drs. Atwater and Benedict under the auspices of the U. S. Department of Agriculture. ${ }^{1}$ The total income and the total outgo of energy in the bodies of several young men were exactly measured, with the result that, expressed in calories, the income and outgo never indeed balanced each other exactly, but came fairly near to doing so. Sometimes one was in excess, sometimes the other, the net outgo varying from 165 calories below the net income to 195 calories above it. If all the experiments are lumped, income and outgo vary by less than one-fifth of one per cent. Now, if Interaction be true how should we expect such a series of experiments as these to turn out? Consider: the weight of the brain is about one-fortieth or one-fiftieth of the weight of the

1 Reported in Bulletin No. 136 of the Department of Agriculture, Office of Experiment Stations, Washington, I903. 
INTERACTION DIFFICULTIES 151

body, and the part of the brain that is supposed to be in direct relation to consciousness is a small fraction of this. Every theory of Interaction which suggests details, moreover, proposes that the action of the mind on the brain consists in only such very slight creation or use of energy as should be necessary to change the direction of moving molecules or delay for a few seconds the transition of potential energy into kinetic; and that the action of brain on mind involves an equally minute amount of energy. Our interactionist, therefore, in spite of his denial of the universality of the conservation of energy, would have expected the differences in income and outgo in Dr. Atwater's experiments to be just about what they were, or possibly even slighter. It is of course possible to postulate that the difference found was altogether due to error and that as a fact income and outgo were exactly balanced. Even had this been the case, however, it would have been perfectly compatible with Interaction; for (especially under conditions such as those of the experiments) it is quite conceivable that the amounts of energy absorbed and created by the mind should balance each other. The outcome of the experiment therefore is quite as much in favor of Interaction as against it, 
and proves nothing whatever as to the applicability of the conservation of energy to conscious beings.

The only possible conclusion from the facts thus far considered is that there is absolutely no reason of either an a priori or an empirical kind for maintaining the universal applicability of the theory of the conservation of energy. The only argument in favor of such a view is the argument from analogy that since the theory holds in the inorganic world therefore it must hold in the organic and conscious world. In other words, it is part of the general view that not only the conservation of energy but all the laws of physics and chemistry must have absolute and unmodified application to the whole material world and that they can never be interfered with by anything else. It was the necessary denial of this universal applicability, it will be remembered, that formed the chief difficulty of Interaction. Here, then, we have the decisive issue in its most crucial form: Can mind ever modify the action and outcome of physical laws?

This is a question of tremendous importance and we should make every effort to approach it fairly; we should also, I am inclined to think, do our best to prove the universality of physical law if that be 
INTERACTION DIFFICULTIES 153 possible. It would be a very weak defense of such a view to put our argument in the form of analogy; to say that the organic and conscious world must be analogous to the inorganic; for that is the very thing to be proved. We shall make a better showing for the mechanical view if we divide our argument into two heads, - -an a priori and an a posteriori. Our a priori argument will then run as follows. It is generally admitted that the laws of physics and chemistry have unobstructed control over all movements and changes in the inorganic world; is it not therefore extremely improbable that the tiny realm of organic matter-or the much tinier realm of matter constituting the bodies of reasoning beings-should resist this dominance and form an exception to an otherwise universal law?

In attempting to give a serious answer to a question concerning probability it is necessary to know whether that question be asked in the light of experience or prior to all experience. If we ask what, prior to all experience, would be the probable situation, we see plainly that there is no possible answer to our question-prior to experience one answer is quite as probable as another. The only question as to probability that will have any real meaning must 
therefore be this: In the light of all our actual experience is it or is it not probable that those laws which hold absolutely for the non-organic world hold also and with equal absoluteness for the organic and conscious world? The question of probability is therefore just the old question of facts and of their interpretation. The upholders of the view that the physical laws of the brain completely determine the action of the mind will refer us to such things as reflex action and habit in normal beings, to the localization of function and the phenomena of aphasia. But plainly the first two of these are perfectly consistent with a view which, like Interaction, agrees that the body is a machine but insists that it is a machine which to some extent is run by the mind. And as to aphasia, though there is no time for even a cursory treatment of the subject, let me remind you that while the earliest investigations of the disease by Broca, Wernicke, and their contemporaries made it appear that memories were stored up in definite brain centers and that memory and presumably thought were altogether dependent upon particular cerebral structures, the most recent work upon the subject has quite upset this entire theory. The whole question is in many ways still vague and unsettled, but 


\section{INTERACTION DIFFICULTIES 155}

the three following points seem pretty well established. Firstly, memory images are not stored up in particular parts of the brain. ${ }^{1}$ Upon this the leading authorities are agreed; definite memories seem to be created by the mind and to be conditioned upon some general type of brain set such as that which Bergson suggests in his interactionist hypothesis. $^{2}$ Secondly, even when no images can be formed it is still possible for the patient to think, to mean, to will. He may be unable to get the meaning of others, because he has forgotten their language; but he is still very conscious of his own meaning and his own wishes and able to cling persistently to a definite purpose even though unable to put the purpose into words. He seems, in short, to be intensely conscious, yet without definite images or symbols. $^{3} \quad$ Thirdly, by persistent activity of the will much of the language loss in aphasia may be regained through a laborious process of reëducation. ${ }^{4}$ Presum-

1 Cf. Head, "Aphasia and Kindred Disorders," Brain, for July, I920; and Franz, "Cerebral Mental Relations," Pschol. Review for March, I92I.

2 "Matter and Memory," passim. Cf. also the essay on "The Soul and the Body," in "Mind-Energy."

3 See in particular the "Memoires du Medecin Aphasique" in the Archives de Psychologie for May, rol8.

4 Almost every work on aphasia shows this. Cf., for example, Prof. Franz's "Presidential Address on Cerebral-Mental Relations" already referred to. 
ably this means the training of new centers to do the work of those destroyed by the original lesion. In any case it seems to indicate clearly the activity of the mind.

So far, then, as I am aware, there is absolutely no experimental or empirical evidence of any kind which gives any support whatever to the denial of the mind's power to modify the workings of the laws of physics and chemistry. On the other hand, we have the unhesitating and universal testimony of every unspoiled individual consciousness, and the equally unquestionable evidence of everyday experience that mind can and does determine conduct. The very structure of the nervous system as an organization of forces in unstable equilibrium, ${ }^{1}$ and the nature of consciousness as ever tending toward action and always interested in it indicate, as our greatest psychologist pointed out, the same conclusion. In the words of Professor James, "it is quite inconceivable that consciousness should have nothing to do with a business which it so faithfully attends." ${ }^{2}$ Moreover, as I have so often repeated, to insist that mechanical laws completely determine all the actions of the

1 Cf. James, "Principles of Psychology," Vol. I, pp. 139-42.

2 Ibid., p. 136. 
human brain and the human body just as they determine the processes of the inorganic world, is to accept the responsibility of explaining the whole of every individual's conduct and the whole of human history with no reference to thought, purpose, or feeling.

To prove the truth or the probability of such a view would require most serious considerations and most cogent reasons. But, as I think we have sufficiently seen, the upholders of this position have not a single relevant empirical fact to rely upon, and not an argument to appeal to, unless it be that of a thoroughly question-begging analogy.

Instead of arguments we are presented with motives. These motives are two in number. The less important is self-defensive in form. We are told that the belief in the universality of physical law is a postulate necessary for natural science, and that if it be denied the whole of natural science will come tumbling down, its very foundations having been destroyed. But what nonsense is this! If we refuse to admit that the laws which control inorganic matter also absolutely dominate that small portion of the material world in which matter comes into relation with personality, how many of the claims of physical science will thereby be undermined? In the whole 
realm of physics and of chemistry, of astronomy and geology, not one. Mechanical science will be forced to give up its claims to absolute sway only in that tiny realm where personality, or perhaps where life, begins to have influence. In this connection it is interesting to note that the demand for the absolute universality of physical laws comes, as a rule, not from the physicists, not from the chemists, but from a small number of biologists, a larger number of psychologists, and most of all from the naturalistic school of the philosophers. The mechanistic philosophers are much more royalist than their king, and the demand for the universal sway of the mechanical seems to vary directly with the square of the distance from headquarters.

The other motive which prompts Naturalism in its attempt to deny the efficiency of mind is of a more positive and ambitious sort. It is, namely, the desire to make all forms of matter, of motion, and of energy susceptible to the same sort of description, explanation, and prediction; the wish to get a single world formula under which everything that happens may be subsumed. "We have achieved the impersonal point of view," hymns one of the most ecstatic of the behaviorists, "in the interpretation of stars and 


\section{INTERACTION DIFFICULTIES 159}

stones and trees and bacteria and guinea pigs. Our next step is to achieve it for the phenomena of human behavior." ${ }^{1}$ Thus shall we at length achieve that consummation devoutly to be wished, that thoroughly scientific point of view, from which we shall be unable to find in man anything essentially different from what we observe in stones, bacteria, and guinea pigs. There is, to be sure, absolutely no evidence to show that such an achievement is possible, no argument to indicate that the actual world is such as to submit to such a formula; but the great longing heart of Naturalism demands that it shall be so, and the naturalistic philosopher solemnly declares that it is so-it is so because it must be so. It would be impossible to find in the most sentimental and unreasoning forms of religious experience a more extreme case of the pious wish or the Will to Believe. Nor can the annals of Scholastic Philosophy or of Protestant Theology give us a more admirable example of dogma, pure and undefiled. No evidence that Galileo could give as to the motion of the earth had any influence upon his judges; the earth did not move because it could not move. In similar fashion

${ }^{1} \mathrm{H}$. Heath Bawden, "The Presuppositions of a Behaviorist," Psychol. Rev., XXV (1918), pp. 173-74. 
we are assured that the mind cannot move nor influence the movements of the body-to say that it does so is heresy, for so one would deny the universality of physical law.-E pur si muove!

Here is the real issue of the mind-body problem, here is the only important question. And looking back over our course with this fact in mind we can now see that there are not, as we had supposed, three or four chief views of this problem, but only two, namely Interaction and its rivals. The various forms of Materialism, of Parallelism, and of Behaviorism are only different ways of saying pretty much the same thing, only varied attempts to prove the same thesis. The aim of all is identical, namely, to write down and explain the whole of reality in physical formulæ, to deny to mind any influence whether direct or indirect upon matter and motion. The first expression of this naturalistic thesis is the blatant form of Materialism. The difficulties to which this gives rise are too patent to permit of its acceptance, so they are later disguised under the gentlemanly costume and the idealistic mask of Parallelism. But the splendid promises of Parallelism lead to disillusion at the end, and the mask which it wore is easily torn from its face. No one weeps its fall, for 


\section{INTERACTION DIFFICULTIES 161}

few besides Fechner and Paulsen were ever very much interested in it except as a means of defeating Interaction and establishing Naturalism. So its old upholders rapidly desert it to give in their allegiance to Behaviorism. Behaviorism, also, would like to avoid the blatancy of Materialism. It has many brave words as to the nobility and the significance of intelligence. But when we get at the real meaning of the words we learn that intelligence is simply a specific form of activity and set in nerves, muscles, and glands. Thus, Behaviorism, in common with its predecessors and allies, is merely a specially devised way of denying the efficiency of consciousness.

And when one stops to face squarely this proposition that mind has no effect on conduct,- -when, I say, one stops to face it squarely, and leaving aside pet theories, gives it serious consideration in the light of all that one knows of oneself and of other men and of human history and civilization-the proposition reveals itself to the steady gaze as unspeakably preposterous. In the words of Professor Lovejoy, "Never, surely, did a sillier or more self-stultifying idea enter the human mind than the idea that thinking as such-that is to say, remembering, planning, reasoning, forecasting,--is a vast irrelevancy having 
no part in the causation of man's behavior or in the shaping of his fortunes-a mysterious redundancy in the cosmos which would follow precisely the same course without it." 1

We are told we must deny the efficiency of consciousness because of the difficulty in believing in any exceptions to the action of mechanical law and the difficulty of imagining how mind can act on matter. I submit that to be so nice with little difficulties, and so omnivorous with monstrosities that approach the mentally impossible is a case of straining at one poor gnat and swallowing a whole caravan of camels. Like others I find it difficult to imagine an idea affecting a brain molecule; but I think I am also like nearly everybody else when I find it impossible to believe that thought and purpose have had nothing to do with building up human civilization and creating human literature and philosophy. How the opponents of Interaction manage to believe these things $I$ confess $I$ find it very difficult indeed to imagine.

I know this is not decisive. I know indeed what the upholder of Naturalism will probably reply. His

1 "Pragmatism as Interactionism," Jour. of Phil., XVII (1920), p. 632 . 
INTERACTION DIFFICULTIES 163 reply, in fact, will be in substance not very different from that of the Red Queen to Alice, after Alice had told her there were some things she couldn't believe. "Can't you?" said the Queen in a pitying tone. "Try again; draw a long breath and shut your eyes."

"There's no use trying," said Alice, "one can't believe impossible things."

"I dare say you haven't had much practice," said the Queen. "When I was your age I always did it for half an hour a day. Why, sometimes I've believed as many as six impossible things before breakfast."

When one remembers the materialistic assertions that consciousness is matter and that logic is ground out by mechanical processes, the parallelistic thesis that the non-existent brain determines wholly the existent mind, the neo-realist denial of all reality to the subjective, the behaviorist identification of thought with the action of the larynx, one sees that Naturalism, like the Red Queen, has had some practice in believing the impossible; that in fact it would be stating its case with great moderation, not to say modesty, if it should claim that sometimes it had believed as many as half a dozen impossible things before breakfast. Moreover, the Red Queen's formula 
for belief is the one which must necessarily be adopted if we are to imitate successfully the remarkable achievements of Naturalism in the arousal of faith in the impossible,-namely, "Draw a long breath and shut your eyes!"

I too can believe a good many things with my eyes shut; but if I keep them persistently open I become less and less impressed with the ambitious claims and the false dignity of Naturalism. And by Naturalism I mean, of course, not natural science but the unempirical philosophy, the a priori theory, which would extend the formulæ of natural science into spheres in which the true scientist has no ambition to advance. Taken in this sense Naturalism appears to me the great hoax of our times. Its seemingly adamantine fortifications, with their tremendous and terrifying guns, are mostly camouflage. Its walls are enormously impressive; but like those of Jericho they will fall before whosoever has the courage coolly to examine their foundations-and to blow upon the trumpet.

This being the case, I must also say frankly that Interaction seems to me the inevitable outcome of our argument. It is the only view that makes history and human life really intelligible. Indeed if we 
INTERACTION DIFFICULTIES 165

were right in believing (and we have seen no reason for doubting it) that Materialism, Parallelism, Interaction, and the denial of the mind-body relation are the only answers to our problem worth serious consideration; and if we were justified also in our conclusion that the relation is a real one, and that neither Materialism nor Parallelism is tenable, and that the alleged difficulties of Interaction are much slighter than at first they seem, it follows that we are plainly compelled by the very process of elimination to conclude that Interaction is the true doctrine and that mind has an independence and a power of its own. And now we can begin to understand the wild attempts of Materialism, Parallelism, NeoRealism, and Behaviorism to invent some method by which Interaction might be avoided. Not for nothing were the strange twistings and writhings of these theories. For if Interaction be accepted a momentous turn has been taken in our philosophy. We shall namely have given in our assent to a Dualism of Process within the universe.

The consequences of such a Dualism of Process are fateful and endless. There is no time to deal with them this afternoon and they must be postponed for consideration to our final lecture. But we can, 
I think, already begin to form some notion of what is involved in this Dualism of Process, to which, by the force of logic and of experience, we seem to have been driven. Such a world view will mean a profound, if not a fundamental, distinction between matter and spirit. It will mean the return of all sorts of possibilities against which the iron gates of Naturalism were forever closed. It will mean that perhaps Plato and Christianity were right after all. 


\section{LECTURE V}

\section{A DUALISM OF PROCESS}

The preceding four lectures formed one consecutive argument as to the nature of the relation between mind and body. The outcome of that argument may be put in negative terms as follows: None of the theories opposed to Interaction are tenable, and none of the objections to Interaction are important. From this outcome we seemed to be justified in drawing the conclusion that Interaction is the true solution of the mind-body problem. Personally I think this is a solution from which there is no escape. It is a solution, moreover, that is pregnant with decisive consequences for our whole view of life and of religion; as, indeed, I hope to show in our next lecture. Before turning to this rather alluring field, however, we must face one more difficult and crucial question; namely this: If Interaction be true, what are they that interact?

A verbal answer to this question is of course simple enough and ready at our hand. It is an easy thing to say that mind and matter interact. The interpre- 
tation of each of these terms, however, has been the subject of volumes of learned disquisition and keen critique. Fortunately one of these terms, namely matter, need cause us little concern. Whether we interpret it realistically or idealistically will have little bearing on the more pragmatic questions of life and religion or on the philosophical position with which I am chiefly concerned. The interpretation of the other term of the interaction relation, namely "mind," is very much more crucial in its bearings upon life's values. In spite, therefore, of the briefness of our time we must now face the important question: What is it that interacts with matter?

Roughly speaking, there are three types of answer to this question. One of them is that it is consciousness, the passing stream or pulse of consciousness, which is affected by the neural stimulus and which in its turn affects the motor discharge. This answer has the merit of simplicity and the merit of trying to stick closely to the facts. But a little reflection, as it seems to me, will show it to be plainly inadequate. If only sensation and impulse were involved, this view, which sees in mind merely a succession of more or less distinct, not to say unrelated, psychic states, would be ample and its simplicity would there- 


\section{A DUALISM OF PROCESS 169}

fore recommend it as the most acceptable hypothesis. But the most significant part of the mind-body relation is the activity of mind as consciousness in guiding and determining purposeful conduct. It would be very difficult to believe that passing psychic states can account for conduct. Human action is of course all too often the outcome of mere impulse, but at times also-and very commonly-it is the outcome of long nourished purposes and firmly grounded character. To fail to recognize this fact and the consequent insufficiency of mere successive psychic pulses as an explanation, is to fail to realize the difference between the man and the invertebrate. The mind that determines human conduct has in it something more durable and more substantial than any transitory state of consciousness.

Closely related to the view just criticized is the suggestion made independently by James and by Bergson, to the effect that consciousness in itself is non-personal, that it exists primarily in a kind of cosmic center or reservoir, and that it showers down upon us from its celestial source and becomes separated and differentiated into the forms we know as personal conscious centers through the action of the brain. Our brains are thus "organs for separating 
it into parts and giving them finite form." 1 The thought itself goes back of both James and Bergson at least as far as Shelley: the reader will remember the suggestive lines:

\section{"Life like a dome of many-colored glass Stains the white radiance of eternity."}

There is a magic in these verses which should make them immune to criticism. But it must be said that if they are to be interpreted in terms of the JamesBergson hypothesis, they are indeed still beautiful poetry but very questionable philosophy or psychology. James himself, it must be added, seems hardly in earnest with his own suggestion,--and indeed it is hard to see how he could be; for such a view is quite out of keeping with his regular empirical attitude, and it is, moreover, almost as defenseless before his own argument against the Mind-stuff Theory as is that theory itself. Nothing that we know of consciousness or of the universe gives us any reason for supposing the existence of such a reservoir of impersonal consciousness as seems to be implied in the hypothesis; nor is it easy to put any meaning into the

1 James, "Human Immortality," Note, page 52. Bergson's view is presented in "Creative Evolution." It must be added that his treatment of the subject in "Matter and Memory" has little in common with the view under discussion. 


\section{A DUALISM OF PROCESS}

assertion that the very personal thoughts and feelings and volitions which I find in my own experience are rays showering down upon me from some "vaster unity." Here as elsewhere "the essence of feeling is to be felt, and as a psychic existent feels so it must be."

The thing that interacts with matter must, then, be something relatively individual and relatively permanent if it is to account for experience as we actually know it. These considerations, together with a hidden fear of some of the seeming difficulties considered in our last lecture, and also the desire to conform mind as closely as possible to the rest of the existent universe, as well as the courteous wish to avoid all unnecessary offense to the susceptibilities of the naturalists, have led some interactionists to propose that mind should be interpreted as a kind of material substance, different, to be sure, in many ways from the matter which chemistry and physics study, but like it in having definite position and extension in space and apparently also in being part of the executive order of the physical world. ${ }^{1}$ The motives for

${ }^{1}$ Cf. Professor Sheldon's admirable Presidential Address at the Twenty-first Annual Meeting of the American Philosophical Association, published in the Philosophical Review, XXXI, pp. 103-34, esp. pp. 129-34. 
such a view are obvious and of course are natural enough. Personally they seem to me quite outweighed by the equally obvious disadvantages, not to say dangers, of the proposal. To say that mind is matter, whether the matter be of the ordinary or of an extraordinary sort, is ultimately as meaningless in the mouth of an interactionist as in that of a materialist, and it is difficult to see where any solid advantages are to be found in so hazardous a proposition. It is not in any material realm that mind is to be found. What we mean by mind is surely something quite different from that. Why seek ye the living among the dead?

Mind, therefore, is not to be identified either with any form of matter or with passing states of consciousness. Yet it must have at least a certain degree of persistence and substantiality in order to explain its control of conduct and all that we know as purpose and character. If so much must be admitted I see no way of avoiding some form of the age-long view of philosophy and of common sense which would interpret mind in terms of self or personality. Such a view is not popular to-day. Yet if Interaction be true it seems to me we must suppose that the reality which interacts with the brain is 


\section{A DUALISM OF PROCESS 173}

some form of self which gets expression in the successive psychic states, which somehow owns these states and is to a great extent characterized by them, but which is not exhausted in them. It has been a common practice to prove the truth of Interaction by means of the existence of the self. The argument, I think, runs as easily in the reverse direction. Granted the truth of Interaction, the existence of the self is nearly or quite unavoidable.

Nor, quite aside from Interaction, do I see how belief in a genuine self is to be avoided. The experience of the philosopher and of the "plain man" alike testify unmistakably to the personal nature of consciousness. The special needs of psychology have compelled the psychologist to isolate various parts of the content of consciousness and to study them out of their total setting and in abstraction from those common characteristics which they share with all the rest of our psychic content; and as a result the psychologist has formed the habit of considering these things by themselves and of reconstructing the "stream of consciousness" out of them. Most of us brought up in scientific circles have borrowed the habit of the psychologist. Thus both the psychologists and the rest of us have to some extent obliterated our imme- 


\section{MATTER AND SPIRIT}

diate self-knowledge, and for purposes of theory have set up in place of what we actually find a description of consciousness which is frankly false and whose raison d'être is the need of studying in artificial isolation elements of consciousness which in reality are never isolated. But when from this artificial construction we turn with a fresh glance to observe our own conscious life we find that it is most emphatically not a succession of psychic pulsations but a series of our own changing states and objects. The only forms of consciousness we know anything about are personal, and with every psychic state there goes a reference, explicit or implicit, to a self which somehow owns or has these states, perceives these objects, acts and feels and knows in these volitions, emotions, and judgments.

"If the self is only a multiplicity of psychic experiences," writes Busse, "the manner and means by which this multiplicity gets put together into the unity of consciousness is not only, as Paulsen puts it, 'not further definable,' but unthinkable. . . . A multiplicity remains under all circumstances what it it is, a multiplicity, a sum of elements somehow bound together. However grouped they remain ever a multiplicity and they melt into a single unified sub- 


\section{A DUALISM OF PROCESS}

ject as little as a number of separate personal consciousnesses can be melted into a single, unified consciousness." 1

The unity of consciousness to which reference is here made need not and should not be taken in any mysterious or transcendental sense. It is one of the simplest facts of every one's unspoiled observation. It does not mean a stark unity, incompatible with variety. It means that with all the changes in our thoughts and experiences we yet find ourselves one and identical.

There is no time in this lecture for a discussion of the nature of the self. Even if there were I should despair of finding a complete definition for it. Our inability fully to define it is due in part to the fact that the self is primal in our experience and is sui generis. The physicists and the mathematicians have somewhat similar difficulties in defining their "first things." The more logical among them, in fact, have ceased to attempt to define them. In the case of the self, moreover, we have an additional difficulty. So strong in us men, and particularly in our primitive ancestors, has been the practical bent, directed toward the world of matter and motion in which our

1 "Geist und Körper," pp. 326-27. 


\section{MATTER AND SPIRIT}

lives as natural beings depend, that language, with all its terms of definition, has been formed on what we might call a material model. Hence the moment we try to define the self otherwise than by enumerating the things that it does, we are forced to make use of objective and quasi-material terms which defeat our very purpose. But if we cannot define the self, we can, like the mathematicians, exhibit it, point to it, indicate what we mean by it. In the words of a recent English writer, "We all realize what it is to be active-it is just living and doing. We all realize what a self is. This realization is far more than knowledge in the ordinary sense. . . . It is a unique and supremely intimate fact, and therefore stands in a class of its own." 1 Moreover, in addition to this direct realization of the self, its reality may also be inferred from such things as knowledge, experience, perception. For "without it they have no significance whatever. ... We cannot speak simply of the existence of thoughts and feelings. There is always the implication of one who feels and thinks." 2

I shall not seek, then, to furnish you with any

${ }^{1}$ Richardson, "Spiritual Pluralism," pp. I3-14.

2 Ibid., p. 20. 


\section{A DUALISM OF PROCESS}

careful definition of self or personality, but simply point you to your own unspoiled intuition. By the self I shall mean that which has ideals and purposes, which wills and suffers and strives and knows. By defining it thus I am merely using the method by which we define and know most of the objects of our thought and action,--namely by the things which it does. That a thing is what it does has been a commonplace of thought since the days of Aristotle. Nor can it be said that the self is a mere "that which"; for the things that it does are not to be separated from it. It is by no means the unqualified blank substance of some of the scholastics, nor merely the pure perceiving subject of some of the idealists. Each self has its own very definite characteristics which are to be learned only empirically. Some of the characteristics shared by every self have been enumerated by Professor Calkins. "First, the self of each of us to some extent persists. ... In the second place, the self with all its persistence truly changes, develops. . . . Third, and very significantly, I am a unique self; there is only one of $m e$; I am an individual; no one, however closely she resembles me, is I. The possibility of this enumeration shows, in the fourth place, that I am a complex self, a unity of 
present with past,-yes, and with future,--self and a totality, also, of many different experiences; I am a perceiving and remembering and thinking and feeling self. These different experiences or aspects of me do not, however, exist apart from me; I obviously am not what Hume called me, a bundle of perceptions, but each of the perceptions or emotions or thoughts is the expression of me who am inclusive of them. Finally, I am a self related to the world in which I seem to myself to be placed. . . . And these characters, it must be added, are immediately experienced. The self, thus described, is observed and not merely inferred." 1

From this enumeration of some of the characteristics of the self it will be noted that the self is not to be confined within or found within any single moment and that its qualities are such as could not be attributed to any cross section of the stream of consciousness. One must take a longitudinal section of the time stream if one is to find the self. It is the sort of thing that changes and grows; change and growth are a part of its nature. Unlike things, whether material or physiological, and unlike what

1 "The Case of the Self Against the Soul," Psycholog. Rev., XXIV, pp. 279-80. 
theology sometimes teaches concerning God, the human self

"partly is and wholly hopes to be."

Each self is of course characterized by its present conscious state, but its present conscious state forms only a small portion of its nature. Much more important in making it what it is are its memories, tendencies, sentiments, its purposes and ideals. These do not exist in the form of present consciousness. To make room, then, for the most significant portions of the personality or character we must have recourse to unconscious mental organization. If there be a self at all, character is surely a part of it, and character is much more than consciousness. Any given passing conscious state is thus merely an aspect or activity of the self. The self may be called a center of psychic powers whose characteristics necessarily transcend any given section of conscious content or phase of conscious experience, and which are essentially inexhaustible by any passing moment.

The reader will probably note in this discussion of the self, and indeed in a large part of this book, the close relation of my position to that of Professor 
McDougall,-a relation which at many points means an indebtedness which I am eager to acknowledge. It may not be out of place, therefore, to quote here his careful statement of the nature of the self or soul as he understands it, a statement that includes within it most of the things that I could wish to say and which have always seemed to me particularly enlightening. "We may describe a soul as a being that possesses, or is, the sum of definite capacities for psychical activity and pscho-physical interaction, of which the most fundamental are (1) the capacity of producing, in response to certain physical stimuli (the sensory processes of the brain), the whole range of sensation qualities in their whole range of intensities; (2) the capacity of responding to certain sensation-complexes with the production of meanings, as for example the spatial meanings; (3) the capacity of responding to these sensations and these meanings with feeling and conation or effort, under the spur of which further meanings may be brought to consciousness in accordance with the laws of reproduction of similars and of reasoning; (4) the capacity of reacting upon the brain-processes to modify their course in a way which we cannot clearly define, but which we may provisionally conceive as a process of 


\section{A DUALISM OF PROCESS 181}

guidance by which streams of nervous energy may be concentrated in a way that antagonizes the tendency of all physical energy to dissipation and degradation." 1

The self then is a genuine reality with a unity and identity of its own, a center of influence and energy, and not to be confounded with a mere sum of qualities or of states. In the words of Mr. John Laird, whose recent study of the "Problems of the Self" has gone into the matter with painstaking and critical judgment, "if anything has a right to be called a distinct particular thing, the soul has such a right preëminently. While the distinctions which we draw between things in the physical world are true and important, there seems to be no good reason, apart from momentary convenience, why we should fix on one boundary rather than another, and that is why scientific thought tends more toward a monism of matter. It is otherwise with the self. Despite the difficulties of personal identity, despite the fact that no self is a perfect or full-rounded whole, there is a greater independence and a more ultimate distinction between selves than between any other beings." 2

1 "Body and Mind," p. 365.

2 Op. cit., pp. 362-63. 
One more empirical fact about the mind or self. To use Green's phrase, it has somehow become "organic to a body." Through this body it comes in touch with the material world; by means of this body it expresses itself. The body may in this sense be called the tool of the mind. The expression must be taken with a certain degree of caution. The relations of mind and body are much more intimate and much more intricate than any of those existing between the hand and its material tool. Yet complicated as are the relations between them, it still is true that the body is not the mind, and that it is used by the mind, and in this sense may not improperly be called its tool. Being limited in its expression to this one very wonderful but still imperfect tool, the mind must, to a considerable extent, submit to the laws of the tool. Moreover, we can study the activities of the mind in objective and scientific fashion only through its bodily expressions. The interweavings of the mind with its physical mechanism are intricate in the extreme, so that it is often very difficult to separate out the strands and say, This is of the mind and this is of the body. But though this is often very difficult I am not at all sure that it is always impossible. The psycho-physical organism has, 


\section{A DUALISM OF PROCESS}

of course, a functional unity; but there is no justification for the conclusion so often drawn from this fact, that therefore analysis is impossible. It is at least conceivable that the really important psychological discoveries of the future will consist quite as much in the sifting out of the purely physical from the purely spiritual features of psycho-physical life, and in exhibiting the exact ways in which the two are interdependent and coöperative, as in the field of measuring sensations and muscular responses which at present occupies so much of the time of our experimentalists. By this suggestion I do not mean to favor a return to the fruitless "rational psychology" of the pre-Kantians. The problems I have in mind should be and may well be investigated in purely empirical and scientific fashion.

The view that I am here presenting is of course frankly dualistic. It is, however, a dualism of process and not necessarily of substance. It is as compatible with Idealism as with Realism. So far as the mind-body problem is concerned, plainly there are many ways in which Idealism can easily adapt itself to Interaction. Thus Busse, ${ }^{1}$ an enthusiastic idealist, holds that reality contains two kinds of beings-both 1 "Geist und Körper," pp. 170-73; also 475-82. 
to be taken idealistically-namely, things and souls. The difference between the two is this: that things affect perception and appear as occupying space; while souls, which are centers of consciousness, neither occupy space nor directly affcct perception. The two kinds of beings mutually influence each other; yet there is no such invariable concomitance of psychical with spatial events as is called for by Parallelism. On such a view the purely physical world of course would not be a complete and closed system, explicable by itself alone. But while physical nature would not be a complete Whole, Reality as such would be; it is not Idealism nor Monism but Naturalism that calls for unbroken mechanical explanation of all events in the physical world. Both Interaction and the related Dualism of Process which I would defend are thus perfectly compatible with Idealism and even with a certain form of Idealistic Monism, a Monism namely that has room within it for conscious and active selves.

What I mean by a Dualism of Process is now, I trust, plain enough. Whether reality is made up of one kind of stuff or whether there are two or more kinds of being within it, there are at any rate two kinds of laws, two kinds of processes to be found 


\section{A DUALISM OF PROCESS 185}

in the activities of the real beings of the world. Throughout the vast spaces of the physical universe where matter and energy come into no immediate relation with conscious persons, the laws of physics and chemistry have absolute sway. Here no energy is created or destroyed, regular mechanical sequence holds, and on the basis of the eternal physical laws and the actual configurations of matter and energy an omniscient mechanic could predict with unerring exactness the whole course of the future. But matter and physical energy do not constitute the whole of reality. However it may be with the other planets and with the infinite starry host, here at any rate, upon this tiny sphere, this mote of earth, tracing its insignificant path through the immensities of space, there are beings who are not altogether subject to the laws of matter and motion. The beings we know as persons have their own ways of acting, their own "laws," if we insist on preserving the word and transferring it to a new realm-ways of acting which are not reducible to physical laws. These personal beings have, as I said above, become "organic" to parts of the physical world. In the activities of the human body, therefore, the two forms of process, the two kinds of "law," meet. The result is both coöpera- 
tion and conflict. Many of the activities of the body take place according to purely physical laws. But not all. The determining power in some of the acts of human bodies is to be found not in the physical and chemical processes but in processes of an utterly different nature, namely, those of the rational and purposive will. At many a juncture personal will, reason, purpose interfere with the working of mechanical law and contravene it. Of course the resulting action of the human body in question will be capable, after the fact, of being described in mechanical terms. But it was not caused by mechanical forces or conditions, it was not a part of any regular mechanical sequence, and it never could have been predicted by the most miraculously omniscient mechanist, even if he had been in possession of all the facts and all the laws of the physical universe.

The question whether such a view is compatible with the evolutionary doctrine will be dependent for its answer upon the meaning one gives to evolution. If evolution be taken to mean a process of continual change in the time stream such that, at certain junctures, something genuinely new may arise, then evolution and the Dualism of Process are by no means incompatible. If, on the other hand, by evolution 


\section{A DUALISM OF PROCESS}

we mean a perpetual unrolling of the eternally given, such that each new stage was predictable from the preceding one, that no really new thing is possible, and that

"With the first clay He did the last man make,"

then plainly we must choose between evolution and Dualism. They can hardly both be true. For conscious selves and their ways of acting are different in kind from material things and their mechanical laws. The material world with its laws may precede and the world of selves may follow, but the material and mechanical world cannot out of its own resources, and acting in its own way, produce and give birth to the world of selves. Purely mechanical processes cannot account for that which is by definition nonmechanical.

One must choose, then, between Dualism and mechanistic evolution. But more is involved in the choice than appears upon the surface. Thereby one must also choose between the efficiency of consciousness and the consequences of denying it which we have dwelt upon in the preceding lectures. One must choose between Interaction and its rivals. And 
I believe that even more than this is involved in the choice. One must, in the last analysis, choose between a theory of knowledge which describes consciousness as we find it and makes possible our reference to the distant, the future, and the past, and a theory which denies all such power of "transcendence," thus making knowledge unintelligible, and which is ultimately forced to identify consciousness with its objects or to reduce it to a mass of unrecognizable mind-dust. This is a serious indictment of mechanistic evolution, but I believe it is an inevitable one. For if the mind be actually capable of transcending itself in such fashion as it plainly seems to do in every judgment which it makes concerning the future and the past, it is altogether a different sort of being from all material things and its ways of acting are as far removed from mechanical causation and sequence as the heavens are above the earth.

Nor am I alone in this view. I have the backing of two of the most considerable advocates of the evolutionary doctrine of mind, namely Professor Strong and Professor Dewey. In Professor Strong's opinion the enormous variety which we think we find in our conscious states and the great contrast between these states are enough, if really existent, to set the mind 


\section{A DUALISM OF PROCESS 189}

apart from material nature in such fashion as to make his own doctrine of the evolution of mind, and the origin of mind out of material nature, quite unthinkable. "No two things in nature," he writes, "are more incomparable with each other or more incapable of reduction to each other than a color and a sound, or any two qualities of different senses; and two different qualities of the same sense-as red and blue, or sweet and bitter, or hot and cold,-are only less incomparable and irreducible. If we were bound to take these qualities as really characterizing the feclings, if introspection spoke the last word in the matter, no evolutionary theory could ever explain the origin of the feelings out of each other or out of anything simpler, but psychology would be perforce as unevolutionary as biology without the origin of species. That simple qualities shall not be ultimate, except as essences given to introspection, is then the sine qua non of evolutionary psychology." 1

In other words, according to Professor Strong, it is impossible to accept "evolutionary psychology," impossible, that is, to reduce mind to the category of physical things or to derive it from them, impossible, therefore, to avoid the dualism I am urging unless 1 "Origin of Consciousness," p. 3II, 


\section{MATTER AND SPIRIT}

we deny to introspection all power of discerning the characters of our psychic states, deny that the qualities which we find in our feelings are really in them, and affirm that these feelings are in reality not at all as they feel but are a kind of mind-stuff whose nature we can hardly even guess.

Professor Dewey attacks a related aspect of the problem of knowledge. If consciousness be subjective, a different existent from its object, it is impossible to see how evolutionary psychology can account for it. He writes: "A belief in organic evolution which does not extend unreservedly to the way in which the subject of experience is thought of, and which does not strive to bring the entire theory of experience and knowing into line with biological and social facts, is hardly more than Pickwickian. There are many, for example, who hold that dreams, hallucinations, and errors cannot be accounted for at all except on the theory that a self (or 'consciousness') exercises a modifying influence upon the 'real object.' The logical assumption is that consciousness is outside of the real object; that it is something different in kind, and therefore has the power of changing 'reality' into appearance, of introducing 'relativities' into things as they are in themselves-in short of in- 


\section{A DUALISM OF IROCESS}

fecting real things with subjectivity. Such writers seem unaware of the fact that this assumption makes consciousness supernatural in the literal sense of the word." 1

The situation could hardly be better expressed. Unless we can somehow manage to identify consciousness with its object (as we have watched the pragmatists and neo-realists vainly trying to do): unless, that is, we can do away with consciousness ir the usual sense altogether, then we must not only give up all hope of accounting for it by means of the physical processes of mechanical evolution, but we must frankly acknowledge that it is "supernatural in the literal sense of the word." That it is supernatural in exactly this literal sense is of course exactly the assertion of Dualism. If we use the word nature to mean those objects and those processes which are studied by the physical sciences, then consciousness and the conduct of persons are literally "supernatural." This does not mean that Dualism would split the world into two unrelated halves. The central thesis of Dualism, namely, Interaction, is an emphatic assertion that the parts of the universe are related. It cannot be too often repeated that the Dualism of 1 "Creative Intelligence," p. 35 . 


\section{MATTER AND SPIRIT}

Process which I am upholding not only permits but emphasizes all that was important in Monism, namely, the conception of a world in which each part may or does interact with every other part. This Monism of Interaction, if so I may call the view I am defending, is not a monism of process and need not be one of substance, but it is a monism of mutual influence. Taken in this sense $I$ trust that Dualism will have lost its terrors for you, as it has for me. Of course I recognize that the term dualist is an epithet of derision, but I trust we shall manage to endure it. In the words of Professor Stumpf, "To many this word seems so dreadful a reproach that they will in no case allow it to be settled upon them; the most painful confusion of thought is to them preferable to any form of Dualism. For my part, I find in it nothing so frightful, provided the unity of the world's interaction remains secured." 1

What I have said should make it plain that the dualistic philosophy is in no way hostile to or suspicious of science. It is hostile only to the $a$ priori claims of those who would push the domain of natural science across the line where experience indicates that it ends. Toward natural science as such, 1 "Rede zur Eröffnung des Internationalen Kongressus," p. 30. 


\section{A DUALISM OF PROCESS 193}

as distinct from Naturalism, no philosophy is more favorable than Dualism. Instead of attempting to throw doubt upon the validity of the conclusions of physical science in the inorganic world as do some forms of Idealism and Panpsychism, Dualism would recognize there its unlimited sway. With the science of biology, whether it be of the mechanistic or of the vitalistic type, Dualism refuses to quarrel. Nor can it be justly called hostile to psychology; though it certainly feels bound to utter a word of friendly warning when it sees psychologists claiming for their subject a status and nature inconsistent with the most obvious, fundamental, and important of its own data-a status which, could it be attained, would mean the destruction of psychology as a separate science and make it merely a "stop-gap for physiology."

One final word on the relation of the dualistic view to philosophy. The serious consideration of Dualism and of what it suggests and involves would, in my opinion, bring about a healthful revival of philosophical interest, and lead contemporary thought out of some of the blind alleys in which it has been wasting its years, into fields more productive and into pathways more promising. Already, in fact, 


\section{MATTER AND SPIRIT}

the current of philosophical interest and speculation seems to be turning. There is a notable revival of interest in the mind-body problem. The formulæ of Parallelism which for so long soothed thought to sleep are now seen to be mostly verbal, and under the leadership of thinkers like Bergson in France, Driesch, Stumpf, and Busse in Germany, McDougall at Harvard, Sheldon at Yale, Lovejoy at Hopkins, Interaction and all that it implies is being seriously studied and defended. No more hopeful point of attack upon the ultimate problems of metaphysics could be found than here, in the relation of mind and body: as I pointed out at the beginning of these lectures, the whole question of matter and spirit centers, as it were, within our very organisms. A study of this problem, therefore, and a serious consideration of Dualism and all that it involves could hardly fail to open up new and enticing vistas of investigation, fresh and fruitful problems for further study. The acceptance of Dualism means not the end but the beginning; it outlines for the philosopher and the psychologist new fields of research; it opens up before their eyes a view of reality that is not only more in accordance with experience, but richer in significant and vital problems and more truly idealistic than 


\section{A DUALISM OF PROCESS 195}

most of the things they have been working at these many years.

The hold which Monism of different sorts has had over the minds of most scientists and philosophers since the days of Darwin and Hegel has made us forget the distinguished place which Dualism has held in the history of human thought. It is seldom recailed that the greatest thinker of antiquity, Plato, was a dualist. In spite of the efforts of the Hegelians to convert and reform and re-create him, there is no getting round the fact that Plato believed in matter as distinct from and independent of mind, in a dualism of process between the material and the thinking world, in the dual nature of man. It was matter which, in Plato's opinion, resisted and prevented the complete working out of the Ideas, so that the world had two realms, the mechanical and the ideal. Though Aristotle is often ambiguous, and sometimes even approximates something like Behaviorism, a large part of his philosophy is clearly dualistic. Descartes and Locke, to mention only the great names, were outspoken dualists; and if we take the philosophy of Kant in its entirety instead of leaving out half of it as is the wont of modern Kantians, the sage of Königsberg must also be counted in the long list 
of thinkers that have upheld the dualist tradition. No sharper cleavage is to be found anywhere in philosophy than that between Kant's noumenal and phenomenal worlds. It was belief in a dualism of process not essentially different from that which $I$ have been urging which formed the basis of his distinction between the real and the phenomenal self and the sure foundation for spiritual freedom and for the very existence of obligation which he so earnestly defended. It might, in fact, be said without fear of serious contradition that if we take the history of thought in its entirety there is no other subject upon which philosophers have come so near to an agreement as upon the Dualism of matter and spirit.

The philosophy of Dualism is then in no wise new. It is far from being "original." Were it original with me or even with our generation, I should have serious doubts of its truth. It is as old as man's religion, as old as man's thought. It is voiced in the writings of most of the thinkers, in the words of all the prophets. In a very real sense it may be said to be the Philosophy of the Human Race. 


\section{LECTURE VI}

THE CONSEQUENCES OF DUALISM IN MORALITY AND RELIGION

In the preceding lecture I attempted to outline, in very sketchy fashion, and on the basis of what had gone before, a metaphysical position for which I suggested the name, a Dualism of Process. The implications of such a doctrine, like those of every metaphysical position, are complicated and perhaps inexhaustible. In this, our final lecture, I wish to point out to you some of these implications and consequences within the fields of morality and religion.

The bearing of Dualism upon morality and ethics is, I think, obvious enough. To be sure, if ethics be only a descriptive science, it is consistent with any and every philosophy. But if ethics be descriptive only and never normative it loses nine-tenths of its importance. The questions whose answers we really want and need are not the academic ones as to the customs of savages and the opinions of philosophers, but the practical ones: What is the difference between right and wrong, and What can be done about it? 
Now unless the mind is efficient, nothing can be done about it, and you merely mock us by reciting to us the history of approval and disapproval. What we mean by moral action is impossible without responsibility; and responsibility in turn is impossible without some form of spiritual freedom and spiritual efficiency. And neither spiritual efficiency nor spiritual freedom is possible for any philosophy which denies the existence of free and efficient spirits whose actions are not to be predicted by the laws of the external cosmos.

The free and efficient self which is presupposed in any genuinely moral world is provided only in some form of pluralistic philosophy such as our proposed Dualism. And here we see perhaps more clearly than elsewhere the practical bearing and significance of the Dualistic Philosophy. The fundamental values of responsibility and individuality stand or fall with it. And not only Ethics, but also Sociology, Criminology, and Education, are vitally interested in the questions which Dualism raises. What attitude you shall take toward various social questions will be determined for you chiefly by the prior question whether you really believe in individuals as does the dualist, or instead dissolve all individuals in some 


\section{CONSEQUENCES OF DUALISM 199}

great monistic melting pot, such as "Society," or the Absolute, or some unimaginable form of behavioristic protoplasm. Consider the social developments of the last half century. The economic view of history has been elaborately developed and has taught us that individual leadership is negligible in human progress. Education has more and more taken as its aim the turning out of masses of human product as much alike as manufactured articles or chemical atoms. Labor unions have used their strength to stifle unusual ability. Socialism has made mighty strides toward its goal of deadening individual enterprise and of turning men and women into cogs of an immense machine. The noble name Democracy has been subverted to connote an ideal of universal mediocrity. Now I submit that it is not without significance that all these intellectual and social movements should have been contemporaneous with the alliance between Naturalism and Absolutism in their attempt, so largely successful, at belittling the value and even denying the genuine reality of the individual self. I do not mean to suggest that a philosophical point of view has been the sole cause of these various movements; but I am thoroughly persuaded that it has had much more to do with them 
than is commonly realized. We can have different pockets in our minds, but we cannot permanently keep their contents separate; and in the long run our metaphysics is bound to have its immeasurable influence upon all our theoretical and all our practical beliefs. Nothing else is so fundamental as metaphysics, and hence nothing else is so important. And once you draw your conclusion on the central metaphysical problem of the mind-body relation and follow out its logic, you will find many of these tremendous practical problems already settled in advance. For example, once more: What shall be your attitude on the treatment of the criminal? Is he merely the outcome of heredity and environment so that his acts are all pre-determined for him? and hence is he to be regarded as an invalid to be cured?-the real guilt, if indeed such a thing as guilt be thinkable, belonging not to him but to Society, or to the original cosmic dust? Or is he really a moral being? Was any creative decision his? Did he actually choose the worse instead of the better course? Is real moral guilt involved in his deed? Is there any genuine distinction between the sane and the insane culprit, and are we justified in holding the sane criminal responsible for his crime? ... One might multiply 


\section{CONSEQUENCES OF DUALISM 201}

vital questions of this sort from this and other fields, all depending for their, answer first of all upon the answer we shall give to the mind-body problem.

The bearing of Interaction, with its dualistic and personalistic implications, upon religion and theology is equally great. The dangers of religion to-day are extremely subtle, and are not always recognized by its defenders. The Atheism and Materialism of our grandfathers' time have wisely doffed their ancient costumes and have put on most gentlemanly, not to say pious, disguises; but behind the masks are the same old faces. The points of their attack upon Christian theology and religious belief are still as of old the idea of God and the idea of man. In the case of the former the attack is peculiarly subtle. For the assailants assume the form of defenders. All sorts of admirable, not to say orthodox, things are said about the idea of God. But on a careful reading of these defenses it transpires that God himself has quite evaporated. The idea of God has grown so great that God himself has disappeared. In fact we are assured that we cannot even think of God nor mean Him nor discuss His existence; for in all such thoughts and discussions the thing we are really thinking and talking about is just our idea. The nat- 


\section{MATTER AND SPIRIT}

ural derivation of this view from the excessive ambition of psychology and an equally excessive confidence in Pragmatism is obvious enough, as well as the absolutely destructive consequences which must flow from such psychologism upon any real theology and any vital religion.

The danger which threatens the Christian view of the individual comes in part from the naturalistic tendencies which we have studied at length, but it gets its disguise from a truly Christian source, namely the love of humanity. This, at least, is the way it appears to me, though I may be entirely mistaken in the matter. At any rate I have the general impression that modern social philanthropy is so in love with Man that it is in danger of losing all its love for men. Steadily and swiftly, both in theory and in practice, the individual is being lost in Society. We are so intent on "the social" that we have almost lost our belief in the individual. And if ever we take the time to think about it, Naturalism whispers into one ear and Absolute Idealism whispers into the other that the individual doesn't really exist.

We have discussed Naturalism to the extent of four lectures, and a few words should here be said concerning Absolute Idealism. As every one knows, 


\section{CONSEQUENCES OF DUALISM 203}

it goes in origin back to Kant. The complexity of intellectual threads that go to make up that remarkable and baffling web known as the Critical Philosophy I shall not attempt to untangle,--either now or at any other time. Life is too short. But I do wish to point out what seems to me two of the most important tendencies in Kant's thinking - two tendencies which between them involve most of the factors that made up his thought. There was on the one hand a dualistic, voluntaristic tendency, connected with his doctrine of the Ding-an-sich, with his belief in the primacy of the will, with his vindication of moral freedom and responsibility, and with his faith in God and immortality. Though this element in his thought was perhaps the most dear to him personally it was certainly the less original part of his contribution to philosophy. The other tendency in his thinking might be described as intellectualistic and monistic. It centers in the deduction of the categories and in the conception of the world of natural science as consisting of "mögliche Erfahrung, ordered and systematized and completely determined by the laws of an over-individual and impersonal experience. I need not remind you how most of the neo-Kantians, especially those of the Hegelian type, with their 


\section{MATTER AND SPIRIT}

almost religious horror for every form of Dualism, have rejected the dualistic, voluntaristic elements in the philosophy of their master, and have developed in keenly logical fashion the implications of his intellectualistic Monism. Thus in the progression of Absolute Idealisms and Objective Idealisms which since Hegel's time have grown out of the Kantian trunk, one can trace a fairly steady increase in the relative emphasis laid upon the intellectualistic side of the Critical Philosophy and an equally steady and equally consistent depreciation of the value and importance of the individual. Green and the Cairdsgood Kantians as they tried to be-resisted this tendency to the best of their ability; but the logic of the system was against them. Their persistence in maintaining the value of the individual did more credit to their feeling for reality than to their feeling for Kant. Royce was not an orthodox Kantianand only a "quasi-Hegelian"; yet the Kantian element in his philosophy was sufficiently strong so that when his Absolute was completed there was little left for human personality. Among contemporary Absolute Idealists Pringle-Pattison is still making desperate efforts to maintain some kind of real and morally responsible finite self; yet how such a self can be 


\section{CONSEQUENCES OF DUALISM 205}

reconciled with his Absolute is, he admits, "necessarily incomprehensible." ${ }^{1}$ It is impossible to read the last pages of his book on the Idea of God without feeling that he is quite non-plussed and that it is his heart rather than his head that persists in the painful endeavor to reunite two irreconcilables. The position of Mr. Clement Webb would be no less uncomfortable but for the fact that ignorance is bliss. The tremendous difficulties of the attempt to retain both human personality and the all-inclusive Absolute never cause him a moment's uneasiness-nor apparently a moment's thought. In spite of much learned and admirable exposition, the chief impression which one takes away from a perusal of his recent Gifford Lectures is that of an astonishing complacency, moving about in worlds not realized.

The true implications of the Kantian Idealism are to be found not in theologians like Webb nor in philosophers who like Pringle-Pattison care more for the facts of human nature than for intellectual consistency, but in thorough-going rationalists such as Bradley and Bosanquet. For the former the self is, like everything else one can name, mere appearance, and in fact a particularly contradictory case of appear1 “The Idea of God," pp. 390 and 391. 
ance. But it is especially in Bosanquet, as it seems to me, that we find the most consistent expression of the logical outcome of Objective Idealism. For him the finite individual has only an adjectival form of being. ${ }^{1}$ It cannot be rightly called a substantive; in fact it cannot be rightly called even an individual. ${ }^{2}$ The only real individual is the Absolute. "Dissociation and deformation, rather than unification and transformation, are the keys to the study of the finite," ${ }^{3}$ for the finite self is a false abstraction. The world of Objective Idealism is an organized system of universals and relations, a kind of cosmic geometry. In this system what we mistakenly call finite individuals are simply the points at which various lines of relation cross. As persons possessed of will they have no more of original and dynamic contribution to make than have the points of a geometrical diagram. The only shred of individuality left them is on the intellectual side, and here, in the words of Pringle-Pattison, they are "at best only different points of view-peepholes, so to speak,-from which an identical content is contemplated." 4 Even as

${ }^{1} \mathrm{Cf}$. his contribution to the Symposium on "The Mode of Being of Finite Individuals," Proc. Arist. So., XVIII, pp. 479-506.

2 See "The Principle of Individuality and Value," passim.

3 "The Value and Destiny of the Individual," p. II.

${ }^{4}$ Symposium, Proc. Arist. So., XVIII, p. 520. 


\section{CONSEQUENCES OF DUALISM 207}

such, moreover, they tend to merge with each other in an indistinguishable identity. And one school of Objective Idealism would take from them even the consciousness which Bosanquet has inadvertently left them, and would interpret all finite and individual consciousness as some form of bodily behavior. ${ }^{1}$

Objective Idealism thus takes all true reality from the finite individual, transferring all that was real in it to the Absolute. How great an individual must then the Absolute be! Yes, truly. Emphatically the Absolute is individual in the literal sense of indivisibility, and also in the sense of uniqueness. But of the other characteristics which individuality usually connotes to our untechnical ears, the Absolute is as innocent as are we. Will, thought, selfhood, personality-the Absolute of Objective Idealism can no more be justly accused of possessing these very nonintellectualistic attributes than can the hypotenuse of a right-angled triangle. The Absolute which derives its descent from Kantian Idealism must in no way be thought of as the God of religion. Far be it from Him - or rather from It - to possess any of the personal qualities which religion longs for in its God.

${ }^{1}$ Cf. Hoernlé, "Studics in Contemporary Metaphysics," especially Chap. VIII. e.g., p. 227 . 
The Absolute is much too inclusive for that. Jenseits von Gut und Böse, it is to be characterized not by personal nor by moral but purely by logical terms. Justice, tender mercy, loving kindnessspeak not of these in the Absolute. Its one supreme attribute, according to Professor Bosanquet, ${ }^{1}$ is noncontradiction.

Volition, purpose, personality, morality being thus banished alike from man and from God, and the contrast between consciousness and matter being so far transcended that the reality which remains might be called one quite as well as the other, the world of Objective Idealism gradually but steadily takes on a strange similarity to that of Naturalism. For Naturalism need by no means assert that only matter exists,-as was indeed amply demonstrated years ago when Thomas Huxley united in his own philosophy extreme Naturalism and a modified form of Berkleyan Idealism. But if Berkleyan Idealism is partly compatible with Naturalism, doubly so is Objective Idealism. The two are at one in almost every detail that is of any pragmatic importance. For both of them everything and every event, all human

1 "Principle of Individuality and Value," p. $44 \mathrm{f}$; Review of Pringle-Pattison's "Idea of God," Mind, XXVI, p. 478. 


\section{CONSEQUENCES OF DUALISM 209}

action quite as much as the revolutions of the stars, is determined by certain external laws. Everything is what it is because of its relation to everything else. All spontaneity, all new creativeness is ruled out as impossible. For Naturalism human personality is an idle and powerless observer of events and deeds over which it has absolutely no influence; for Objective Idealism it is in some ways even less than that-an illusory appearance with no reality of its own. In such a purely logical system human freedom is of course unthinkable and moral responsibility becomes absurd. Rigid determinism rules both the naturalistic and the idealistic universe. In fact of the two the idealistic is, if possible, the more completely deterministic. For while Naturalism views events as determined by the past only, Objective Idealism insists that they are determined by the future as well. Reality, in short, is for it a logical series that can be read backwards as well as forwards. And this double banning of all spontaneity and freedom, with characteristic irony, it names purpose. This interesting retention of old words with a new and inverted meaning is one of the notable features of this philosophy which in characteristically paradoxical fashion calls itself Idealism. In fact, after we have taken into 
account the double determinism of Objective Idealism and its denial of all reality to the personal self, the chief difference between it and Naturalism consists exactly in its terminology. The worlds of the two philosophies are identical in most respects except their labels. Nothing different is to be expected in the one from what we must expect in the other, except that the old weary round is in one case called "material," in the other "spiritual." It is the same old prison house with a new coat of paint.

If we refuse to allow ourselves to be duped and hypnotized by the lofty vocabulary of Objective Idealism, the world with which it presents us is one that has very little left for the religious man. It is, therefore, somewhat surprising that so many of its most enthusiastic advocates during the past century should have been deeply religious men and that their advocacy of it should have been so largely prompted by their religious interests. The propaganda of German Idealism in England, from the time of Coleridge to the death of Edward Caird, the similar spread of it in this country by earnest and devout men such as the late Professor George S. Morris, and the preaching of something vaguely like it in Germany by that admirable and very lovable and 


\section{CONSEQUENCES OF DUALISM 211}

hopelessly vague preacher, Rudolf Eucken, all these movements have had in them much of the spirit of the religious missionary. A number of elements have contributed to this peculiar result. Perhaps most fundamental of all is the undeniable emotional appeal which some form of Absolute has always had and always will have over many minds. But an almost equally fundamental explanation, as I view it, is to be found in the fact that the religious supporters of Objective Idealism to whom I have referred never fully grasped the logical consequences of their own presuppositions. Personally I am convinced that these consequences are just about what Bosanquet and his school have depicted. But I am also convinced that the Cairds and Morrises and the rest would never have been satisfied with the Bosanquetian Idealism. Not seeing as clearly as Bosanquet and Hoernlé what was involved in their presuppositions, they tried to retain in their philosophy really incompatible ideas, and they were lured on to stick to the Absolute, spite of apparent inconsistencies, in the hope that thus the triumph of the ideal over the actual might be logically demonstrated and that, in the form of the Absolute, God might be preserved. Their hope for the triumph of the ideal 


\section{MATTER AND SPIRIT}

has been realized:-but let it be noted how this has been accomplished. Objective Idealism demonstrates the victory of the ideal by identifying the ideal with the real. The Ideal is eternally triumphant-but what is the Ideal? Ah, we finite "peepholes" of the universe must not arrogate to ourselves the privilege of determining by our own feelings and purposes what the Ideal is. If we would find the Ideal we must look to the Real and see what it is that is eternally triumphant. Whatever that may be, that is the Ideal; and thus we have proved its triumph.

Once the true inwardness of Idealism's vindication of the Ideal has been made clear, I doubt if the religious soul will find much comfort therein. And the same is true of the concept of the Absolute as a substitute for God. There is no doubt, to be sure, that the thought of the Absolute brings at times a certain sense of security and peace. But the peace is like to be that of the dead wilderness or of the geometrical diagram, and the security is abstract and verbal only. In the oft-quoted words of Professor James, the Absolute "gives us absolute safety if you will, but it is compatible with every relative danger. . . . Whatever the details of experience may prove to be, after 


\section{CONSEQUENCES OF DUALISM 213}

the fact of them the Absolute will adopt them." ${ }^{1}$ As Professor James used to point out in his class-room, Absolute Idealism would find itself as amply demonstrated and as completely fulfilled in the veriest hell as in the most blissful heaven.

I have dwelt thus at length upon Absolute Idealism because I believe it is of the utmost importance for the leaders of the religious life to understand its true significance and to refuse to be hypnotized by its noble vocabulary. As a support for the religious life Absolute Idealism is a broken reed. It contains elements and tendencies essential to its very structure which are bound to lead to the repudiation of most of the things which religion holds most dear. It is, to be sure, the inevitable outcome of the Neo-Kantian form of Idealism, but that does not necessarily imply that it is true. In my opinion, indeed, no one can maintain its truth without flying in the face of some of the most indubitable facts of life. In the words of Pringle-Pattison, it is the substitution of a "logical analysis of knowledge" for "an account of living experience." 2

If neither Naturalism nor Absolute Idealism is

1 "A Pluralistic Universe," p. I 36.

2 Symposium, p. 5 Ig. 


\section{MATTER AND SPIRIT}

consistent with the facts of experience or compatible with the demands of the religious consciousness, whither shall we turn? Personal Idealism is proposed by a number of philosophers both in this country and in England as a form of thought designed expressly to meet the present emergency. And indeed much can be said for it. All of the important values of religion and morality are by it preserved. Noble as is the edifice which it would erect for us, however, I am constrained to point out that it is founded on something dangerously like the sand. For either the personal idealist must take refuge in some form of Panpsychism or else build his philosophy on Kantian foundations; and more likely than not he will try both. Each of these courses has its great dangers. Panpsychism - at least without Kantian supplementations-leads one into a fantastic construction of external nature and leaves one almost resourceless before the problem of nature's laws; and on the other hand, to quote Perry's lively figure, "once the Kantian theory of knowledge is accepted, Personal Idealism is on a slippery inclined plane with the Absolute waiting at the bottom." ' You get the picture. An enormous crocodile of an Absolute with 1 "Present Conflict of Ideas," p. 218. 


\section{CONSEQUENCES OF DUALISM 215}

jaws extended at a terrifyingly obtuse angle, waiting at the foot of a steep and slippery plank, down which is shooting the pathetic figure of the personal idealist destined in no time to make one more little meal for the All-Inclusive. There is no escape for him; he will easily be swallowed in one small gulp. For the Absolute cannot be expected to make two bites of even a personal idealist.

Though with all my heart I wish the best of fortune to the personal idealist in his exciting adventure, I have no wish to sit on his inclined plane. So great respect have I for the Absolute that I mean to take no chances and to come nowhere near him. To drop the figure, it seems to me that what the times call for in philosophy is not a Personal Idealism but a Personal Realism,-a philosophy that should be frankly and thoroughly dualistic, a recognition of the fact to which unspoiled experience seems so plainly to point, that the world of matter and the world of spirit are not made of the same stuff. Such a philosophy would be in a peculiarly favorable position for reconciling the conflicting claims of natural science and of religion and morality. It would apply the so-called "scientific method in philosophy" to those regions of reality to which it patently applies 


\section{MATTER AND SPIRIT}

and for which it was made; while for the realm of the spirit it would reserve that more intuitive and empirical method which "Spiritual Pluralism" would extend, at much cost, to the whole world. Thus it would to some purpose render unto Cæsar the things that are Cæsar's and unto God the things that are God's. A discussion of the feasibility of such a Realism, however, would involve us in an epistemological excursion for which there is here no time. I will therefore merely say in passing that, for reasons which I have in part indicated elsewhere,${ }^{1}$ I regard a philosophy of Personal Realism perfectly sound epistemologically; for the purposes of these lectures, however, I shall be glad to join forces with the personal idealist and with all others who, whatever they may think of the world's ultimate substance, agree with me in finding in the world at least a Dualism of Process.

Such a Dualism, whatever its view of the ultimate substance, seems to me the only genuine Idealism. A genuine Idealism, I call it, because it both refuses to bring down the ideal to the actual and at the same time asserts that though the ideal is not actual now there is a living possibility of its progressive realiza-

1 "Essays in Critical Realism." 


\section{CONSEQUENCES OF DUALISM 217}

tion. Such a Dualism, I believe, is the only philosophical position which can safeguard the spiritual interests of man. I am aware that to many this wili sound paradoxical in the extreme. For all of us, I suppose, from the very beginning of our philosophical education have been informed repeatedly and authoritatively that Monism is the only spiritual Weltanschaunng; and the dualist has been so anathematized that the name has become almost a reproach to a philosopher. Who has not heard the taunt, "Ah, sir, if you maintain that, you are a dualist!"-a taunt to which no reply is possible. In spite of which, let me say it again, Dualism seems to me the only position that can safeguard man's spiritual interests. Nor do I know of any philosophy that can better satisfy the demands of the religious consciousness. And I think this can be shown not only by an analysis of the teachings of Dualism, with its vindication of the personal self, of freedom and responsibility, but also by a review of the great religions of the world.

That Islam is frankly, even crudely, dualistic, I expect no one would seriously deny. Dualism is, of course, at the very heart of Zoroastrianism, with its magnificent picture of the cosmic struggle between 
Ahura Mazda and Angro Mainyu, and its inexhaustible incentive to the soldiers of God. Hinduism naturally presents a more complex problem; for Hinduism itself is so complex that what is true of one aspect of it may not hold of another. Plainly the worldview back of the religion of the Rig Veda, as well as the world view involved in the popular polytheistic Hinduism of to-day, is dualistic (in our sense of the word), as well as pluralistic. When we come to the Advaita Vedanta of Çankara, however, we are faced with one of the most absolute of Monisms. Yet it must be observed that the Monism of the Vedanta is of a peculiar sort. Thoroughly idealistic though it is, it has but little in common with the Kantian Idealism. Among the post-Kantians, it is Fichte to whom it is most akin. But even here the difference is considerable. Kantian Idealism was founded and post-Kantian Idealism has been developed with the structure of natural science constantly in view. Logic and natural science between them form in a sense the skeleton or ground plan of the world picture which Kantian Idealism gives us. All this is completely lacking in the Vedanta. The Vedanta begins and ends not with the world of natural science but with the self. Both forms of Idealism-the east- 
CONSEQUENCES OF DUALISM 219

ern and the western-divide the world into two parts,-appearance and reality. They draw the line between the two, moreover, in about the same place. But while for western Idealism the world of science is real and the self is an illusion, for the Idealism of the East it is the world of natural science that is illusory and the self alone that is real. From this difference it has resulted that, as we have seen, Kantian Idealism has steadily approximated to the position of Naturalism, whereas the Vedanta, in spite of its rigorous insistence upon a monism of substance, has from the beginning upheld a view of body and soul which in no essential and pragmatic principle differs from the dualism of process found so commonly in the teachings of religion. For though the Vedanta insists that there is but one reality, that this is spirit, and that the body and the whole external world is but illusion, a dualism of great pragmatic significance breaks out within this monism,the dualism, namely, between the illusory and the real. Illusion has its ways of acting and its tremendous grip upon the finite spirit; it must be dominated, it must be brought into subjection if the spirit is to be free and to realize its own inherent divinity. Hence for the Vedanta there is much the same strug- 


\section{MATTER AND SPIRIT}

gle between the spirit and the flesh, much the same dualism within man and within the world, that is to be found in the other religions. If this is true of Çankara's Advaita Vedanta, even more obviously does it hold of the less monistic interpretations of the Vedanta, of the religion of Bhagavad Gita with its personal God, and of the philosophies of the Great Sects. And not only these but all forms of Hindu religious thought lay their unfailing and their supreme emphasis upon the soul. Here, I believe, is the central point of them all, here is the fundamental Credo which makes Hinduism, in spite of its bewildering sects and branches, in some true sense one religion. In their thought of God they vary through all the phases of polytheism, theism, pantheism, and atheism; but in their insistence upon the reality and the supreme importance of the self, and its contrast to the external world of matter or illusion, in this they are at one.

Nor is the case very different with Buddhism, in spite of its denial of the kind of substantial soul which the Vedanta teaches. For even the doctrine of the Founder, as handed down in the Southern Buddhism of to-day, recognizes a very real self,-namely the union of the will to live and the moral character 
CONSEQUENCES OF DUALISM 221

(Tanha and Karma $)^{1}$ which, upon reflection, will be found to constitute a very good substitute for the substantial ego of the other Indian faiths. Northern Buddhism, moreover, has largely returned to a belief in a substantial ego; and as a pragmatic matter, wherever you find Buddhism you will find a recognition of the struggle between the spirit and the flesh, and a sharp distinction between the world of matter and the world of mind.

If now we turn to regions of religious thought nearer our own, we find the religion of ancient Israel frankly and naïvely dualistic. All things, indeed, were made by God, but the world of matter and the world of individual finite spirits are never identified nor confused. This dualistic view was as a matter of course taken directly over into Christianity. Nor was it in any way diluted, rather was it strengthened, by the contribution which was early made to Christian theology from Greek thought. I am aware of the fact that it is customary with contemporary objective idealists to read into Plato their own Kantian and Hegelian views, and to dub as non-Platonic most of the things that Plato actually said. Plato, it

${ }^{1}$ See the admirable and, in a sense, authoritative presentation of the matter in Subhadra Bhikshu's "Buddhist Catechism" (Colombo, 1908), pp. 36-37. 
seems, was a forerunner of the truth, one who saw it in prophetic vision from afar, and who in relation to Bosanquet is to be classed, if not indeed among the Prophets, at least among the Sibyls. The hopelessly non-historical nature of such an interpretation of the great Greek thinker I need hardly point out. I merely submit that any fair reading of what Plato actually wrote- a reading of the lines instead of a reading between the lines-will bring out with great emphasis the contrast, so constantly dear to his thought, between soul and body, between spirit and matter. A consideration of the intellectual atmosphere of the Fourth Century B.C., moreover, confirms this dualistic interpretation of Plato. We must not forget that among the chief influences playing upon him were the teachings of Socrates and of the Orphics; and both of these, notably the latter, were profoundly dualistic in their view of man and nature. In fact one of the chief effects which Platonism had upon Christianity was to carry into it much of the Orphic dualism.

For only by a willful shutting of our eyes to the facts and by an arbitrary construction of a so-called Christian theology to suit our personal and passing taste, can we deny that Christianity from its origin 


\section{CONSEQUENCES OF DUALISM 223}

on has been profoundly dualistic. The fancy of our age for Spencerian Unknowables, for Naturalistic Monisms, and for Hegelian Absolutes may make us forget the essential position within the Christian faith of the contrast and the war between the flesh and the spirit, but nothing is more fundamental to it than they. In the words of Professor Alexander, "At the core of the Christian religion there is a dogma which cuts deep to the truth of human nature. It is the dogma of the antithesis and struggle of the flesh and the spirit, of the World and the Word, the dogma of the suffering and striving man, which is nowhere so vividly expressed as in the terrible image of St. Paul,- - the world is crucified unto me and I unto the world." " 1 And one might say with no exaggeration that all of the Christian faith and hope center around a conception of human personality and its superiority to the laws of matter and force, for which neither Naturalism nor Objective Idealism can consistently make room.

The discussion of this topic might be expanded to almost any length, but I think I have said enough to remind you of what every student must be aware,

1 "Apologia pro Fide." Presidential Address at the 19th Annual Meeting of the Am. Phil. Assn., Phil. Rev., XXIX, p. Irg. 
namely, that the great religions of the world, including our own, have not only been essentially and profoundly dualistic, but that they have found in that Dualism the only means for a spiritual interpretation of man's nature and for a hopeful outlook upon his destiny. This contrast between the laws of spirit and the laws of matter, and the faith based upon it, has, in fact, been the very kernel of their truth, the vital part of their teachings which has survived the breakdown of creed and dogma and the wreck of the endless details of the ancient faiths. For it is this dualistic view which in its application to man forms the very root and core of the moral struggle and of the eternal hope. It points to what is man's tragedy and his glory. Consider him: rooted and anchored in a particular piece of matter which he only very partially dominates, definitely limited and localized in time and space, he yet feels his own innate transcendence of the body and with Plato knows himself a spectator of all time and all being; through his body the inheritor of the beast, yet also in part not beast, realizing himself as more than animal and certainly more than nerve cells and tissues, as more than a passive peephole of the Absolute's world, feeling within himself a power of real initiative and moral 
CONSEQUENCES OF DUALISM 225

responsibility, and at times guessing and hoping that he is somehow akin to something divine to which he stretches out his hands.

If Dualism be true, there are two orders of being in this world: the one the natural order of mechanical causation and regular sequence which science studies; the other the order of mind and of personal activity. This latter we may well call the supernatural. If I really am a self and a free agent, and if my will be not an illusion, then whenever I raise a stone from the ground by the exertion of my arm, directed and determined by my will, I thereby interfere with and interrupt the predictable sequences of the merely natural world. There are, as religion has always taught, two realms, the natural and the supernatural; and you and I belong to the latter. Whether the Supernatural Realm-the realm of spirit-reaches out beyond our ken and includes other and non-human selves and perhaps a God-this there is no time here to discuss, and this, I should add, is still chiefly a matter not of knowledge but of faith. But if we accept the dualistic philosophy, this much at least we know: that the Supernatural Realm exists, because you and I are members of it. "Beloved, now are we the Sons of God." 
"Now are we the sons of God, and it doth not yet appear what we shall be." But if Dualism be true there is good hope that when He shall appear we shall be like Him; and that the death of the body shall not be the end of us. Without some form of dualistic philosophy I do not see how we can have any personal hope at all. If the soul be an epiphenomenon of the brain, it will perish when the brain ceases to function. If it be merely a stream of consciousness, it lacks that identity and that character which are needed to give meaning to immortality. If it be merely a "peephole" in a Bosanquetian universe it is of the essence of transciency, except in that, like our bodies and everything else which passes away, we do, to the extent of having lived at all, just so far characterize the world's past. In Bosanquet's words, "It is natural to suppose that our brief existence is the temporal appearance of some character of the whole. . . . While we serve as units, the Absolute lives in us a little and for a little time; when its life demands our existence no longer, we yet blend with it as the pervading features or characters which we were needed for a passing moment to emphasize and in which our reality enriches the universe." "

1 Symposium, p. 506. 


\section{CONSEQUENCES OF DUALISM 227}

That is all. Only a philosophy which recognizes in us men genuine individuals, real on our own account, and which teaches that the laws of matter and motion do not completely determine the existence and activities of the spirit,--in short only a dualistic philosophy is compatible with any significant form of personal immortality. But such a philosophy is not only compatible with it; it goes a long way toward making it probable.

For if it be true, as we have found reason to believe, that the body is in a real sense the tool of the mind, why must we believe that when the tool is destroyed the mind which used it also perishes? To be sure, as we know them here, the two coöperate, and the mind can express itself only by using the material tool to which it has become organic. In no instance, therefore, can we find an expression of the mind or self which is purely spiritual. Always it must submit itself, to some extent, to the nature of the tool which it uses. To do this is the precondition of its expressing itself at all in this world and as we know it here. But all this is no argument for identifying the self with the body or for concluding that when the body ceases to function the self also ceases. The tones which we hear from the violin 
when the master plays it-are they due to the artist or to the instrument? Surely to both united, each limiting and each aiding the other. Yet for all that we do not identify the one with the other nor say that since the tones come immediately from the violin, therefore there is no master and none is needed. To say this would be the wisdom of Monism. But we who are not monists believe that behind the wood and horse-hair and cat-gut of the machine we can trace the hand,-yes, and the personality-of the master. Suppose now the violin be broken; must we conclude that therefore the violinist also ceases to exist, or that, at any rate, he can never play again? Surely not if we be good dualists. We know that in this universe there are other instruments on which the master may play. And have we reason to be . sure that only violins can be replaced?

But I need not dwell longer upon this aspect of the question. For it must be obvious to all that if Dualism be true, then, as Socrates said long ago, "it behooves us to be of good hope about death." And indeed we can do no better than turn back to our Plato; for almost all his many arguments upon the subject come really to this: that the mind being different in nature from the body and subject to dif- 


\section{CONSEQUENCES OF DUALISM 229}

ferent laws, there is no good reason to suppose that the death of the body is relevant to the life of the mind.

A quarter of a century ago there were discovered in Southern Italy a number of graves made by the ancient Orphics. In each there was found, bound round the neck of the dead man, or clasped in his hand, a golden tablet, with an inscription which combined directions for his entrance into the next world and a brief epitome of his faith. One of them reads thus:

"Thou shalt find on the left of the House of Hades a wellspring;

And by the side thereof standing a white cypress.

To this well-spring approach not near.

But thou shalt find another by the Lake of Memory,

Cold water flowing forth; and there are Guardians before it. Say: I am a child of Earth and of Starry Heaven. But my race is of Heaven alone."

The inscription is incomplete. Another tablet, of which much is lost, begins abruptly:

"I am parched with thirst and I perish. Nay, drink of me, The well-spring flowering forever on the Right where the cypress is.

Who art thou?

Whence art thou? I am a child of Earth, and of Starry Heaven." 
In these last words, repeated from tablet to golden tablet, and held in the pathetic grasp of hand after clinging hand, as if the whole hope of the future hung, as indeed it does, upon the truth of the line, there is expressed the central faith not only of the Orphic religion but of all religion, the fundamental assertion of the mind's self-consciousness and of the heart's desire, as well as the essential teaching of the dualistic philosophy. I am a child of Earth-yes, that is plain, alas, all too plain; but a child of Starry Heaven too. 


\section{INDEX}

Absolute Idealism, 199, 202, 204, 205, 207-2I3

Alexander, H. B., 223

A ristotle, I77, 195

Attention, 8I-85

Atwater, W. O., I50, I5I

Bawden, H. H., I58, I59

Becher, I40

Behaviorism, III-I29, I3I, I60, I6I, I65, 195

Benedict, F. G., 150

Bergson, H., I55, I69, I70, 194

Berkeley, 63

Bode, B. H., 92-96

Bosanquet, B., 98-102, 205-208, 2I I, 222, 226

Bradley, F. H., 205

Breese, B. B., 83

Buddhism, 220, 221

Busse, L., II9, I42, I74, I83, 194

Calkins, M. W., I77, I 78

Christianity, 8, 166, 201, 202, 221, 222, 223

Clifford, II, 78

o Conservation of Energy, Io, II, Kant, 195, 196, 203, 204 60,99 , 101, 103, 142-152

Critical Realism, 37, 45, 216

De Laguna, II3

- Descartes, I0, 33, 90, 195

Dewey, J., 96, 188, 190

Dualism, 99-102, I65, I66, 183, 184, I85, 186, 187-196, 197, I 98 , $203,204,216,217-230$

Ethics, 197, 198, 199, 200

Eucken, R., $2 \mathrm{II}$

Evolution, I I, I86-190

Fechner, 55, I6I

Franz, S. I., I55

Frost, E. P., I22

God, 179, 20N, 2II, 212, 225

Green, 182, 204

Haeckel, E., 21

Head, I 55

Hinduism, II8, I19, I 20

Hoernlé, R. F. A., IO4, 2 I I

Höffding, H., 55

Hume, 136, I37, 140, 178

Idealism, I33, I83, I84, 193

Immortality, 226-229

Individual, 198, 199, 200, 202-207

Interaction, 5, 6-II, I5, 4I, 95, 99. $132-156,160,161,162,165$, I68, I69, I73, I9I, 192, 194

Islam, 217

Israel, 22I

James, W., $78,79,80,83$, rog, I56, I69, I70, 21 3

Ladd, G. T., I40, 14I

Laird, J., 18I

Lashley, 124

Lasswitz, 55

Locke, 195

Lovejoy, A. O., 96, 125-128, I6I, I62, 194

McDougall, W., I8o, I81, 194

Materialism, 5, II-47, 48, 73, 89, 94, 95. 99, I03, I I 8, I 32, I46, I60, 165, 201 
Mind-dust Theory, 78-86, I69

Monism, I84, I92, 195, 217, 228 Montague, W. P., 22, 29-35, 42, 46, 146

Morris, G. S., 210

Münsterberg, H., 5I, 78

Naturalism, 9, IO, II, I5, 36, 38, $39,4 \mathrm{I}, 49$, I20, I 58; 165, I66, 184, 199, 202, 209, 213, 223

Natural Selection, I6, I7, I8, 88

Neo-Realism, I04-I II, I65

Objective Idealism, 97-I05, I Io, II I, 204, 205-2I3, 223

Orphics, The, 222, 229, 230

Panpsychism, 58, 59, 63, 64, 67, $73,193,214$

Parallelism, I I, I5, 24, 4I, 48-88, $89,90,95,99,132,160,161,165$, 194

Paulsen, 59, 60, 61, 62, 71, 72, 88, I6I, I74

Perry, R. B., 2I4

Personal Idealism, 214, 215

Peterson, II 8

Picard, M., 81, 82, 83, 84, 85

Plato, 8, I66, I95, 221, 222, 224, 228

Pragmatism, 92-97, 134, 202

Pringle-Pattison, A. S., 204, 205 , 206, 213
Religion, 201, 217-224, 230

Richardson, 176

Royce, J., 204

Russell, B., I37, I38

Santayana, G., 22

Self, I72-I81, 198

Sellars, R. W., 22, 36-46

Sheldon, W. H., I7I, 194

Singer, E. A., I22

Socrates, 228

Spencer, H., 78

Strong, C. A., 22, 23, 24, 64, 65, $69,80,84,85,86,87,188,189$

Stumpf, I42, I44, I46, I48, I92, I94

Unity of Consciousness, 77, 78, $79-85$

Vedanta, 2I8, 2I9, 220

Warren, H. C., I3, I4, 22, 24, 25, $26,27,28,29,35,46,52,56$

Watson, J. B., II3, I2I, I22, I23, 124, 126

Webb, C., 205

Wentscher, 145

Wundt, I35, I42, I45

Ziehen, 5 I

Zoroastrianism, 217, 218 



\section{LUN - 51987}

\section{PLEASE DO NOT REMOVE CARDS OR SLIPS FROM THIS POCKET}

\section{UNIVERSITY OF TORONTO LIBRARY}




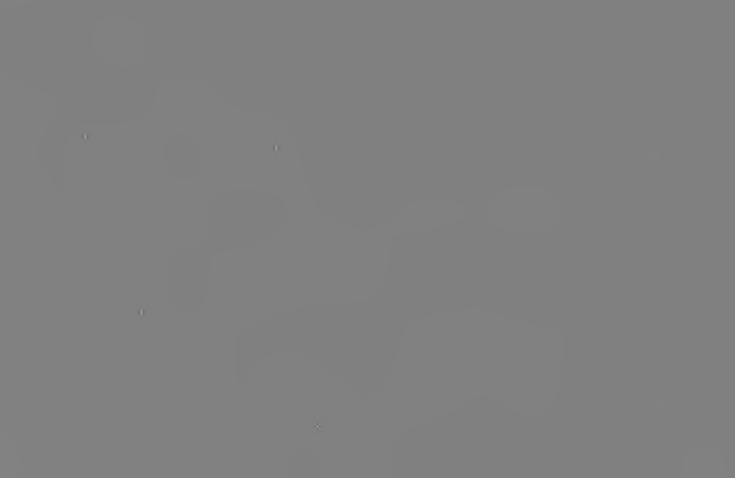

